\title{
Linear and Nonlinear Dielectric Ceramics for High-Power Energy Storage Capacitor Applications
}

\author{
Mahesh Peddigari*, Haribabu Palneedi*, Geon-Tae Hwang*, and Jungho Ryu***; \\ *Functional Ceramics Group, Korea Institute of Materials Science, Changwon 51508, Korea \\ **School of Materials Science and Engineering, Yeungnam University, Gyeongsan 38541, Korea
}

(Received August 13, 2018; Accepted August 28, 2018)

\begin{abstract}
Dielectric materials with inherently high power densities and fast discharge rates are particularly suitable for pulsed power capacitors. The ongoing multifaceted efforts on developing these capacitors are focused on improving their energy density and storage efficiency, as well as ensuring their reliable operation over long periods, including under harsh environments. This review article summarizes the studies that have been conducted to date on the development of high-performance dielectric ceramics for employment in pulsed power capacitors. The energy storage characteristics of various lead-based and lead-free ceramics belonging to linear and nonlinear dielectrics are discussed. Various strategies such as mechanical confinement, self-confinement, coreshell structuring, glass incorporation, chemical modifications, and special sintering routes have been adopted to tailor the electrical properties and energy storage performances of dielectric ceramics. In addition, this review article highlights the challenges and opportunities associated with the development of pulsed power capacitors.
\end{abstract}

Key words : Dielectric ceramic, Capacitor, Energy storage density, Electric polarization, Breakdown strength

\section{Introduction}

$\mathrm{C}$ apacitors are widely employed as passive components in many electronic devices. They are used for carrying out a host of functions such as pulse discharging, filtering, voltage smoothing, coupling, de-coupling, dc blocking, power conditioning, snubbing, electromagnetic interference suppression, and commutation in pulsed power and power electronics applications. ${ }^{1)}$ The technology of capacitors as storage media for electrical energy dates back to the beginning of the $20^{\text {th }}$ century. Through the various stages of development, different materials such as glass, paper, mica, lacquer, polymers, and ceramics have been utilized as capacitor elements. ${ }^{2}$ In a dielectric capacitor, the insulating material placed between two parallel conductive plates becomes polarized and stores electrical charge in proportion to the electric potential between its terminals (Fig. 1).

In the past two decades, lots of efforts have been made towards the development of energy storage technologies such as batteries, electrochemical capacitors, and dielectric capacitors to meet the requirement of on-demand utilization of the electricity generated from renewable energy sources. As indicated by the Ragone plot shown in Fig. 2(a), there are significant differences in the energy density and power density of these storage devices, which are attributed to the differences in their energy storage mechanisms and charge-

\footnotetext{
'Corresponding author: Jungho Ryu

E-mail : jhryu@ynu.ac.kr

Tel : +82-53-810-2474
}

discharge processes. In contrast to the other storage devices, dielectric capacitors can release the stored energy in an extremely short period of time (microseconds-milliseconds) and generate an intensely pulsed current or voltage, which make them suitable for applications in pulsed power elec-

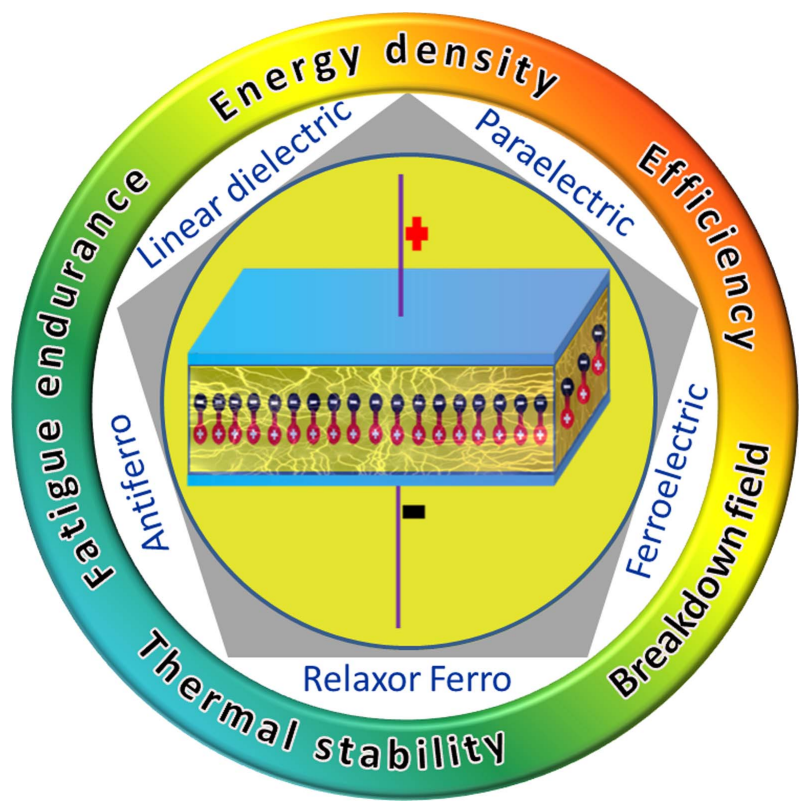

Fig. 1. Schematic of a dielectric capacitor, wherein the separation and alignment of electric charges is accomplished by an applied electric field. The different types of dielectric materials and the key parameters used for the evaluation of their energy storage performances are also indicated. 
(a)

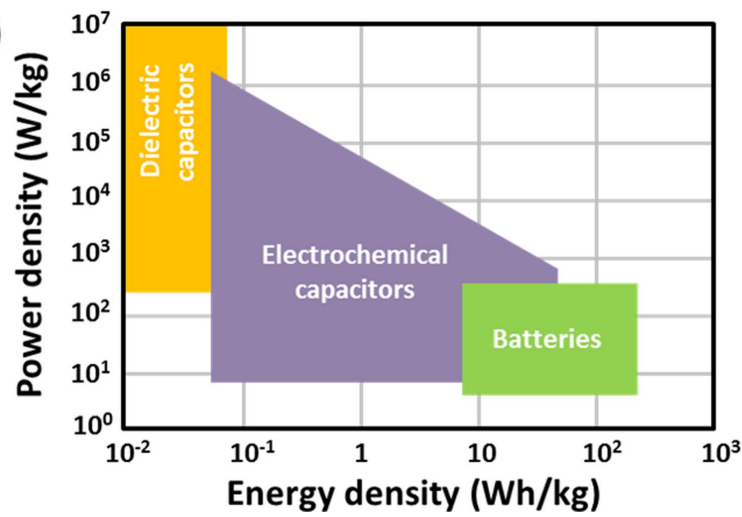

(b)

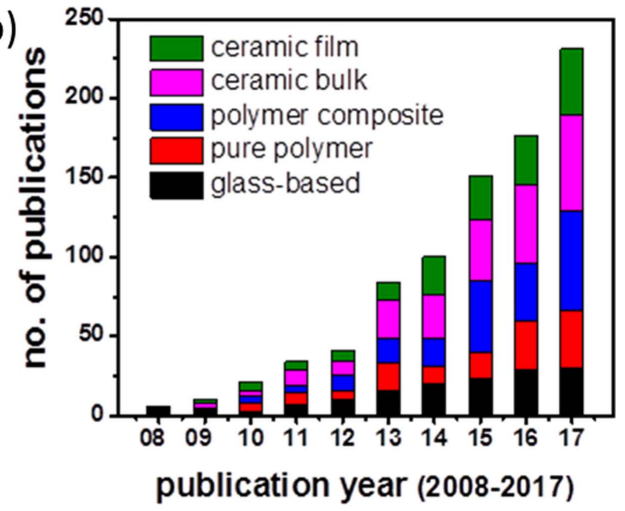

Fig. 2. (a) Ragone plot showing a comparison of the power densities and energy densities of dielectric capacitors, electrochemical capacitors, and batteries. (b) Bar chart showing the number of articles published on dielectric capacitors that are related to energy storage each year for the past ten years (from 2008 to 2017) (Source: Web of Science database; Keyword searched: dielectric capacitor (filter: energy storage)).

tronic systems. Further, unlike the cases of electrochemical capacitors and batteries with liquid electrolytes and involving chemical reactions, dielectric capacitors exhibit superior thermal and mechanical stability and can be operated under higher voltages (several hundred to thousand volts) for longer durations.

In view of their potential applications in pulsed power electronics for use in various commercial, civilian, and military systems, as well as considering the significantly increasing number of publications on dielectric capacitors for energy storage applications in recent years (Fig. 2(b)), this area of research is currently one of the hot topics in the domain of energy storage technologies. The applications of dielectric capacitor-based pulsed power electronics include medical equipment (defibrillators, pacemakers, surgical lasers, X-ray units), scientific research (nuclear effects simulations, high-power accelerators, high-intensity magnetic field experiments), commercial systems (camera flash, food sterilization, metal forming, cable fault detection equipment, underground oil and gas exploration), energy systems (grid-connected photovoltaics and wind turbine generators, power grid fluctuation suppression, high-frequency inverters), transportation (hybrid electric vehicles, electric trains, electric aircrafts), avionics (space-shuttle power systems, rocket propulsion systems), military (active armors, electrochemical guns, radars, high-power microwave devices, ballistic missiles), etc.

Although dielectric capacitors possess high power densities with fast discharge rates, their energy density should be further increased to reduce the volume of the capacitors. Currently, linear dielectric polymer materials with low dielectric constants but high breakdown fields are employed in commercial pulsed power capacitors, exhibiting energy density $<5 \mathrm{~J} / \mathrm{cm}^{3}$. To be competitive with supercapacitors, the dielectric capacitors should offer energy density $>30 \mathrm{~J} /$ $\mathrm{cm}^{3}{ }^{3)}$ Hence, much of the research on emerging dielectric materials is being carried out in pursuit of enhanced energy density, which would make the dielectric capacitors useful for an even wider variety of applications. The energy storage performance of these capacitors is evaluated in terms of energy density and storage efficiency, which are related to permittivity $(\varepsilon)$ and polarization $(P)$ of the dielectric material and the external applied field $(E)$ (Fig. 1). For linear dielectrics with negligible loss, the energy density $(U)$ can be expressed as $U=\frac{1}{2} \varepsilon_{0} \varepsilon_{r} E^{2}$, where $\varepsilon_{0}$ and $\varepsilon_{r}$ are the vacuum permittivity and relative permittivity, respectively. For nonlinear dielectrics, which exhibit some energy dissipation, the stored (or charge) energy density $\left(U_{s t}\right)$ and recoverable (or discharge) energy density $\left(U_{\text {rec }}\right)$ can be determined from the polarization-electric field $(P-E)$ hysteresis measurements through the following equations:

$$
\begin{aligned}
& U_{s t}=\int_{0}^{P_{\max }} E d P \\
& U_{r e c}=\int_{P_{r}}^{P_{\max }} E d P
\end{aligned}
$$

where $P_{r}$ and $P_{\max }$ are the remnant and maximum polarizations, respectively. The energy loss density $\left(U_{\text {loss }}\right)$ is equal to the hysteresis loss, i.e., the area of the P-E loop. Accordingly, the energy storage efficiency of the capacitor is represented by the ratio between $U_{\text {rec }}$ and $U_{s t}$ as follows:

$$
\eta=\frac{U_{r e c}}{U_{s t}}=\frac{U_{r e c}}{U_{r e c}+U_{l o s s}}
$$

It can be concluded from the above equations that high values of permittivity, maximum (saturation) polarization, and breakdown strength (BDS) will lead to larger energy densities, while low dielectric/hysteresis losses and low remnant polarizations will facilitate greater energy storage efficiencies of dielectric materials. In addition, the material should possess low electronic/ionic conductivity for sustaining high electric fields. However, attaining all these desired qualities in a single dielectric material is a challenging task. An increase in the dielectric constant is often accompanied by an increase in the dielectric loss, leading to thermal man- 

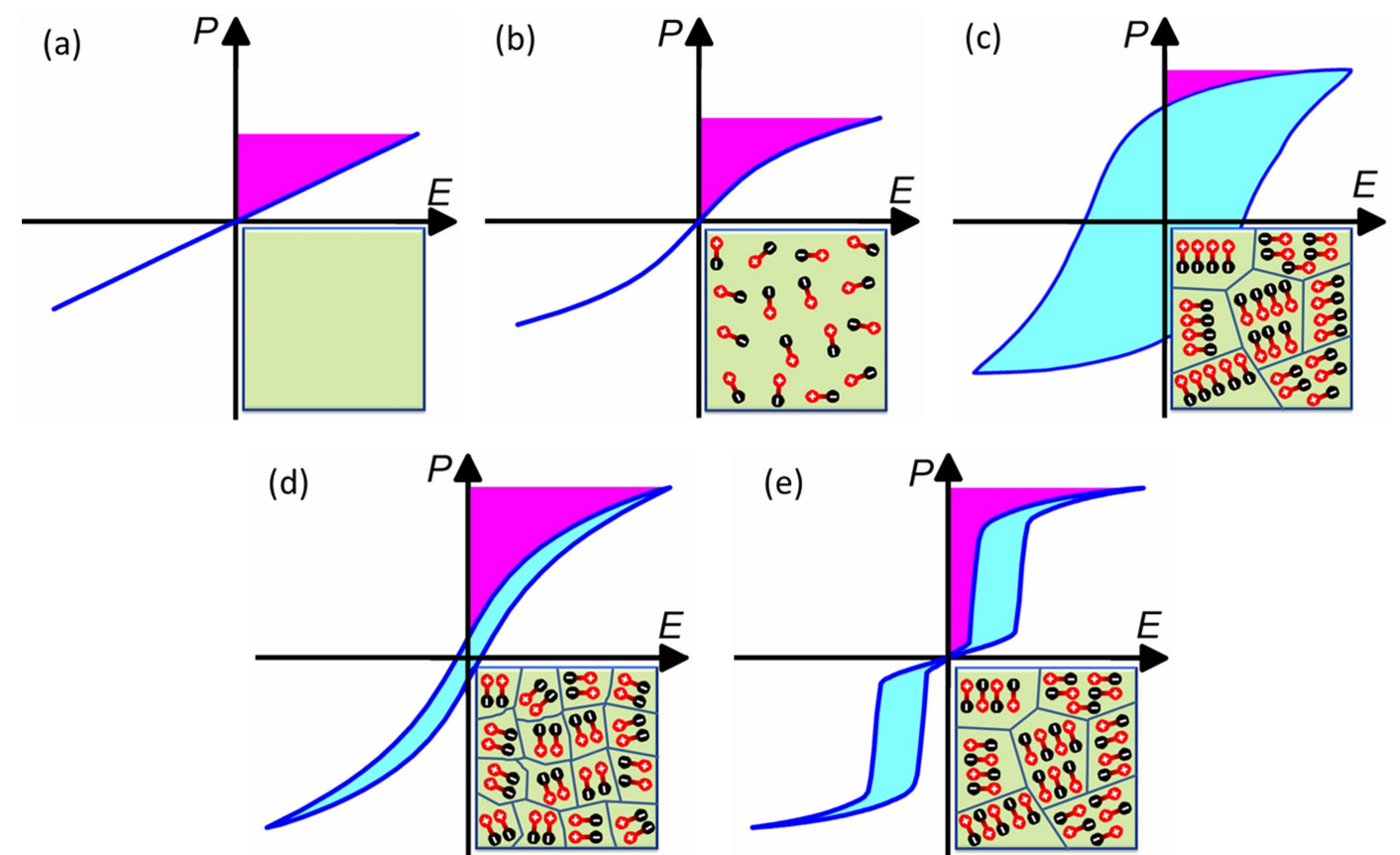

Fig. 3. Electric field dependent polarization characterizations of (a) linear dielectric, (b) paraelectric, (c) normal ferroelectric, (d) relaxor ferroelectric, and (e) antiferroelectric materials. The inset shows the dipole/domain structures of the corresponding materials. ${ }^{6}$

agement problems. On the other hand, an increase in the applied field stress can lead to early failure and low reliability of the capacitors. ${ }^{4}$ For maintaining the physical integrity, effective thermal management, and reliable operation of dielectric capacitors over a long time period, high electric fatigue endurance (> $10^{6}$ cycles) and good thermal stability $\left(-90^{\circ} \mathrm{C}\right.$ to $\left.250^{\circ} \mathrm{C}\right)$ of the dielectric material are essential (Fig. 1). Through a better understanding of the physical phenomena governing the properties of the dielectrics, efforts can be directed to realize an optimum combination of the aforementioned criteria.

To achieve high energy storage performances, various dielectric materials based on polymers, glasses, and ceramics have been studied. Polymer dielectrics exhibit high breakdown field (> $7 \mathrm{MV} / \mathrm{cm}$ ), but low dielectric permittivity $(<10)$ and poor thermal stability $\left(<100^{\circ} \mathrm{C}\right)$. In order to improve their permittivity, recently, several polymer-based composites dispersed with dielectric ceramic fillers in different shapes and quantities have been developed.5) Glassbased oxide dielectrics possess greater permittivities and larger breakdown fields (> $10 \mathrm{MV} / \mathrm{cm}$ ) compared to those of polymer dielectrics. Dielectric ceramics in bulk form exhibit permittivity in the range 10-2000 and their breakdown fields are of the order of $0.1-1 \mathrm{MV} / \mathrm{cm}$. Depending on their dipolar/domain structures and electric-field-dependent changes in the polarization behavior, dielectric materials can be categorized into five major classes, namely, linear dielectrics $(\mathrm{LD})$, paraelectrics $(\mathrm{PE})$, ferroelectrics $(\mathrm{FE})$, relaxor ferroelectrics (RFE), and antiferroelectrics (AFE) (Fig. 3). Each of these dielectric materials has its own advantages and limitations with regard to energy storage capability.
Although many review papers have been published on the dielectric capacitors based on polymers and their composites, reports dedicated to dielectric ceramics are rare..$^{2,3,5,7-13)}$ Recently, Yao et $a l .{ }^{3)}$ reviewed the energy storage performances of homogeneous/inhomogeneous-structured dielectrics of polymers, glasses, and ceramics. Chauhan et al. ${ }^{13)}$ presented a review on anti-ferroelectric ceramics for energy storage capacitors. The present review covers most of the literature on dielectric ceramics and provides a comprehensive overview of the studies on the energy storage properties of the bulk ceramics belonging to $\mathrm{LD}, \mathrm{PE}, \mathrm{FE}, \mathrm{RFE}$, and AFE.

\section{Dielectric Ceramics for Energy Storage Capacitors}

\subsection{Linear dielectrics}

LD offer high BDS and linear polarization response to an applied electric field with minimal dielectric loss, which allows for large recoverable energy densities and efficiencies. Therefore, various $\mathrm{LD}$ ceramic compositions have been investigated for achieving high energy storage performance; some of the compositions are listed in Table 1. It is well known that the energy storage density of the linear dielectric is linearly proportional to the permittivity of the medium and the square of the maximum applied field. A larger BDS contributes more to achieving a high energy storage density. Since the BDS is mainly affected by the phase purity and microstructural features of the ceramics, many efforts have been made to improve it by using suitable dopants/oxide additives, ${ }^{14-18)}$ low melting glasses, ${ }^{19)}$ novel 
Table 1. Energy Storage Properties Reported for Various Dielectric Ceramics. (Here, LD Refers to Linear Dielectric; PE, Paraelectric; RFE, Relaxor Ferroelectric; and AFE, Antiferroelectric)

\begin{tabular}{|c|c|c|c|c|c|}
\hline Type & Material & $U_{\text {st }} / U_{\text {rec }}\left(\mathrm{J} / \mathrm{cm}^{3}\right)$ & $\eta(\%)$ & $\mathrm{BDS}(\mathrm{kV} / \mathrm{cm})$ & Ref \\
\hline$\overline{\mathrm{LD}}$ & Mn-doped $\mathrm{CaTiO}_{3}-\mathrm{CaHfO}_{3}$ & 9.5 & - & 1200 & 14) \\
\hline $\mathrm{LD}$ & Zr-doped $\mathrm{CaTiO}_{3}$ & 2.7 & - & 756 & 16) \\
\hline $\mathrm{LD}$ & $\mathrm{CaTiO}_{3}$ & 11.8 & - & 1188 & 20) \\
\hline $\mathrm{LD}$ & $\mathrm{Bi}_{0.48} \mathrm{La}_{0.02} \mathrm{Na}_{0.48} \mathrm{Li}_{0.02} \mathrm{Ti}_{0.98} \mathrm{Zr}_{0.02} \mathrm{O}_{3}$-doped $\mathrm{SrTiO}_{3}$ & 2.59 & 85 & 323 & 22) \\
\hline $\mathrm{PE}$ & ZnO-doped $\mathrm{Ba}_{0.3} \mathrm{Sr}_{0.7} \mathrm{TiO}_{3}$ & 3.9 & - & 400 & 25) \\
\hline $\mathrm{PE}$ & $\mathrm{Ba}_{0.3} \mathrm{Sr}_{0.7} \mathrm{TiO}_{3}-\mathrm{SrTiO}_{3}$ (multilayer) & 2.3 & & 220 & 35) \\
\hline $\mathrm{PE}$ & $\mathrm{Al}_{2} \mathrm{O}_{3}$ and $\mathrm{SiO}_{2}$ coated $\mathrm{Ba}_{0.4} \mathrm{Sr}_{0.6} \mathrm{TiO}_{3}$ & 5.09 & - & 493 & 36) \\
\hline $\mathrm{PE}$ & $\mathrm{SiO}_{2}$-coated $\mathrm{Ba}_{0.5} \mathrm{Sr}_{0.5} \mathrm{TiO}_{3}$ & 2 & 80 & 290 & 37) \\
\hline $\mathrm{FE}$ & $\mathrm{KNbO}_{3}$-doped $\mathrm{Bi}_{0.5} \mathrm{Na}_{0.5} \mathrm{TiO}_{3}-\mathrm{BaTiO}_{3}$ & 1.72 & - & 168 & 45) \\
\hline $\mathrm{FE}$ & $\mathrm{NaNbO}_{3}$-doped $\mathrm{BaTiO}_{3}-\mathrm{K}_{0.5} \mathrm{Bi}_{0.5} \mathrm{TiO}_{3}$ & 1.96 & 67 & 220 & 52) \\
\hline $\mathrm{FE}$ & $\mathrm{Bi}\left(\mathrm{Mg}_{2 / 3} \mathrm{Nb}_{1 / 3}\right) \mathrm{O}_{3}$-doped $\mathrm{K}_{0.5} \mathrm{Na}_{0.5} \mathrm{NbO}_{3}$ & 4.02 & $\sim 57$ & 400 & 53) \\
\hline RFE & $\mathrm{BaTiO}_{3}-\mathrm{BiScO}_{3}$ & 6.10 & & 730 & 61) \\
\hline RFE & Mn-doped $\mathrm{BaTiO}_{3}-\mathrm{Bi}\left(\mathrm{Mg}_{2 / 3} \mathrm{Nb}_{1 / 3}\right) \mathrm{O}_{3}$ & 1.70 & 90 & 210 & 63) \\
\hline RFE & Glass added $\mathrm{BaTiO}_{3}-\mathrm{Bi}\left(\mathrm{Mg}_{1 / 2} \mathrm{Ti}_{1 / 2}\right) \mathrm{O}_{3}$ & 1.97 & 94 & 250 & 65) \\
\hline $\mathrm{RFE}$ & $\mathrm{Na}_{0.73} \mathrm{Bi}_{0.09} \mathrm{NbO}_{3}$-doped $\mathrm{BaTiO}_{3}-\mathrm{Bi}_{0.5} \mathrm{Na}_{0.5} \mathrm{TiO}_{3}$ & 1.70 & 82 & 172 & 67) \\
\hline RFE & La-doped $\mathrm{Bi}_{0.5}\left(\mathrm{Na}_{0.82} \mathrm{~K}_{0.18}\right)_{0.5} \mathrm{Ti}_{0.96} \mathrm{Zr}_{0.02} \mathrm{Sn}_{0.02} \mathrm{O}_{3}$ & 1.95 & 71 & 155 & 70) \\
\hline $\mathrm{RFE}$ & MgO-doped $\mathrm{Bi}_{0.5} \mathrm{Na}_{0.5} \mathrm{TiO}_{3}-\mathrm{Ba}_{0.85} \mathrm{Ca}_{0.15} \mathrm{Ti}_{0.85} \mathrm{Zr}_{0.1} \mathrm{Sn}_{0.05} \mathrm{O}_{3}$ & 1.62 & 79 & 190 & 77) \\
\hline RFE & $\mathrm{BaSnO}_{3}$-doped $\mathrm{Na}_{0.5} \mathrm{Bi}_{0.5} \mathrm{TiO}_{3}$ & 1.91 & 86 & 190 & 78) \\
\hline RFE & $\mathrm{Ba}\left(\mathrm{Zr}_{0.2} \mathrm{Ti}_{0.8}\right) \mathrm{O}_{3}$-doped $\mathrm{Bi}_{0.5} \mathrm{Na}_{0.5} \mathrm{TiO}_{3}-\mathrm{NaNbO}_{3}$ & 1.69 & 78 & 175 & 83) \\
\hline $\mathrm{RFE}$ & $\mathrm{Na}_{0.73} \mathrm{Bi}_{0.09} \mathrm{NbO}_{3}$-doped $\mathrm{Bi}_{0.48} \mathrm{La}_{0.02} \mathrm{Na}_{0.48} \mathrm{Li}_{0.02} \mathrm{Ti}_{0.98} \mathrm{Zr}_{0.02} \mathrm{O}_{3}$ & 2.04 & 55 & 178 & 86) \\
\hline RFE & $\operatorname{Sr}\left(\mathrm{Sc}_{0.5} \mathrm{Nb}_{0.5}\right) \mathrm{O}_{3}$-doped $\left(\mathrm{K}_{0.5} \mathrm{Na}_{0.5}\right) \mathrm{NbO}_{3}$ & 2.48 & 81 & 295 & 87) \\
\hline RFE & $\mathrm{SrTiO}_{3}$-doped $\left(\mathrm{K}_{0.5} \mathrm{Na}_{0.5}\right) \mathrm{NbO}_{3}$ & $\begin{array}{l}4.03 \\
3.67\end{array}$ & $\begin{array}{c}\sim 52 \\
72\end{array}$ & $\begin{array}{l}400 \\
400\end{array}$ & 88) \\
\hline RFE & $\mathrm{ZnO}$-doped $\left(\mathrm{K}_{0.5} \mathrm{Na}_{0.5}\right) \mathrm{NbO}_{3^{-}}-\mathrm{Sr}\left(\mathrm{Sc}_{0.5} \mathrm{Nb}_{0.5}\right) \mathrm{O}_{3}$ & 2.6 & 73 & 400 & 89) \\
\hline RFE & $\mathrm{Bi}\left(\mathrm{Mg}_{2 / 3} \mathrm{Nb}_{1 / 3}\right) \mathrm{O}_{3}$-doped $\left(\mathrm{K}_{0.5} \mathrm{Na}_{0.5}\right) \mathrm{NbO}_{3}$ & 4.08 & 62 & 300 & 91) \\
\hline $\mathrm{RFE}$ & $\mathrm{La}\left(\mathrm{Mg}_{1 / 2} \mathrm{Ti}_{1 / 2}\right) \mathrm{O}_{3}$-doped $\mathrm{BiFeO}_{3}-\mathrm{BaTiO}_{3}$ & 1.66 & 82 & 130 & 94) \\
\hline RFE & $\mathrm{Bi}_{0.5} \mathrm{Na}_{0.5} \mathrm{TiO}_{3}-\mathrm{BaAl}_{0.5} \mathrm{Nb}_{0.5} \mathrm{O}_{3}$-doped $\mathrm{SrTiO}_{3}$ & 1.89 & 77 & 190 & 96) \\
\hline RFE & $\left(\mathrm{Na}_{0.5} \mathrm{Bi}_{0.5}\right) \mathrm{TiO}_{3}$-doped $\mathrm{SrTiO}_{3}$ & 1.70 & 69 & 210 & 98) \\
\hline RFE & $\mathrm{ZrO}_{2}$-doped $\mathrm{SrTiO}_{3}-\left(\mathrm{Na}_{0.5} \mathrm{Bi}_{0.5}\right) \mathrm{TiO}_{3}$ & 2.84 & 71 & 285 & 100) \\
\hline RFE & $\mathrm{Bi}_{0.5} \mathrm{Na}_{0.5} \mathrm{TiO}_{3}-\mathrm{Ba}_{0.94} \mathrm{La}_{0.04} \mathrm{Zr}_{0.02} \mathrm{Ti}_{0.98} \mathrm{O}_{3}$-doped $\mathrm{SrTiO}_{3}$ & 2.83 & 85 & 320 & 101) \\
\hline $\mathrm{RFE}$ & $\mathrm{BaTiO}_{3}$-doped $\mathrm{SrTiO}_{3}-\mathrm{Na}_{0.5} \mathrm{Bi}_{0.5} \mathrm{TiO}_{3}$ & 1.78 & 77 & 170 & 102) \\
\hline RFE & $\mathrm{SnO}_{2}$-doped $\mathrm{SrTiO}_{3}-\mathrm{Na}_{0.5} \mathrm{Bi}_{0.5} \mathrm{TiO}_{3}-\mathrm{BaTiO}_{3}$ & 2.25 & 79 & 240 & 103) \\
\hline RFE & Nd-doped $\mathrm{BiFeO}_{3}-\mathrm{BaTiO}_{3}$ (multilayer) & $\begin{array}{l}1.82 \\
6.74\end{array}$ & $\begin{array}{l}41 \\
77\end{array}$ & $\begin{array}{l}180 \\
540\end{array}$ & 95) \\
\hline $\mathrm{AFE}$ & $\mathrm{Pb}_{0.97} \mathrm{La}_{0.02}\left(\mathrm{Zr}_{0.90} \mathrm{Sn}_{0.05} \mathrm{Ti}_{0.05}\right) \mathrm{O}_{3}$ & 4.43 & 61 & 227 & 112) \\
\hline $\mathrm{AFE}$ & $\left(\mathrm{Pb}_{0.97} \mathrm{La}_{0.02}\right)\left(\mathrm{Zr}_{0.8} \mathrm{Sn}_{0.145} \mathrm{Ti}_{0.055}\right) \mathrm{O}_{3}$ & 4.38 & $\sim 72$ & $\sim 250$ & 118) \\
\hline $\mathrm{AFE}$ & $\mathrm{Pb}_{0.97} \mathrm{La}_{0.02}\left(\mathrm{Zr}_{0.50} \mathrm{Sn}_{0.44} \mathrm{Ti}_{0.06}\right) \mathrm{O}_{3}$ & 4.2 & 82 & 260 & 114) \\
\hline $\mathrm{AFE}$ & $\mathrm{Pb}_{0.97} \mathrm{La}_{0.02}\left(\mathrm{Zr}_{0.58} \mathrm{Sn}_{0.35} \mathrm{Ti}_{0.07}\right) \mathrm{O}_{3}$ & 2.35 & 86 & $\sim 120$ & 120) \\
\hline $\mathrm{AFE}$ & Sr-doped $\left(\mathrm{Pb}_{0.97} \mathrm{La}_{0.02}\right)\left(\mathrm{Zr}_{0.75} \mathrm{Sn}_{0.195} \mathrm{Ti}_{0.055}\right) \mathrm{O}_{3}$ & 5.56 & 68 & $\sim 350$ & 116) \\
\hline $\mathrm{AFE}$ & $\left(\mathrm{Pb}_{0.87} \mathrm{Ba}_{0.1} \mathrm{La}_{0.02}\right)\left(\mathrm{Zr}_{0.68} \mathrm{Sn}_{0.24} \mathrm{Ti}_{0.08}\right) \mathrm{O}_{3}$ & 3.2 & - & 180 & 127) \\
\hline $\mathrm{AFE}$ & Y-doped $\left(\mathrm{Pb}_{0.87} \mathrm{Ba}_{0.1} \mathrm{La}_{0.02}\right)\left(\mathrm{Zr}_{0.65} \mathrm{Sn}_{0.3} \mathrm{Ti}_{0.05}\right) \mathrm{O}_{3}$ & 2.75 & 71 & 130 & 131) \\
\hline $\mathrm{AFE}$ & $\left(\mathrm{Pb}_{0.858} \mathrm{Ba}_{0.1} \mathrm{La}_{0.02} \mathrm{Y}_{0.008}\right)\left(\mathrm{Zr}_{0.65} \mathrm{Sn}_{0.3} \mathrm{Ti}_{0.05}\right) \mathrm{O}_{3}-\left(\mathrm{Pb}_{0.97} \mathrm{La}_{0.02}\right)\left(\mathrm{Zr}_{0.9} \mathrm{Sn}_{0.05} \mathrm{Ti}_{0.05}\right) \mathrm{O}_{3}$ & 4.65 & $\sim 60$ & 200 & 132) \\
\hline $\mathrm{AFE}$ & $\left(\mathrm{Pb}_{0.858} \mathrm{Ba}_{0.1} \mathrm{La}_{0.02} \mathrm{Y}_{0.008}\right)\left(\mathrm{Zr}_{0.65} \mathrm{Sn}_{0.3} \mathrm{Ti}_{0.05}\right) \mathrm{O}_{3}-\left(\mathrm{Pb}_{0.97} \mathrm{La}_{0.02}\right)\left(\mathrm{Zr}_{0.9} \mathrm{Sn}_{0.05} \mathrm{Ti}_{0.05}\right) \mathrm{O}_{3}$ & 6.40 & 62 & $\sim 300$ & 133) \\
\hline $\mathrm{AFE}$ & $\left(\mathrm{Bi}_{0.46} \mathrm{Na}_{0.46} \mathrm{Ba}_{0.05} \mathrm{La}_{0.02}\right) \mathrm{Zr}_{0.03} \mathrm{Ti}_{0.97} \mathrm{O}_{3}$ & 1.89 & - & 83 & 141) \\
\hline $\mathrm{AFE}$ & $\mathrm{Bi}_{0.55} \mathrm{Na}_{0.45} \mathrm{TiO}_{3}-\mathrm{BaTiO}_{3}$ & 1.76 & - & $\sim 80$ & 143) \\
\hline $\mathrm{AFE}$ & La-doped $\left(\mathrm{Bi}_{0.5} \mathrm{Na}_{0.5}\right)_{0.94} \mathrm{Ba}_{0.06} \mathrm{TiO}_{3}$ & 1.66 & - & 105 & 147) \\
\hline $\mathrm{AFE}$ & $\mathrm{AgNbO}_{3}$ & 2.1 & - & 174 & 153) \\
\hline $\mathrm{AFE}$ & Ta-doped $\mathrm{AgNbO}_{3}$ & 4.2 & 69 & 240 & 154) \\
\hline $\mathrm{AFE}$ & $\mathrm{MnO}_{2}$-doped $\mathrm{AgNbO}_{3}$ & 2.5 & 56 & 150 & $152)$ \\
\hline $\mathrm{AFE}$ & W-doped $\mathrm{AgNbO}_{3}$ & 3.3 & 50 & 200 & 155) \\
\hline $\mathrm{AFE}$ & Bi-doped $\mathrm{AgNbO}_{3}$ & 2.45 & 55 & 175 & 156) \\
\hline
\end{tabular}



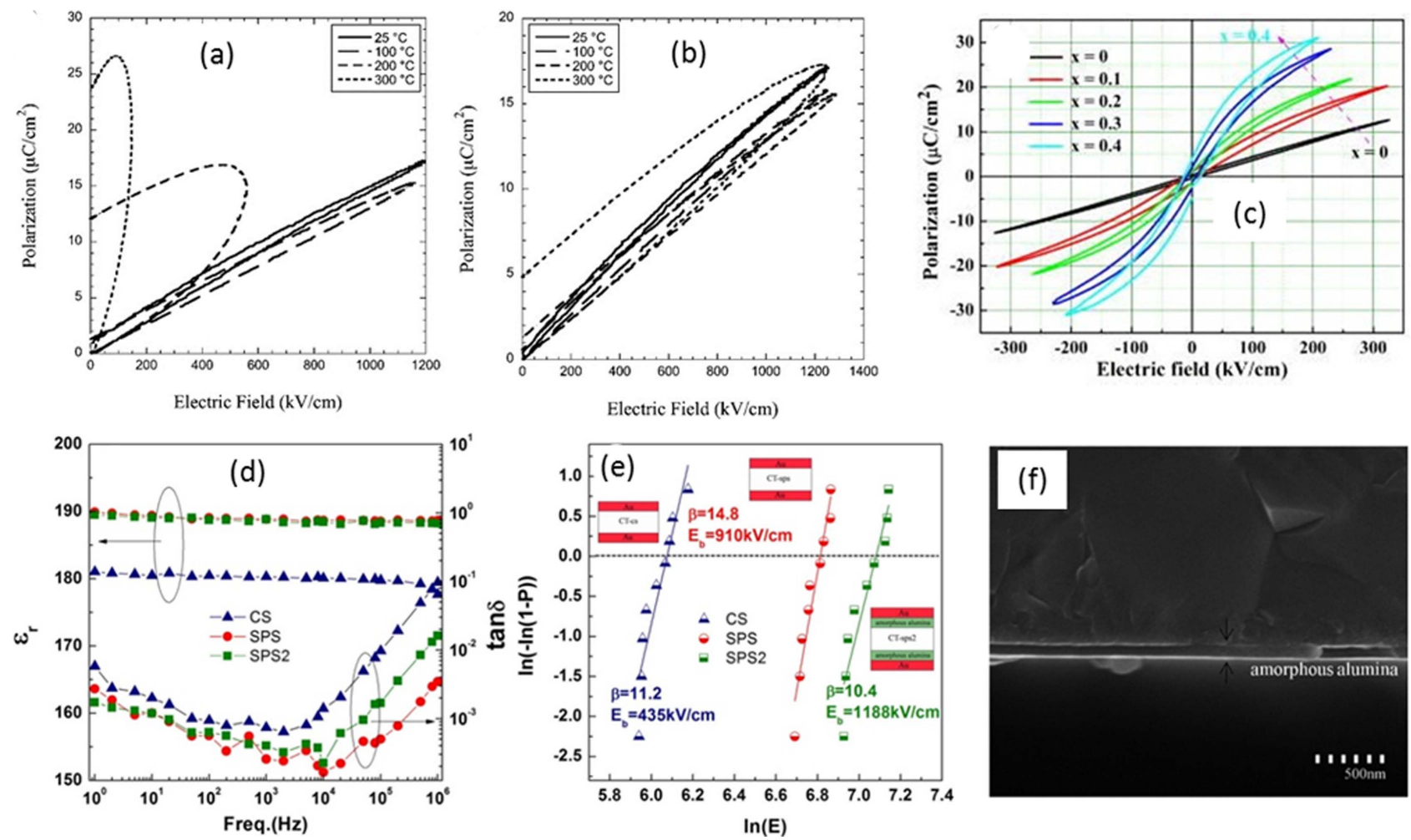

Fig. 4. $P$ - $E$ hysteresis loops of (a) pure and (b) $\mathrm{Mn}$-doped $0.8 \mathrm{CaTiO}_{3}-0.2 \mathrm{CaHfO}_{3}$ ceramics measured at different temperatures. ${ }^{14)}$ (c) $P$ - $E$ loops of $(1-x) \mathrm{SrTiO}_{3}-x \mathrm{Bi}_{0.48} \mathrm{La}_{0.02} \mathrm{Na}_{0.48} \mathrm{Li}_{0.02} \mathrm{Ti}_{0.98} \mathrm{Zr}_{0.02} \mathrm{O}_{3}(x=0-0.4)$ ceramics. ${ }^{22)}$ (d) Frequency dependence of the dielectric properties and (e) Weibull distribution of the dielectric breakdown strength of $\mathrm{CaTiO}_{3}$ ceramics subjected to conventional sintering and spark plasma sintering (the inset shows a schematic of the layered capacitor devices). (f) Crosssectional SEM image of the amorphous alumina coating deposited on the surface of the $\mathrm{CaTiO}_{3}$ ceramic. $^{20)}$

sintering technologies, ${ }^{20)}$ utilizing the core-shell structures of initial particles, ${ }^{21)}$ etc.

Shay et $a l .{ }^{14)}$ investigated the energy storage properties of pure and $\mathrm{Mn}$-doped $0.8 \mathrm{CaTiO}_{3}-0.2 \mathrm{CaHfO}_{3}(\mathrm{CHT})$ capacitors fabricated via tape casting. For the evaluation of the high electric field behavior of the CHT ceramics, single layers of CHT capacitors (thickness of $9 \mu \mathrm{m}$ ) consisting of Pt internal electrodes were fabricated. Pure CHT ceramics displayed a large energy density of $9 \mathrm{~J} / \mathrm{cm}^{3}$ at $1200 \mathrm{kV} / \mathrm{cm}$ at room temperature (RT) owing to their high BDS and low hysteresis loss, however, a drastic reduction in the energy density was observed at elevated temperatures (Fig. 4(a)). Further, incorporation of Mn dopants into the CHT matrix significantly enhanced the BDS up to $1300 \mathrm{kV} / \mathrm{cm}$ and resulted in a much higher energy density of $9.6 \mathrm{~J} / \mathrm{cm}^{3}$. Moreover, the temperature dependence of BDS and the ionic and electronic conductivities of the CHT ceramics were minimized (Fig. 4(b)).

In another study, Zhou et al. ${ }^{16)}$ investigated the energy storage properties of $\mathrm{Zr}$-doped $\mathrm{CaTiO}_{3}$ (CT) ceramics prepared by the conventional sintering method. With increasing concentration of $\mathrm{Zr}^{4+}$, the dielectric constant was found to decrease, while the BDS of the CT ceramics increased from $435 \mathrm{kV} / \mathrm{cm}$ to $756 \mathrm{kV} / \mathrm{cm}$. As a result, the highest energy storage density of $2.7 \mathrm{~J} / \mathrm{cm}^{3}$ was achieved for the $\mathrm{CaZr}_{0.4} \mathrm{Ti}_{0.6} \mathrm{O}_{3}$ system. The larger BDS achieved in the $\mathrm{Zr}$ - contained CT system is attributed to the decreased average field strength at the grain boundaries owing to its smaller grain size. Similarly, Mg-modified $\mathrm{SrTiO}_{3}$ (ST) ceramics exhibited finer grains with reduced grain activation energies, leading to much improved BDS $(362 \mathrm{kV} / \mathrm{cm})$ than pure $\mathrm{ST}$ ceramics $(279 \mathrm{kV} / \mathrm{cm})$; as a result, a larger $U_{\text {rec }}$ of $1.86 \mathrm{~J} /$ $\mathrm{cm}^{3}$ along with a higher efficiency $(\eta)$ of $89.3 \%$ were achieved in the $\mathrm{Sr}_{0.99} \mathrm{Mg}_{0.01} \mathrm{TiO}_{3}$ system. ${ }^{18)}$

Since the BDS greatly depends on grain size, many researchers anticipated that grain size reduction is a feasible way to increase the DBS of a system. Zhao et $a l{ }^{19)}$ produced fine-grained ST ceramics with an average grain size of $400 \mathrm{~nm}$ through the addition of $\mathrm{SiO}_{2}$, which led to an improvement in the BDS from $242 \mathrm{kV} / \mathrm{cm}$ to $361 \mathrm{kV} / \mathrm{cm}$ and resulted in a high $U_{\text {rec }}$ of $1.15 \mathrm{~J} / \mathrm{cm}^{3}$. The addition of low temperature sintering aids such as $\mathrm{ZnNb}_{2} \mathrm{O}_{6}(\mathrm{ZN})$ and $\mathrm{NiNb}_{2} \mathrm{O}_{6}$ (NN) also decreased the grain size of ST-based ceramics, along with significant reductions in dielectric constant and dielectric loss. Moderate addition (6 wt.\%) of $\mathrm{ZN}$ to $\mathrm{Sr}_{0.97} \mathrm{Nd}_{0.02} \mathrm{TiO}_{3}$ ceramics resulted in a high $U_{\text {rec }}$ of $2.37 \mathrm{~J} / \mathrm{cm}^{3}$ at the applied electric field of $493 \mathrm{kV} / \mathrm{cm} .{ }^{15)}$ On the other hand, the addition of $\mathrm{NN}$ to $\mathrm{Sr}_{0.97} \mathrm{La}_{0.02} \mathrm{TiO}_{3}$ ceramics enhanced the BDS by boosting the grain boundary resistance, which led to an improved $U_{\text {rec }}$ of $1.36 \mathrm{~J} / \mathrm{cm}^{3}$ (at 324 $\mathrm{kV} / \mathrm{cm}) .{ }^{17)}$

Surface modifications of particles through high-resistance 
coatings were also employed to enhance the BDS of dielectric ceramics, where the coating acts as a shell and controls the grain growth occurring during sintering. Zeng et al. ${ }^{21)}$ adopted the core-shell method to improve the BDS of ST ceramics by using $\mathrm{SiO}_{2}$ as a coating layer. The $\mathrm{SiO}_{2}$ layers with controlled thicknesses $(2-13 \mathrm{~nm})$ were coated on finegrained ST particles by using Stöber process. The inter-diffusion occurring between the $\mathrm{SiO}_{2}$ shell and the ST cores during sintering facilitated grain growth suppression and secondary phase $\left(\mathrm{Sr}_{2} \mathrm{TiSi}_{2} \mathrm{O}_{8}\right)$ formation, which resulted in enhanced BDS with reduced polarization. As the concentration of $\mathrm{SiO}_{2}$ increased, an enhancement in the BDS was observed up to 3 wt. $\% \mathrm{SiO}_{2}$; above this concentration, BDS decreased due to abnormal grain growth. Optimized energy storage properties $\left(U_{\text {rec }}\right.$ of $1.2 \mathrm{~J} / \mathrm{cm}^{3}$ and $\eta$ of $78.1 \%$ at 310 $\mathrm{kV} / \mathrm{cm}$ ) were realized for ST coated with $2.5 \mathrm{wt} . \% \mathrm{SiO}_{2}$.

On the other hand, by taking advantage of doping with high permittivity (or high polarization) materials, it could be possible to enhance the energy storage properties of $\mathrm{LD}$ materials. In this fashion, Yang et al. obtained a high $U_{\text {rec }}$ of $2.59 \mathrm{~J} / \mathrm{cm}^{3}$ along with an $\eta$ of $85 \%$ even at the low electric field of $323 \mathrm{kV} / \mathrm{cm}$ in ST ceramics by doping with $\mathrm{Bi}_{0.48} \mathrm{La}_{0.02} \mathrm{Na}_{0.48} \mathrm{Li}_{0.02} \mathrm{Ti}_{0.98} \mathrm{Zr}_{0.02} \mathrm{O}_{3}$ (BLNLTZ). ${ }^{22)}$ As shown in Fig. 4(c), the incorporation of BLNLTZ in ST ceramics significantly enhanced the saturation polarization from 7.95 $\mathrm{\mu C} / \mathrm{cm}^{2}$ to $30.35 \mu \mathrm{C} / \mathrm{cm}^{2}$ by decreasing the BDS of the ST ceramics. In another study, substitution of $\mathrm{BiScO}_{3}$ into the crystal lattice of $\mathrm{CaTiO}_{3}$ resulted in improved dielectric and ferroelectric properties with enhanced BDS, which resulted in a higher $U_{\text {rec }}$ of $1.55 \mathrm{~J} / \mathrm{cm}^{3}$ and $\eta$ of $90.4 \%$ at $270 \mathrm{kV} / \mathrm{cm}$, along with a power density of $1.79 \mathrm{MW} / \mathrm{cm}^{3}$ in $0.9 \mathrm{CaTiO}_{3}$ $0.1 \mathrm{BiScO}_{3}$ ceramics. ${ }^{23)}$ The enhanced energy storage properties were attributed to the enlarged bandgap caused by a strong hybridization between the $\mathrm{O}_{2 \mathrm{p}}$ and $\mathrm{Ti}_{3 \mathrm{~d}}$ in the valence and conduction bands, as well as $\mathrm{O}_{2 \mathrm{p}}$ and $\mathrm{Sc}_{3 \mathrm{~d}}$ hybridization in the conduction band.

Usually, enhancement in energy storage properties is achieved in LDs by compromising BDS or $\varepsilon_{r}$. It would be more beneficial if there is an improvement in both BDS and $\mathcal{E}_{r}$ or an improvement in one property by maintaining the other property constant, though it is challenging. In this regard, few attempts have been made to improve the BDS as well as $\varepsilon_{r}$ to realize high energy density properties. Zhou et $a l .{ }^{20)}$ produced fine-grained $(\sim 1 \mu \mathrm{m})$ high-density (99\% of theoretical density) $\mathrm{CaTiO}_{3}$ (CT) ceramics by employing spark plasma sintering (SPS) technique. The SPS samples exhibited significantly improved dielectric properties (Fig. 4(d)) along with high BDS (Fig. 4(e)), resulting in a greatly enhanced $U_{\text {rec }}$ of $6.9 \mathrm{~J} / \mathrm{cm}^{3}$ at the applied electric field of 910 $\mathrm{kV} / \mathrm{cm}$ compared to that of conventionally sintered CT ceramics $\left(U_{\text {rec }}\right.$ of $1.5 \mathrm{~J} / \mathrm{cm}^{3}$ at $435 \mathrm{kV} / \mathrm{cm}$ ). These remarkable properties of SPS-CT ceramics are attributed to the presence of discontinuous breakdown channels and microcrack networks, and the improved resistivity and thermal conductivity associated with small and uniform microstructures. In addition, with the introduction of amorphous alumina thin films in between the SPS-CT ceramic and the electrodes (SPS2), as shown in Fig. 4(f), a much improved BDS of $1188 \mathrm{kV} / \mathrm{cm}$ and $U_{\text {rec }}$ of $11.8 \mathrm{~J} / \mathrm{cm}^{3}$ were obtained.

\subsection{Paraelectric ceramics}

In contrast to $\mathrm{LD}$, nonlinear dielectrics such as $\mathrm{PE}$ ceramics having Curie temperatures below room temperature (RT) exhibit moderate $\mathcal{E}_{r}$ and BDSs with low dielectric losses and weakly nonlinear $P$ - $E$ hysteresis that are promising for energy storage applications. Initially, Fletcher et al. ${ }^{24)}$ demonstrated the feasibility of achieving the maximum energy storage density by using PE ceramic compositions (Sr-doped $\mathrm{BaTiO}_{3} ; \mathrm{BST}$ ) and realized energy storage of up to $8 \mathrm{~J} / \mathrm{cm}^{3}$ at $1000 \mathrm{kV} / \mathrm{cm}$. Afterwards, many efforts have been made to improve the energy storage performance of $\mathrm{PE}$ ceramics. Dong et $a l .^{25)}$ investigated the energy storage properties of $\mathrm{ZnO}$-doped $\mathrm{Ba}_{0.3} \mathrm{Sr}_{0.7} \mathrm{TiO}_{3}(\mathrm{BST}+x$ wt. $\% \mathrm{ZnO}(x$ $=0-5)$ ) ceramics prepared by conventional sintering. The doping of $\mathrm{ZnO}$ to BST promoted densification and grain size reduction. As a result, improvements in the $\varepsilon_{r}$ and BDS and a reduction in $\tan \delta$ were observed at the optimal composition of BST +1.6 wt.\% $\mathrm{ZnO}$, leading to a higher $U_{\text {rec }}$ of $3.9 \mathrm{~J} /$ $\mathrm{cm}^{3}$ at $400 \mathrm{kV} / \mathrm{cm}$. In another study, enhancement in DBS and reduction in $\tan \delta$ were observed at the expense of $\varepsilon_{r}$ in BST ceramics doped with $\mathrm{MgO}$ nanopowder. ${ }^{26)}$ The sample with the composition $0.7 \mathrm{BST}-0.3 \mathrm{MgO}$ exhibited the maximum $U_{\text {rec }}$ of $1.14 \mathrm{~J} / \mathrm{cm}^{3}$ at $331 \mathrm{kV} / \mathrm{cm}$.

Many studies have been conducted on the effect of grain size on the energy storage properties of BST-based ceramics as a result of the increasing requirement of miniaturization of electronic components. ${ }^{27-29)}$ Song et al. ${ }^{27)}$ prepared BST ceramics with different grain sizes (in the range 0.5-5.6 $\mu \mathrm{m}$ ) by using the conventional sintering method and varying the sintering temperature. As the grain size decreased from 5.6 $\mu \mathrm{m}$ to $0.5 \mu \mathrm{m}, \mathcal{E}_{\mathrm{r}}$ decreased with the appearance of a diffusetype transition (due to internal stress effect and polar nanoregions (PNRs)), whereas the BDS and maximum polarization were significantly enhanced. The improvement in the BDS is attributed to the enhanced grain boundary density. As a result, an improved $U_{\text {rec }}$ of $1.28 \mathrm{~J} / \mathrm{cm}^{3}$ at 243 $\mathrm{kV} / \mathrm{cm}$ was achieved in BST ceramics with an average grain size of $0.5 \mu \mathrm{m}$. In another study, BST ceramics of various grain sizes $(0.405-1.635 \mu \mathrm{m})$ were synthesized by oxalate co-precipitation method and conventional and plasma-activated sintering (PAS) methods. ${ }^{28)}$ Although the BST ceramics prepared through the PAS method exhibited small grains $(0.405-0.550 \mu \mathrm{m})$ with a dense microstructure, the $\operatorname{BDS}(154-191 \mathrm{kV} / \mathrm{cm})$ and $U_{\text {rec }}\left(0.63-0.94 \mathrm{~J} / \mathrm{cm}^{3}\right)$ values are very small owing to the smaller relative grain boundary resistance that resulted from residual oxygen vacancies $\left(R_{\mathrm{gb}} /\left(\mathrm{R}_{\mathrm{g}}+\mathrm{R}_{\mathrm{gb}}\right)\right.$, where $\mathrm{R}_{\mathrm{g}}$ and $\mathrm{R}_{\mathrm{gb}}$ are the resistances of the grains and grain boundaries). On the other hand, the conventionally sintered samples displayed larger $R_{\mathrm{gb}} /\left(\mathrm{R}_{\mathrm{g}}+\mathrm{R}_{\mathrm{gb}}\right)$ values than the PAS samples, and showed an increasing trend with decreasing grain size, resulting in a larger $U_{\text {rec }}$ of $1.70 \mathrm{~J} / \mathrm{cm}^{3}$ at $281 \mathrm{kV} / \mathrm{cm}$ that was obtained for the BST 
ceramic with grain size $0.66 \mu \mathrm{m}$.

Grain refinement had a great impact on the improvement of dielectric strength; however, it is difficult to achieve fine grains with uniform microstructures by using the conventional sintering route due to the uncontrolled grain growth that occurs during sintering. In this regard, various other sintering techniques such as microwave sintering $(\mathrm{MWS})^{30)}$ and SPS $^{31,32)}$ techniques have been employed to improve the energy storage properties of BST PE ceramics. Zhe et al. ${ }^{30}$ produced fine-grained $(\sim 0.65 \pm 0.17 \mu \mathrm{m})$ BST ceramics with a dense and uniform microstructure by using the MWS method. The as-sintered MWS sample (at $990^{\circ} \mathrm{C}$ ) exhibited high $\tan \delta(>0.1)$ and further thermal annealing in air at $1100^{\circ} \mathrm{C}$ for $10 \mathrm{~h}$ improved both the dielectric properties $\left(\varepsilon_{\mathrm{r}}\right.$ $\sim 910$ and $\tan \delta \sim 0.01$ ) and the insulation properties. As a result, the thermally annealed MWS sample exhibited the maximum BDS of $180 \mathrm{kV} / \mathrm{cm}$, compared to the conventionally sintered samples $(130-154 \mathrm{kV} / \mathrm{cm})$, which resulted in a larger $U_{\text {rec }}$ of $1.15 \mathrm{~J} / \mathrm{cm}^{3}$ with an efficiency of $82 \%$. In another study, Huang et al. ${ }^{31)}$ investigated the SPS effect on the energy storage properties of BST ceramics. For this, ultrafine BST powders (45-105 nm) synthesized by sol-gel method and calcined at various temperatures $\left(750-1050^{\circ} \mathrm{C}\right.$ for $3 \mathrm{~h}$ ) have been used. Further, the samples were sintered at $1000^{\circ} \mathrm{C}$ for $5 \mathrm{~min}$. The rapid densification promoted by SPS allows direct grain boundary diffusion at higher temperatures by circumventing the surface diffusions that occur at low temperatures. As a result, highly dense microstructures (relative densities above 99\%) with fine grains (173-238 nm) and few pores and cracks were obtained in the SPS sample. With increasing calcination temperature, enhancement in $\mathcal{E}_{r}$ and $\mathrm{BDS}$ and reduction in $\tan \delta$ were observed up to $950^{\circ} \mathrm{C}$, which resulted in a maximum $U_{\text {rec }}$ of $1.23 \mathrm{~J} / \mathrm{cm}^{3}$ at $240 \mathrm{kV} / \mathrm{cm}$ and efficiency of $94.5 \%$; above this temperature, the properties slightly decreased. Usually, electrical breakdown in ceramics tends to occur at the weak links through the penetration of electrical currents at sufficiently high electric fields. However, electrical breakdown occurred in the SPS sample at relatively higher electric fields through the melting of grains rather than through the weak links. This significantly enhanced the BDS of the SPS sample containing fine grains with a pore-free microstructure, resulting in improved energy storage properties $\left(U_{\text {rec }}\right.$ of $1.13 \mathrm{~J} / \mathrm{cm}^{3}$ and $\eta$ of $86.8 \%$ ) compared to those of the conventionally sintered sample. ${ }^{32)}$

Since the sintering atmosphere also affects the microstructural and electrical properties of ceramic capacitors, some attempts have been made to investigate the effect of sintering atmosphere on the energy storage properties of BST-based paraelectric ceramics. ${ }^{33,34)}$ Jin et al. ${ }^{33)}$ synthesized BST powders by the hydrothermal method and subsequently sintered the ceramics in $\mathrm{N}_{2}$, air, and $\mathrm{O}_{2}$ atmospheres. The ceramics sintered in $\mathrm{N}_{2}$ and air atmospheres exhibited higher average grain sizes in the range 1.09-1.11 $\mu \mathrm{m}$, whereas the sample sintered in $\mathrm{O}_{2}$ displayed an average grain size of $0.44 \mu \mathrm{m}$. The smaller grains with a homoge- nous microstructure in the $\mathrm{O}_{2}$-sintered sample could be attributed to the reduction in oxygen vacancies, which hindered grain growth as well as mass transport during sintering. Consequently, the $\mathrm{O}_{2}$-sintered sample displayed relaxorlike behavior with diffused-type transition (diffuseness coefficient $=1.618$ ) and improved saturation polarization and BDS, which led to enhanced $U_{\text {rec }}$ of $1.08 \mathrm{~J} / \mathrm{cm}^{3}$ and $\eta$ of $73.8 \%$ at $167.5 \mathrm{kV} / \mathrm{cm}$ compared to the samples sintered in other atmospheres.

Gao et $a l .^{35)}$ achieved high energy storage properties in $\mathrm{Ba}_{0.7} \mathrm{Sr}_{0.3} \mathrm{TiO}_{3}-\mathrm{SrTiO}_{3}$ (BST-ST) multilayer ceramics by taking advantage of the high polarization of BST ceramics and the high BDS of ST ceramics. A series of BST-ST multilayer ceramics have been fabricated by laminating various periodic combinations of the BST and ST layers. Introduction of the ST layer greatly decreased the dielectric loss and enhanced the BDS, however, a further increase in the number of ST layers drastically increased the leakage current due to the large accumulation of space charges and oxygen vacancies at the heterogeneous interfaces. At the optimal combination of B5S (i.e., a periodic combination of 5 BST layers and 1 ST layer), the multilayer ceramic exhibited a high BDS of $220 \mathrm{kV} / \mathrm{cm}$ and $U_{\text {rec }}$ of $2.3 \mathrm{~J} / \mathrm{cm}^{3}$. Moreover, the BST-ST ceramics displayed good temperature- and frequency-stable dielectric properties.

In order to enhance the breakdown strength of the BST ceramics, the core-shell structure has been widely employed. Highly insulating oxides such as $\mathrm{Al}_{2} \mathrm{O}_{3}$ and $\mathrm{SiO}_{2}$ were used as coatings on PE particles. ${ }^{36-38)}$ Huang et al. prepared coreshell structures of BST@ $\mathrm{SiO}_{2}$ nanoparticles through the wet-chemical method and further sintered them by using the SPS technique. ${ }^{38)}$ Upon increasing the $\mathrm{SiO}_{2}$ concentration of BST $+x$ mol\% $\mathrm{SiO}_{2}$ (i.e., $x=0,5,8,12.5,25$, and 50), the average thickness of the $\mathrm{SiO}_{2}$ layer increased monotonously from $2.5 \mathrm{~nm}$ to $35 \mathrm{~nm}$. The SPS sintered sample displayed a significant amount of the secondary phase $(\mathrm{Ba}, \mathrm{Sr})_{2} \mathrm{TiSi}_{2} \mathrm{O}_{8}$, and it's intensity was enhanced with increasing $\mathrm{SiO}_{2}$ concentration. At lower concentrations $(x \leq$ 12.5) of $\mathrm{SiO}_{2}$, the BDS of the BST@ $\mathrm{SiO}_{2}$ ceramics significantly improved up to $400 \mathrm{kV} / \mathrm{cm}$ at the expense of $P_{\max }$. However, excess amount of the $\mathrm{SiO}_{2}$ coating worsened both the BDS and $P_{\max }$ of the BST@ $\mathrm{SiO}_{2}$ ceramics. The BST ceramics containing $8 \mathrm{~mol} \% \mathrm{SiO}_{2}$ were the optimal combinations owing to their large $U_{\text {rec }}$ of $1.6 \mathrm{~J} / \mathrm{cm}^{3}$ and $\eta$ of $90.9 \%$. In another study, BST nanoparticles coated with $\mathrm{SiO}_{2}$ and sintered using conventional sintering exhibited much improved energy storage properties such as a large $U_{\text {rec }}$ of $2 \mathrm{~J} / \mathrm{cm}^{3}$ and an $\eta$ of $80 \%$ even at the low electric field of $290 \mathrm{kV} / \mathrm{cm}^{37)} \mathrm{On}$ the other hand, the BST ceramics fabricated from the nanoparticles coated with both $\mathrm{Al}_{2} \mathrm{O}_{3}$ and $\mathrm{SiO}_{2}$ layers could withstand a larger electric field of up to $493 \mathrm{kV} / \mathrm{cm}$, as a result, an enormous energy storage density of $5.09 \mathrm{~J} / \mathrm{cm}^{3}$ was achieved. ${ }^{36)}$ Since glasses exhibit large BDS values, some attempts have been made to produce BST ceramics that can withstand higher electric fields by adding glasses. In this regard, Yang et $a l .^{39)}$ studied the effect of glass 
$\left(\mathrm{Bi}_{2} \mathrm{O}_{3}-\mathrm{B}_{2} \mathrm{O}_{3}-\mathrm{SiO}_{2} ; \mathrm{BBS}\right)$ addition on the energy storage properties of BST ceramics. The addition of glass to BST ceramics decreased the sintering temperature effectively and improved the frequency stability, BDS, and $P_{\max }$. The BST ceramics containing 9 wt\% BBS exhibited excellent energy storage properties of $U_{\text {rec }} 1.98 \mathrm{~J} / \mathrm{cm}^{3}$ and $\eta 90.57 \%$ at $279 \mathrm{kV} /$ $\mathrm{cm}$.

With respect to the other family of BST ceramics, Zhang et $a l .{ }^{40)}$ attempted to study the energy storage properties of Cadoped ST ceramics. The incorporation of $\mathrm{Ca}$ ions at the Srsites of the ST ceramics led to improvements in $\varepsilon_{\mathrm{r}}$ and BDS, while a reduction in $\tan \delta$ was observed. At the applied electric field of $333 \mathrm{kV} / \mathrm{cm}$, the $\mathrm{Sr}_{0.98} \mathrm{Ca}_{0.02} \mathrm{TiO}_{3}$ sample revealed a $U_{\text {rec }}$ of $1.95 \mathrm{~J} / \mathrm{cm}^{3}$, with $\eta$ being $72.3 \%$, which is 2.8 times larger than that of pure ST ceramics.

Since the materials with a PE phase at RT display outstanding energy storage properties, many researchers explored the idea of shifting the Curie temperature $\left(T_{\mathrm{C}}\right)$ of ferroelectrics through intentional doping. Zhou et al ${ }^{41)}$ succeeded in reducing the $T_{\mathrm{C}}$ of the $\left(\mathrm{Ba}_{0.85} \mathrm{Ca}_{0.15}\right)\left(\mathrm{Zr}_{0.10} \mathrm{Ti}_{0.90}\right) \mathrm{O}_{3}$ (BCZT) ceramics to below RT by doping with a B-site $\left(\mathrm{Ni}_{1 / 3} \mathrm{Nb}_{2 / 3}\right)^{4+}(\mathrm{NN})$ complex ion. The BCZT-NN ceramics showed a single-phase perovskite structure and good frequency and temperature stability. Furthermore, doping with NN reduced the $P-E$ hysteresis loss and enhanced the BDS of BCZT ceramics. The maximum $U_{\text {rec }}$ of $0.66 \mathrm{~J} / \mathrm{cm}^{3}$ with an $\eta$ of $88.1 \%$ at $200 \mathrm{kV} / \mathrm{cm}$ was achieved in the case of BCZT-0.3NN. In another study, $\mathrm{YNbO}_{4}(\mathrm{YN})$ dopant was used to tailor the dielectric and ferroelectric properties of BT ceramics. ${ }^{42)}$ With increasing $\mathrm{YN}$ concentration, the $T_{\mathrm{C}}$ of $(1-x)$ BT- $x \mathrm{YN}(x=0-15 \%)$ ceramics was shifted from $130^{\circ} \mathrm{C}$ to below RT, along with a significant suppression in the dielectric nonlinearity and the $P-E$ loops becoming slimmer with lower $P_{\mathrm{r}}$ and enhanced BDS values; as a result, a maximum $U_{\text {rec }}$ of $0.614 \mathrm{~J} / \mathrm{cm}^{3}$ with an $\eta$ of $86.8 \%$ at $173 \mathrm{kV} / \mathrm{cm}$ was obtained for $0.93 \mathrm{BT}-0.07 \mathrm{YN}$, which was 2.4 times larger than that of the pure BT ceramic.

\subsection{Ferroelectric ceramics}

$\mathrm{FE}$ ceramics exhibiting nonlinear electric field dependent polarization characteristics with high saturation polarizations (high permittivities) are of particular interest in achieving superior energy storage properties under smaller electric fields. However, the high dielectric loss and fat $P-E$ hysteresis loops resulting from domain switching enforce the low BDS as well as smaller energy storage density of FE ceramics. Among the various FE ceramics, a few efforts have been made to improve the energy storage properties of $(\mathrm{Bi}, \mathrm{Na}) \mathrm{TiO}_{3}(\mathrm{BNT}),{ }^{43-45)} \mathrm{Ba}(\mathrm{Zr}, \mathrm{Ti}) \mathrm{O}_{3} \quad(\mathrm{BZT}),{ }^{46-48)} \mathrm{BaTiO}_{3}$ (BT) ${ }^{49-52)}$ and $(\mathrm{K}, \mathrm{Na}) \mathrm{NbO}_{3}(\mathrm{KNN})^{53)}$ based ceramics. Gao et $a l^{43)}$ studied the effect of tetragonality ratio (c/a ratio) on the energy storage properties of (0.9- $x) \mathrm{Bi}_{0.5} \mathrm{Na}_{0.5} \mathrm{TiO}_{3}-x \mathrm{Ba}$ -
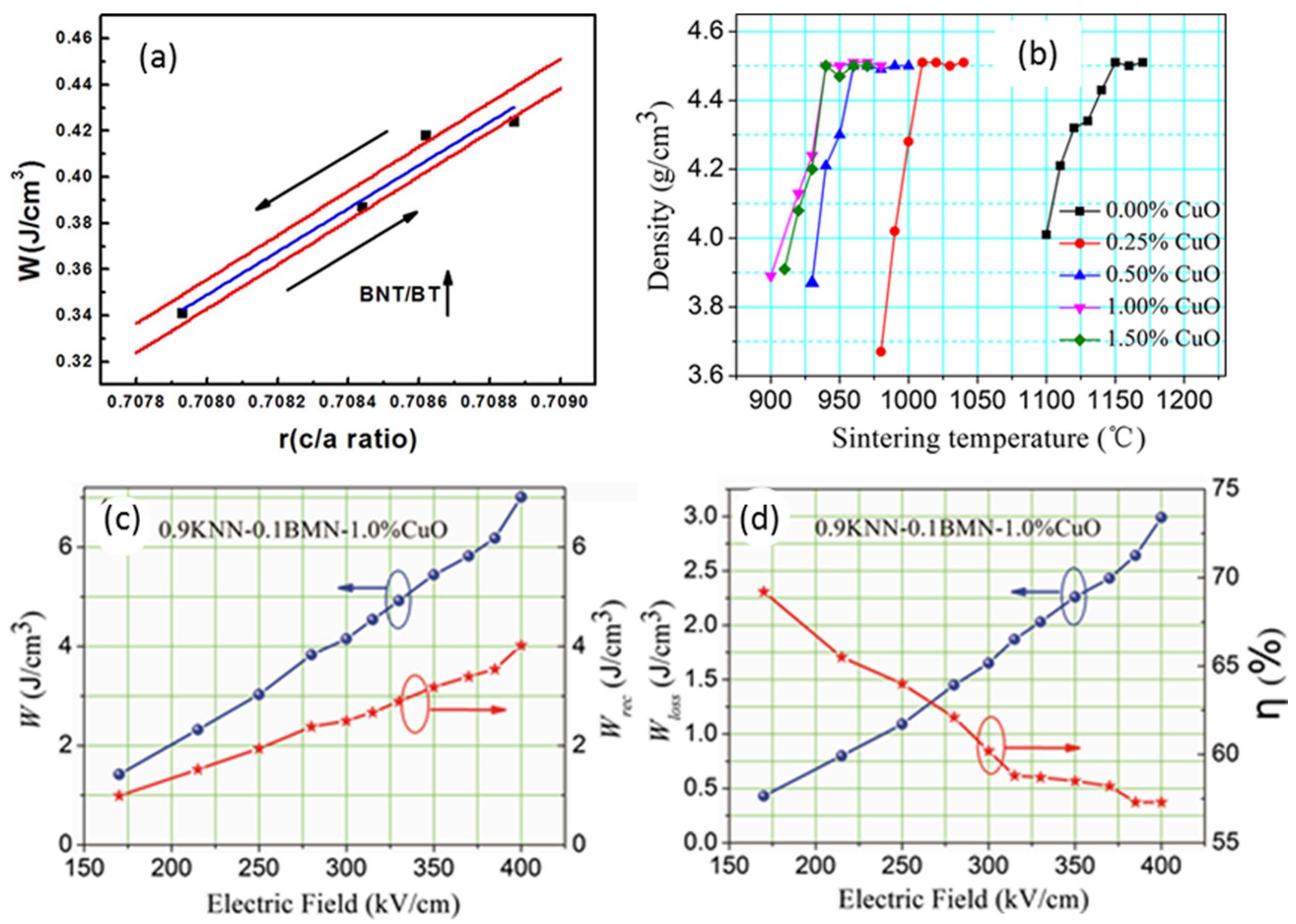

Fig. 5. (a) cla ratio (marked in black dots)-dependent energy storage density of $\mathrm{Bi}_{0.5} \mathrm{Na}_{0.5} \mathrm{TiO}_{3}-x \mathrm{BaTiO}_{3}-0.1 \mathrm{~K}_{0.5} \mathrm{Na}_{0.5} \mathrm{NbO}_{3}(x=$ 0.060-0.069) ceramics; here, the calculated result is indicated by the red line, whereas the linear fitting result is indicated by the blue line. The direction of arrow represents the increase in the BNT/BT ratio. ${ }^{43)}$ (b) Variation in the relative density of $0.9\left(\mathrm{~K}_{0.5} \mathrm{Na}_{0.5}\right) \mathrm{NbO}_{3}-0.1 \mathrm{Bi}\left(\mathrm{Mg}_{2 / 3} \mathrm{Nb}_{1 / 3}\right) \mathrm{O}_{3}-x$ mol\% $\mathrm{CuO}(x=0-1.5)$ ceramics as a function of sintering temperature. (c) and (d) illustrate the energy storage properties of $0.9 \mathrm{KNN}-0.1 \mathrm{BMN}-1.0 \% \mathrm{CuO}$ ceramics. $^{53)}$ 
$\mathrm{TiO}_{3}-0.1 \mathrm{~K}_{0.5} \mathrm{Na}_{0.5} \mathrm{NbO}_{3}(x=0.060-0.069)$ [BNT-BT-KNN] ceramics by varying the $\mathrm{BNT} / \mathrm{BT}$ ratio. As the $\mathrm{BNT} / \mathrm{BT}$ ratio increased, the cla ratio also increased initially (up to $x=$ 0.063), and then decreased. The sample having a larger $c / a$ ratio $(\sim 0.709)$ exhibited the maximum value of $P_{\mathrm{s}}-P_{\mathrm{r}}$, which led to an enhanced $U_{\text {rec }}$ of $0.424 \mathrm{~J} / \mathrm{cm}^{3}$ at $50 \mathrm{kV} / \mathrm{cm}$. The $c / a$ ratio dependence of the $U_{\text {rec }}$ of BNT-BT-KNN ceramics is depicted in Fig. 5(a), which reveals an almost linear relation. In another study, highly dense BCT and BZT ceramics prepared by conventional sintering exhibited larger c/a ratios of 1.027 and 1.002, as a result, much improved energy densities of $1.41 \mathrm{~J} / \mathrm{cm}^{3}$ ( $\eta$ of $61 \%$ ) and $0.71 \mathrm{~J} / \mathrm{cm}^{3}$ ( $\eta$ of $19 \%$ ) at $150 \mathrm{kV} / \mathrm{cm}$, respectively, were realized. $\left.{ }^{47}\right)$ On the contrary, in spite of the decrease in the $c / a$ ratio from 1.010 to 1.003, $\mathrm{NaNbO}_{3}(\mathrm{NN})$ modified $0.92 \mathrm{BaTiO}_{3}-0.08 \mathrm{~K}_{0.5} \mathrm{Bi}_{0.5} \mathrm{TiO}_{3}$ (BTKBT) ceramics displayed much improved energy storage properties $\left(U_{\text {rec }}\right.$ of $1.96 \mathrm{~J} / \mathrm{cm}^{3}$ and $\eta$ of $67.4 \%$ at the electric field of $220 \mathrm{kV} / \mathrm{cm}$ ) due to the reduction in grain size that was facilitated by the defect dipoles $\left(V_{N a}^{\prime}-V_{\ddot{O}}-V_{N a}^{\prime}\right)$ induced during sintering. ${ }^{52)}$

Sreenivas et $a l^{46)}$ investigated the energy storage properties of (1- $x$ ) BZT- $x$ BCT $(x=0.10-0.30)$ based ceramic capacitors sintered at $1600^{\circ} \mathrm{C}$. For all compositions, the ceramics exhibited a single-phase perovskite structure without any secondary phases and the average grain sizes were in the range $20-30 \mu \mathrm{m}$. The ceramic corresponding to $x=0.15$ displayed a relatively higher $\varepsilon_{\mathrm{r}}(8400)$ with low $\tan \delta$ and large BDS of $170 \mathrm{kV} / \mathrm{cm}$, leading to an enhanced $U_{\text {rec }}$ of $0.68 \mathrm{~J} / \mathrm{cm}^{3}$ with an $\eta$ of $72 \%$.

Microstructural modification of FE nanoparticles was also adopted for improving the energy storage properties of FE ceramics. Ma et $a l .^{50)}$ utilized the double coating technique to prepare multilevel core-shell structures of BT@ $\mathrm{La}_{2} \mathrm{O}_{3} @ \mathrm{SiO}_{2}$ particles. The combined effects of structural distortion, which led to an improvement in the dielectric property due to $\mathrm{La}_{2} \mathrm{O}_{3}$ and the acceleration of sintering, as well as density promotion by $\mathrm{SiO}_{2}$, led to enhanced energy storage properties $\left(U_{\text {rec }}\right.$ of $0.54 \mathrm{~J} / \mathrm{cm}^{3}$ and $\eta$ of $85.7 \%$ at $136 \mathrm{kV} / \mathrm{cm}$ ) in BT@ $\mathrm{La}_{2} \mathrm{O}_{3} @ \mathrm{SiO}_{2}$ ceramics containing 9 wt\% $\mathrm{SiO}_{2}$. However, excess amounts of $\mathrm{SiO}_{2}(>9 \mathrm{wt} \%)$ promoted the interface reaction and the formation of the $\mathrm{Ba}_{2} \mathrm{TiSi}_{2} \mathrm{O}_{8}$ secondary phase, which lead to the collapse of the energy storage properties.

It is well known that fine grains with pore-free structures are favorable for improving the BDS and energy density properties of ceramics. Since the microstructural features of ceramics are affected by the fabrication method, many researchers have attempted to tailor the energy storage properties of the FE ceramics fabricated by various methods. ${ }^{45,51)} \mathrm{Xu}$ et $a l .{ }^{45)}$ investigated the energy storage properties of (1- $x)$ 0.93BNT-0.07BT- $x \mathrm{KNbO}_{3}(x=0-0.07)$ (BNTBT$\mathrm{KN}$ ) ceramics synthesized via wet-chemical method and sintered using the conventional method. Initially, the BNT-BT and $\mathrm{KN}$ powders were synthesized by sol-gel and hydrothermal methods to obtain fine powders and the stoichiometric mixtures were sintered at $1050-1175^{\circ} \mathrm{C}$ for $2 \mathrm{~h}$. The ceramic with $x=0.05(5 \mathrm{KN})$ exhibited the maximum $U_{\text {rec }}$ of $1.72 \mathrm{~J} /$ $\mathrm{cm}^{3}$ owing to its higher BDS $(168 \mathrm{kV} / \mathrm{cm})$, increased $\varepsilon_{\mathrm{r}}$ (1550), and reduced grain size $(1.03 \mu \mathrm{m})$ compared to those of pure BNTBT ceramics. Moreover, the wet-chemical synthesized $5 \mathrm{KN}$ ceramics displayed an almost $90 \%$ enhanced BDS and 74\% enhanced recoverable energy density compared with the $5 \mathrm{KN}$ ceramics prepared via the solid-state method $\left(U_{\text {rec }}\right.$ of $0.99 \mathrm{~J} / \mathrm{cm}^{3}$ at $\left.88.5 \mathrm{kV} / \mathrm{cm}\right)$. In another study, Ma et $a l .{ }^{51)}$ demonstrated the feasibility of achieving finegrained highly dense BT ceramics even at sufficiently low temperatures by employing the cold sintering method. The pellets were prepared from hydrothermal precursors of BT nanoparticles and cold sintered at $180^{\circ} \mathrm{C}$ for different dwelling times (15-120 min). Subsequently, all sintered samples were dried and annealed in air at $900^{\circ} \mathrm{C}$ for $3 \mathrm{~h}$ to induce densification. Among all the samples, that sintered for 60 min exhibited a relatively high density (96.8\%) and improved dielectric properties ( $\varepsilon_{\mathrm{r}}$ of 2332 and $\tan \delta$ of 0.01 at $1 \mathrm{kHz}$ ). The fine grains associated with the high density resulted in an improved energy density of $1.45 \mathrm{~J} / \mathrm{cm}^{3}$ with an $\eta$ of $85.6 \%$ at the applied electric field of $90 \mathrm{kV} / \mathrm{cm}$.

By utilizing the potential of sintering aids to reduce the sintering temperature, $\mathrm{Qu}$ et $a l^{53)}$ produced highly dense fine-grained $0.9\left(\mathrm{~K}_{0.5} \mathrm{Na}_{0.5}\right) \mathrm{NbO}_{3}-0.1 \mathrm{Bi}\left(\mathrm{Mg}_{2 / 3} \mathrm{Nb}_{1 / 3}\right) \mathrm{O}_{3} \quad(\mathrm{KNN}$ $\mathrm{BMN}$ ) ceramics through liquid phase sintering. The sintering temperatures of the $\mathrm{KNN}-\mathrm{BMN}$ ceramics were effectively decreased from $1150^{\circ} \mathrm{C}$ to $930^{\circ} \mathrm{C}$ with the addition of $\mathrm{CuO}$, as shown in Fig. 5(b). Moreover, CuO-modified KNNBMN (KNN-BMN-1.0 mol\% CuO) ceramics could withstand high electric fields of up to $400 \mathrm{kV} / \mathrm{cm}$ owing to their dense microstructure without any porosity and displayed a large polarization difference $\left(P_{\mathrm{s}}-P_{\mathrm{r}}\right)$ due to the strong hybridization between $\mathrm{Bi}_{6 p}$ and $\mathrm{O}_{2 p}$, leading to exceptional energy storage properties ( $U_{\text {rec }}$ of $4.02 \mathrm{~J} / \mathrm{cm}^{3}$ and $\eta$ of $57.3 \%$ ) (Fig. $5(\mathrm{c}-\mathrm{d}))$.

\subsection{Relaxor ferroelectric ceramics}

RFE ceramics are drawing much attention for energy storage applications owing to their outstanding dielectric and FE properties. Similar to the FE, RFE materials also exhibit large permittivities and saturation polarizations, but possess lower remnant polarizations and slimmer hysteresis loops, which are essential for realizing extremely high energy densities and efficiencies. These materials are mainly characterized by the broad frequency-dependent peak of the temperature-dependent dielectric susceptibility and the slim $P-E$ hysteresis loops. The RFE behavior is assumed to originate from the PNR, which usually appears below Burn's temperature.

\subsubsection{Lead-based RFE ceramics}

Quite a few lead-based relaxor ceramics such as $\mathrm{PbZrO}_{3}$ $\left(\mathrm{SrTiO}_{3}\right){ }^{54)} \mathrm{Pb}\left(\mathrm{Mn}_{1 / 3} \mathrm{Nb}_{2 / 3}\right) \mathrm{O}_{3}-\mathrm{PbTiO}_{3},{ }^{55-57)}$ and La-doped $\mathrm{Pb}(\mathrm{Zr}, \mathrm{Ti}) \mathrm{O}_{3}{ }^{58-60)}$ were examined for energy storage applications by considering the human health and environmental concerns and their thermal stabilities. Recently, Zhang et 

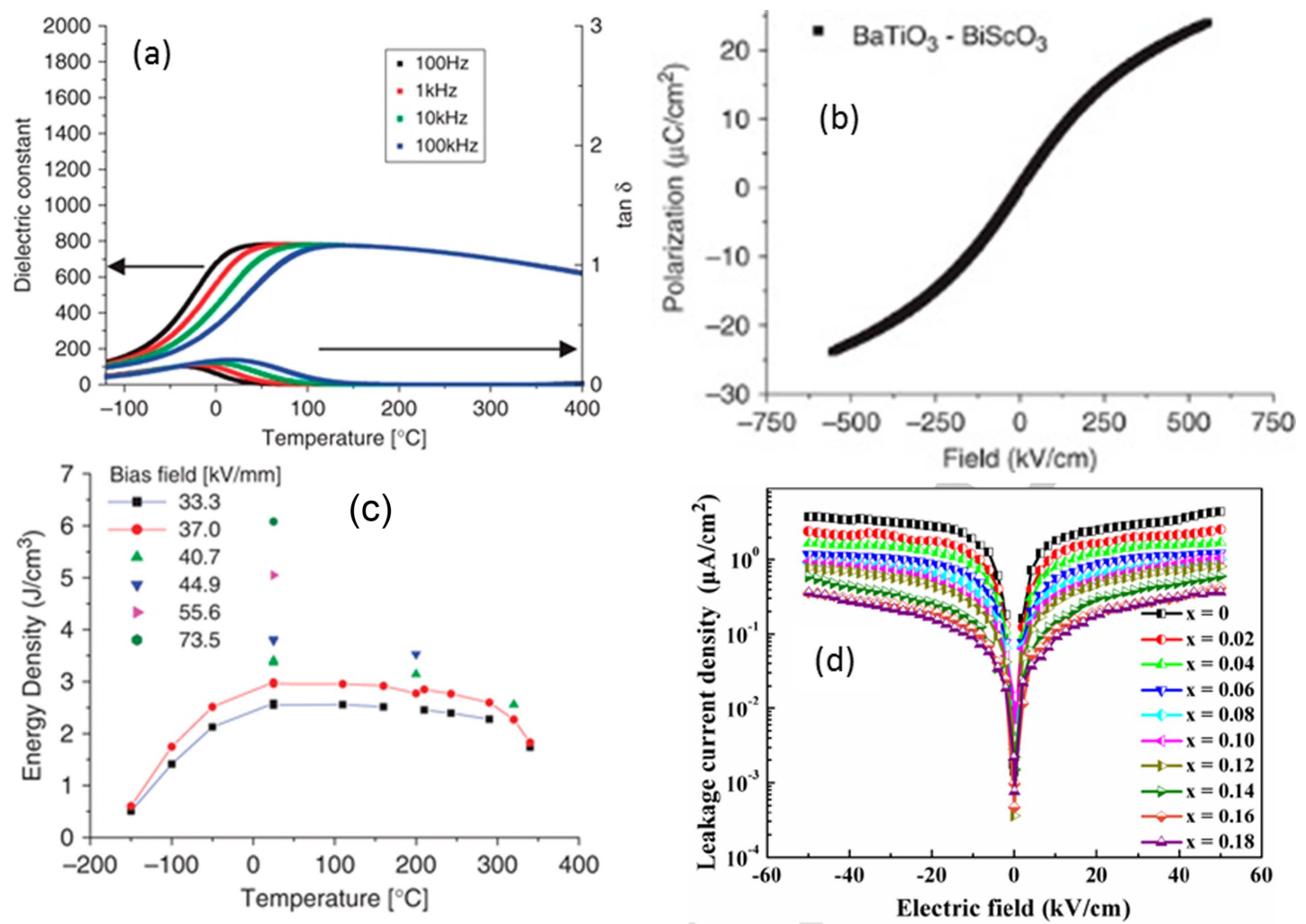

Fig. 6. (a) Temperature dependence of the dielectric properties of $0.7 \mathrm{BaTiO}_{3}-0.3 \mathrm{BiScO}_{3}$ ceramic measured at different frequencies, (b) P-E loop of the BT-BS ceramic measured at room temperature, and (c) the energy storage density of a thin BT-BS dielectric layer measured at different electric fields. ${ }^{61)}$ (d) Leakage current density properties of $\mathrm{Bi}_{(0.5-x)} \mathrm{La}_{x}\left(\mathrm{Na}_{0.82} \mathrm{~K}_{0.18}\right)_{0.5} \mathrm{Ti}_{0.96} \mathrm{Zr}_{0.02} \mathrm{Sn}_{0.02} \mathrm{O}_{3}$ $(x=0-0.18)$ ceramics, measured at room temperature. ${ }^{70)}$

$a l .{ }^{54)}$ investigated the energy storage performance of $(1-x)$ $\mathrm{PbZrO}_{3}-x \mathrm{SrTiO}_{3}(\mathrm{PZ}-\mathrm{ST})(x=10-30 \mathrm{~mol} \%)$ ceramics prepared by the solid state reaction method. The incorporation of ST in the PZ matrix induced relaxor behavior by transforming the macrodomains of $\mathrm{PZ}$ into microdomains, which resulted in slim hysteresis loops with enhanced saturation polarizations. As a result, a maximum $U_{\text {rec }}$ of $0.46 \mathrm{~J} / \mathrm{cm}^{3}$ with an $\eta$ of $79.3 \%$ at the applied electric field of $79.3 \mathrm{kV} / \mathrm{cm}$ was achieved in 0.7PZ-0.3ST relaxor ceramics. Moreover, 0.7PZ-0.3ST ceramics displayed oxygen-vacancy $\left(V_{\ddot{o}}\right)$-induced high-temperature dielectric relaxation. In another study, Zhang et al ${ }^{57)}$ reported relaxor behavior in $\mathrm{Pb}\left(\mathrm{Mn}_{1 / 3} \mathrm{Nb}_{2 / 3}\right) \mathrm{O}_{3^{-}}$ $\mathrm{PbTiO}_{3}(\mathrm{PMN}-\mathrm{PT})$ ceramics that was induced by the formation of complex defect dipoles $V_{\ddot{o}}-\mathrm{Nb}^{4+}$. Li et al. ${ }^{58)}$ investigated the effect of excess amount of lead $(\mathrm{PbO})$ on the energy storage properties of $\left(\mathrm{Pb}_{0.97(1+x)} \mathrm{La}_{0.02}\right)\left(\mathrm{Zr}_{0.95} \mathrm{Ti}_{0.05}\right) \mathrm{O}_{3}$ (PLZT2/95/5) ( $x=0-15 \%)$ ceramics. As the concentration of $\mathrm{PbO}$ increased, the $U_{\text {rec }}$ of the PLZT2/95/5 ceramics increased from $0.36 \mathrm{~J} / \mathrm{cm}^{3}$ to $1.94 \mathrm{~J} / \mathrm{cm}^{3}$ at the electric field of $90 \mathrm{kV} / \mathrm{cm}$ due to the increased dielectric relaxation resulting from the volatilization of $\mathrm{PbO}$ during sintering. Further, $U_{\text {rec }}$ also showed temperature dependence and reached a maximum value of $2.12 \mathrm{~J} / \mathrm{cm}^{3}$ ( $\eta$ of $92.98 \%$ ) at $120^{\circ} \mathrm{C}$ due to the $\mathrm{AFE}$ to RFE phase transition in the PLZT2/95/5 ceramics containing more than $10 \% \mathrm{PbO}$. Besides, Gao et al..$^{59)}$ reported that the $\left(\mathrm{Pb}_{0.9} \mathrm{La}_{0.1}\right)\left(\mathrm{Zr}_{0.65} \mathrm{Ti}_{0.35}\right) \mathrm{O}_{3}$ (PLZT10/65/35) ceramics dis- played good temperature stability with a slight variation in $U_{\text {rec }}(<15 \%)$ over the temperature range $24-83^{\circ} \mathrm{C}$, when measured at $25 \mathrm{kV} / \mathrm{cm}$. This temperature stability results from the continuous formation and growth of PNRs with temperature, as well as the applied electric field. In addition, the other PLZT ceramics $\left(\left(\mathrm{Pb}_{0.88} \mathrm{La}_{0.08}\right)\left(\mathrm{Zr}_{0.91} \mathrm{Ti}_{0.09}\right) \mathrm{O}_{3}\right.$; PLZT8/91/9) also exhibited good fatigue lives of up to $10^{5}$ electric field cycles without any significant degradation. ${ }^{60}$ Moreover, the PLZT8/91/9 ceramics were able to withstand large electric fields of up to $170 \mathrm{kV} / \mathrm{cm}$, leading to the realization of a superior $U_{\text {rec }}$ of $3.04 \mathrm{~J} / \mathrm{cm}^{3}$ and an $\eta$ of $92 \%$.

\subsubsection{Lead-free RFE ceramics}

(a) $\mathrm{BaTiO}_{3}$-based RFE ceramics

$\mathrm{BaTiO}_{3}$-based RFE ceramics and solid solutions are considered as one of the most promising candidates for energy storage applications. Ogihara et al. ${ }^{61)}$ demonstrated the high-temperature stable energy storage properties of $0.7 \mathrm{Ba}$ $\mathrm{TiO}_{3}-0.3 \mathrm{BiScO}_{3}$ (BTBS) ceramics prepared via the tape casting method. From Fig. 6(a), the appearance of diffusive and dispersion phase transitions is indicative of the relaxor behavior of BTBS ceramics, which is also evidenced from the slim P-E loops (Fig. 6(b)). Further, the BDS was found to increase with decreasing thickness of the capacitor, and relatively high BDS $(730 \mathrm{kV} / \mathrm{cm})$ and $U_{\text {rec }}\left(6.1 \mathrm{~J} / \mathrm{cm}^{3}\right)$ were obtained for a $15 \mu \mathrm{m}$ thick BTBS single layer capacitor. 
Moreover, the BTBS capacitors exhibited good thermal stability over a wide temperature range $0-300^{\circ} \mathrm{C}$ (Fig. 6(c)), and the obtained results are superior to those of the commercially available capacitors. Since then, many researchers have investigated the energy storage performance of various BT-based RFE solid solutions such as $\mathrm{BaTiO}_{3}$ $\mathrm{Bi}\left(\mathrm{Mg}_{2 / 3} \mathrm{Nb}_{1 / 3}\right) \mathrm{O}_{3},{ }^{62,63)} \quad \mathrm{BaTiO}_{3}-\mathrm{Bi}\left(\mathrm{Mg}_{1 / 2} \mathrm{Nb}_{1 / 2}\right) \mathrm{O}_{3}{ }^{64,65)} \quad \mathrm{BaTiO}_{3-}$ $\mathrm{Bi}\left(\mathrm{Zn}_{2 / 3} \mathrm{Nb}_{1 / 3}\right) \mathrm{O}_{3}{ }^{6}{ }^{66}$ and $\mathrm{BaTiO}_{3}-\mathrm{Bi}_{0.5} \mathrm{Na}_{0.5} \mathrm{TiO}_{3}-\mathrm{Na}_{0.73} \mathrm{Bi}_{0.09} \mathrm{NbO}_{3}{ }^{67}{ }^{6}$ Wang et al. ${ }^{62)}$ reported that the addition of $\mathrm{Bi}\left(\mathrm{Mg}_{2 / 3} \mathrm{Nb}_{1 / 3}\right) \mathrm{O}_{3}$ (BMN) to BT ceramics induced relaxor behavior that was attributed to the large difference in ionic radii of B-site cations and A-site cations. With increasing concentration of BMN, the diffused phase transition became flat and exhibited good temperature stability $\left(\varepsilon_{\mathrm{r}} \sim 628-787\right)$ over a wide temperature range $\left(-50-300^{\circ} \mathrm{C}\right)$. Moreover, the decrease in $\varepsilon_{\mathrm{r}}$ and increase in resistivity with $\mathrm{BMN}$ concentration leads to an improvement in the BDS of BT-BMN ceramics, which helps to enhance the $U_{\text {rec }}$. The highest $U_{\text {rec }}$ of $1.13 \mathrm{~J} / \mathrm{cm}^{3}$ with an $\eta$ of $96 \%$ at the applied electric field of $143.5 \mathrm{kV} / \mathrm{cm}$ was achieved for 0.9BT-0.1BMN. Li et al. ${ }^{63)}$ prepared $\mathrm{MnCO}_{3}$ doped 0.9BT-0.1BMN ceramics to improve the energy storage properties by mitigating the dielectric as well as ferroelectric losses. As reported, acceptor $\left(\mathrm{Mn}^{2+}\right)$ doping-induced dipoles $\left(\mathrm{Mn}^{2+}-V_{o}^{\prime \prime}\right)$ can generate an internal electric field, which can act as a restoring force to return the domain to its original state after removing the external field. Therefore, the $P_{\max }-P_{\mathrm{r}}$ and BDS improved significantly with an increase in $\mathrm{MnCO}_{3}$ concentration, while $\varepsilon_{\mathrm{r}}$ and tan $\delta$ slightly decreased. However, further increasing the $\mathrm{MnCO}_{3}$ concentration resulted in both $P_{\max }-P_{\mathrm{r}}$ and BDS of 0.9BT-0.1BMN being reduced. The optimum energy storage properties were achieved in 0.9BT-0.1BMN-3 $\mathrm{wt} \% \mathrm{MnCO}_{3}$ ceramics with $U_{\text {rec }}$ of $1.7 \mathrm{~J} / \mathrm{cm}^{3}$ and $\eta$ of $88.6 \%$ at the applied electric field of $210 \mathrm{kV} / \mathrm{cm}$. Solid solution modification of BT with $\mathrm{Bi}\left(\mathrm{Mg}_{1 / 2} \mathrm{Ti}_{1 / 2}\right) \mathrm{O}_{3}$ (BMT) has led to a dispersive and temperature-independent $\varepsilon_{\mathrm{r}}$ behavior over the temperature range $-50-300^{\circ} \mathrm{C}{ }^{64,68)}$ The maximum $U_{\text {rec }}$ of $1.81 \mathrm{~J} / \mathrm{cm}^{3}$ with an efficiency of $88 \%$ at the electric field of $287 \mathrm{kV} / \mathrm{cm}$ was obtained in 0.88BT-0.12BMT ceramics. ${ }^{64)}$ In another study, the addition of $\mathrm{B}_{2} \mathrm{O}_{3}-\mathrm{SiO}_{2}$ glass to 0.88BT-0.12BMT ceramics further enhanced the BDS as well as thermal stability and improved the energy density from $1.64 \mathrm{~J} / \mathrm{cm}^{3}$ to $1.97 \mathrm{~J} /$ $\mathrm{cm}^{3}$, with $\eta$ being above $94 \%{ }^{65)}$ In a separate study, the addition of $\mathrm{Bi}\left(\mathrm{Zn}_{2 / 3} \mathrm{Nb}_{1 / 3}\right) \mathrm{O}_{3}(\mathrm{BZN})$ enhanced the insulation ability of BT ceramics by increasing the activation energies of both the grains and grain boundaries. ${ }^{66)}$ Moreover, a significant reduction in dielectric nonlinearity and linear-like $P-E$ loops with negligible hysteresis loss were noticed at higher concentrations of BZN. Among the ceramics of various compositions, a maximum $U_{\text {rec }}$ of $0.79 \mathrm{~J} / \mathrm{cm}^{3}$ with $\eta$ $93.5 \%$ at $131 \mathrm{kV} / \mathrm{cm}$ was realized in the case of $0.85 \mathrm{BT}$ 0.15BZN. Yang et al. ${ }^{67)}$ considered the doping of $\mathrm{Na}_{0.73} \mathrm{Bi}_{0.09} \mathrm{NbO}_{3}$ (NBN) to be a good choice to improve the $P_{\max } P_{\mathrm{r}}$ and BDS of $0.65 \mathrm{BaTiO}_{3}-0.35 \mathrm{Bi}_{0.5} \mathrm{Na}_{0.5} \mathrm{TiO}_{3}$ (0.65BT-0.35BNT) ceramics. With increasing NBN content, the degree of relaxor behavior increased despite the increase in grain size from $0.21 \mu \mathrm{m}$ to $0.56 \mu \mathrm{m}$. Meanwhile, the dielectric as well as energy storage properties of (1- $x) 0.65 \mathrm{BT}-0.35 \mathrm{BNT}-x \mathrm{NBN}(x=0-0.14)$ ceramics initially improved and then decreased. A high $U_{\text {rec }}$ of $1.70 \mathrm{~J} / \mathrm{cm}^{3}$ with $\eta 82 \%$ at $172 \mathrm{kV} / \mathrm{cm}$ was achieved in $0.92(0.65 \mathrm{BT}-0.35 \mathrm{BNT})-0.08 \mathrm{NBN}$ ceramic. Wu et al. ${ }^{69)}$ adopted the microstructural modification of $\mathrm{BT}$ particles with $\mathrm{BiScO}_{3}$ (BS) coating by employing the core-shell method to tailor the energy storage properties. With the BS coating, grain size suppression, BDS improvement, conductivity reduction, and broadened peaks with sequential disappearance of structural transitions were observed. Moreover, the local compositionally graded structures arose from the diffusion of $\mathrm{Bi}$ and $\mathrm{Sc}$ into the $\mathrm{BT}$ matrix that resulted in temperature-independent dielectric properties. All these factors improved the energy storage properties $\left(U_{\text {rec }}\right.$ of $0.68 \mathrm{~J} / \mathrm{cm}^{3}$ and $\eta$ of $81 \%$ at $120 \mathrm{kV} / \mathrm{cm}$ ) of $3 \mathrm{~mol} \%$ BS-coated BT ceramics.

\section{(b) $(\mathrm{Na}, \mathrm{Bi}) \mathrm{TiO}_{3}$-based $\mathrm{RFE}$ ceramics}

Among the lead-free ceramics, $(\mathrm{Na}, \mathrm{Bi}) \mathrm{TiO}_{3}(\mathrm{NBT})$-based FE ceramics were extensively studied owing to their excellent ferroelectric properties that can be ascribed to the (Na, $\mathrm{Bi})^{2+}$ ions, especially the lone-pair $6 \mathrm{~s}^{2}$ electronic configuration of $\left.\mathrm{Bi}^{3+} \cdot{ }^{71}\right)$ At RT, NBT exhibits a rhombohedral FE structure that transforms to a weakly polar tetragonal phase at elevated temperatures, which is either a RFE or an AFE phase. Therefore, many efforts have been made to induce relaxor behavior and improve the BDS of the NBT ceramics by doping and forming binary/ternary solutions.

Recently, Liu et $a l .{ }^{72)}$ reported the energy storage properties of BNT-based binary solutions such as $\mathrm{Ba}_{0.06} \mathrm{Na}_{0.47} \mathrm{Bi}_{0.47} \mathrm{TiO}_{3}$ $\mathrm{Ln}_{1 / 3} \mathrm{NbO}_{3}(\mathrm{BNBT}-\mathrm{LnN}, \mathrm{Ln}=\mathrm{La}, \mathrm{Nd}, \mathrm{Sm})$ ceramics. The introduction of $\mathrm{LnN}$ in BNBT ceramics significantly reduced the polarizations $\left(P_{\mathrm{r}}\right.$ and $\left.P_{\max }\right)$ and promoted the relaxor behavior, which lead to a maximum $U_{\text {rec }}$ of $1.239 \mathrm{~J} / \mathrm{cm}^{3}$ at $100 \mathrm{kV} / \mathrm{cm}$ in the case of $0.98 \mathrm{BBNT}-0.02 \mathrm{SmN}$. The deliberate doping of $\mathrm{Sr}_{0.85} \mathrm{Bi}_{0.1} \mathrm{TiO}_{3}(\mathrm{SBT})$ in NBT ceramics induced ergodic relaxor behavior with reduced $P_{\mathrm{r}}$ and improved $P_{\max }$, as a result, a larger $U_{\text {rec }}$ of $1.5 \mathrm{~J} / \mathrm{cm}^{3}$ and an $\eta$ of $73 \%$ were achieved under a relatively lower electric field $(85 \mathrm{kV} / \mathrm{cm}){ }^{73)}$ In addition, the BDS and ionic conductivity of the BBNT ceramics were enhanced, whereas the $P_{\mathrm{r}}, P_{\max }$, and electronic conductivity reduced with $\mathrm{SrZrO}_{3}$ (SZ) doping. ${ }^{74}$ )

$\mathrm{Pu}$ et $a .^{75)}$ investigated the effect of $\mathrm{Sn}^{4+}$ doping on the energy storage properties of $0.55 \mathrm{Bi}_{0.5} \mathrm{Na}_{0.5} \mathrm{TiO}_{3}-0.45 \mathrm{Ba}_{0.85}$ $\mathrm{Ca}_{0.15} \mathrm{Ti}_{0.9} \mathrm{Zr}_{0.1} \mathrm{O}_{3}$ (0.55BNT-0.45BCTZ) ceramics. With the increase in $\mathrm{Sn}^{4+}$ concentration, a diffuse-type phase transition with broad plateau-like dielectric constant maxima over a wide temperature range was observed. In addition, the low ionic polarizability of $\mathrm{Sn}^{4+}$ facilitated the softening of the current peaks and the reduction of hysteresis loss. As a consequence, improved energy storage properties $\left(U_{\text {rec }}\right.$ of $1.21 \mathrm{~J} / \mathrm{cm}^{3}$ and $\eta$ of $72.29 \%$ at $130 \mathrm{kV} / \mathrm{cm}$ ) were realized in $0.55 \mathrm{Bi}_{0.5} \mathrm{Na}_{0.5} \mathrm{TiO}_{3}-0.45 \mathrm{Ba}_{0.85} \mathrm{Ca}_{0.15} \mathrm{Ti}_{0.85} \mathrm{Zr}_{0.1} \mathrm{Sn}_{0.05} \mathrm{O}_{3} \quad$ (0.55BNT$0.45 \mathrm{BCTZS})$ ceramics. In an extension of this study, the energy storage properties of BNT-BCTZ were further 
enhanced by doping with $\mathrm{MgO}$ and utilizing microwave sintering. ${ }^{76,77)}$

Since reduction in leakage current is an effective way to enhance the BDS of ceramics, Yang et al. ${ }^{70)}$ considered $\mathrm{La}^{3+}$ doping for minimizing the remnant polarization and leakage current of BNT-based ceramics. With increasing $\mathrm{La}^{3+}$ concentration in $\mathrm{Bi}_{(0.5-x)} \mathrm{La}_{x}\left(\mathrm{Na}_{0.82} \mathrm{~K}_{0.18}\right)_{0.5} \mathrm{Ti}_{0.96} \mathrm{Zr}_{0.02} \mathrm{Sn}_{0.02} \mathrm{O}_{3}$ (BNKTZS- $x \mathrm{~L})(x=0-0.18)$ ceramics, a gradual decrease in grain size, as well as structural transition with enhanced relaxor behavior, was noticed. Moreover, BNKTZS- $x \mathrm{~L}$ ( $x=$ $0.06-0.18)$ samples exhibited good temperature stability with improved temperature coefficient of capacitance $(\leq \pm 15 \%$ at $\left.150^{\circ} \mathrm{C}\right)$. The polarization $\left(P_{\mathrm{r}}\right.$ and $\left.P_{\max }\right)$ properties and leakage current density (Fig. $6(\mathrm{~d})$ ) of BNKTZS- $x$ L ceramics decreased continuously with increasing $x$, as a result, the hysteresis loss decreased, while the BDS was enhanced from $80 \mathrm{kV} / \mathrm{cm}$ to $155 \mathrm{kV} / \mathrm{cm}$. A maximum $U_{\text {rec }}$ of $1.95 \mathrm{~J} / \mathrm{cm}^{3}$ with an $\eta$ of $71 \%$ was obtained for BNKTZS-0.1L. In another study, the introduction of $\mathrm{BaSnO}_{3}(\mathrm{BSN})$ into NBT ceramics also suppressed the phase transition temperature as well as the leakage current peaks and increase the ability of the ceramics to withstand higher electric fields, which in turn resulted in the BDS increasing from $140 \mathrm{kV} / \mathrm{cm}$ to 240 $\mathrm{kV} / \mathrm{cm}$ and yielded a maximum $U_{\text {rec }}$ of $1.91 \mathrm{~J} / \mathrm{cm}^{3}$ and $\eta$ of $86.4 \%$ for 0.75 NBT-0.25BSN. ${ }^{78)}$

On the other hand, BNT-based ternary systems based on the solid solutions of various $\mathrm{ABO}_{3}$-type ferro/non-ferroelectrics at the morphotrophic phase boundary (MPB) were also extensively studied to expand the thermal stability range as well as to increase the energy storage capacity by shifting the transition temperature (especially $T_{\mathrm{m}}$ ) towards RT. ${ }^{79}$ ) Among the BNT-based ternary systems, $\left(\mathrm{Bi}_{0.5} \mathrm{Na}_{0.5}\right) \mathrm{TiO}_{3}-$ $\left.\left(\mathrm{Bi}_{0.5} \mathrm{~K}_{0.5}\right) \mathrm{TiO}_{3}-\left(\mathrm{K}_{0.5} \mathrm{Na}_{0.5}\right) \mathrm{NbO}_{3},{ }^{80}\right) \quad \mathrm{Bi}_{0.5} \mathrm{Na}_{0.5} \mathrm{TiO}_{3}-\mathrm{BaTiO}_{3}-$ $\mathrm{Na}_{0.73} \mathrm{Bi}_{0.09} \mathrm{NbO}_{3},{ }^{81)} \quad \mathrm{BiTi}_{0.5} \mathrm{Zn}_{0.5} \mathrm{O}_{3}-\mathrm{Bi}_{0.5} \mathrm{Na}_{0.5} \mathrm{TiO}_{3}-\mathrm{BaTiO}_{3}{ }^{82)}$ $\left.\mathrm{Bi}_{0.5} \mathrm{Na}_{0.5} \mathrm{TiO}_{3}-\mathrm{NaNbO}_{3}-\mathrm{Ba}\left(\mathrm{Zr}_{0.2} \mathrm{Ti}_{0.8}\right) \mathrm{O}_{3}{ }^{83}\right) \quad \mathrm{Bi}_{0.5} \mathrm{Na}_{0.5} \mathrm{TiO}_{3}-$ $\mathrm{BaTiO}_{3}-\mathrm{NaTaO}_{3},{ }^{84} \quad \mathrm{Na}_{0.5} \mathrm{Bi}_{0.5} \mathrm{TiO}_{3}-\mathrm{BaTiO}_{3}-\mathrm{NaNbO}_{3},{ }^{85)}$ and $\mathrm{Bi}_{0.48} \mathrm{La}_{0.02} \mathrm{Na}_{0.48} \mathrm{Li}_{0.02} \mathrm{Ti}_{0.98} \mathrm{Zr}_{0.02} \mathrm{O}_{3}-\mathrm{Na}_{0.73} \mathrm{Bi}_{0.09} \mathrm{NbO}_{3}{ }^{86)}$ exhibited excellent energy storage properties $\left(>1 \mathrm{~J} / \mathrm{cm}^{3}\right)$ with good temperature stability and fatigue-free behavior.

(c) $\left(\mathrm{K}_{0.5} \mathrm{Na}_{0.5}\right) \mathrm{NbO}_{3}(\mathrm{KNN})$-based $\mathrm{RFE}$ ceramics

A Few studies have been dedicated to improving the DBS of KNN-based ceramics through compositionally controlled grain size and porosity reduction. ${ }^{87-91)} \mathrm{Qu}$ et al. achieved a high energy storage density in $\operatorname{Sr}\left(\mathrm{Sc}_{0.5} \mathrm{Nb}_{0.5}\right) \mathrm{O}_{3}$ (SSN)-doped fine-grained $\mathrm{KNN}$ ceramics $((1-x) \mathrm{KNN}-x \mathrm{SSN}, x=0-0.3)$ prepared by conventional sintering. ${ }^{87)}$ The crystal structure of the KNN ceramics gradually transformed from orthorhombic symmetry to cubic symmetry, accompanied by a decrease in grain size from $4 \mu \mathrm{m}$ to $0.4 \mu \mathrm{m}$, and a strong frequency dispersion of $\varepsilon_{\mathrm{r}}$ with diffuse phase transitions were observed with increasing concentration of SSN. Moreover, the small grain size together with reduced porosity favored good transparency in the visible region as well as enhanced DBS up to $295 \mathrm{kV} / \mathrm{cm}$, as a result, a larger $U_{\text {rec }}$ of $2.02 \mathrm{~J} / \mathrm{cm}^{3}$ with an $\eta$ of $81.4 \%$ were realized in $0.8 \mathrm{KNN}$ -
0.2SSN ceramics. The addition of a sintering aid such as $\mathrm{ZnO}$ further enhanced the DBS from $295 \mathrm{kV} / \mathrm{cm}$ to $400 \mathrm{kV} /$ $\mathrm{cm}$, resulting in an improved $U_{\text {rec }}$ of $2.6 \mathrm{~J} / \mathrm{cm}^{3}$ and an $\eta$ of $73.2 \%$ for $0.8 \mathrm{KNN}-0.2 \mathrm{SSN}$ ceramics containing $0.5 \mathrm{~mol} \%$ $\mathrm{ZnO}{ }^{89)}$ Inspired by these results, different dopants such as $\mathrm{ST},{ }^{88)} \mathrm{Sr}\left(\mathrm{Zn}_{1 / 3} \mathrm{Nb}_{2 / 3}\right) \mathrm{O}_{3}(\mathrm{SZN}){ }^{90)} \mathrm{Bi}_{2} \mathrm{O}_{3},{ }^{92)}$ and $\mathrm{Bi}\left(\mathrm{Mg}_{2 / 3} \mathrm{Nb}_{1 / 3}\right) \mathrm{O}_{3}$ $(\mathrm{BMN})^{91)}$ were used to reduce the average grain size and improve the BDS of KNN ceramics and obtain the maximum $U_{\text {rec }}(\eta)$ values of $4.03 \mathrm{~J} / \mathrm{cm}^{3}(52 \%)$ at $400 \mathrm{kV} / \mathrm{cm}, 1.5 \mathrm{~J} /$ $\mathrm{cm}^{3}(50 \%)$ at $175 \mathrm{kV} / \mathrm{cm}, 1.04 \mathrm{~J} / \mathrm{cm}^{3}$ at $189 \mathrm{kV} / \mathrm{cm}$, and 4.08 $\mathrm{J} / \mathrm{cm}^{3}(62.7 \%)$ at $300 \mathrm{kV} / \mathrm{cm}$.

\section{(d) Other lead-free RFE ceramics}

This section provides an overview of the energy storage performances of various solid solutions of $\mathrm{BiFeO}_{3}{ }^{93-95)}$ and $\mathrm{ST}^{96-103)}$ based lead-free RFE ceramics. A few attempts have been made to study the doping effect of low dielectric loss materials such as $\mathrm{Ba}\left(\mathrm{Mg}_{1 / 3} \mathrm{Nb}_{2 / 3}\right) \mathrm{O}_{3}(\mathrm{BMN})^{93)}$ and $\mathrm{La}\left(\mathrm{Mg}_{1 / 2} \mathrm{Ti}_{1 / 2}\right) \mathrm{O}_{3}$ $(\mathrm{LMT})^{94)}$ on the energy storage performance of $0.67 \mathrm{BiFeO}_{3}$ $0.33 \mathrm{BaTiO}_{3}(0.67 \mathrm{BF}-0.33 \mathrm{BT})$ ceramics. The doping of these materials favored the decrease in the size of PNRs and enhanced their dynamics, consequently, a steady decrease in $P_{\mathrm{r}}$ and shifting of temperature $\left(T_{\mathrm{m}}\right)$ corresponding to the $\mathcal{E}_{\mathrm{r}}$ maxima towards $\mathrm{RT}$ with the increase in dielectric relaxation behavior (i.e., increased values of $\gamma$ and $\Delta T_{\text {relax }}=T_{\mathrm{m} @ 1 \mathrm{kHz}}$ - $T_{\mathrm{m} @ 1 \mathrm{MHz}}$ with increasing dopant concentration) and temperature stability were observed. Moreover, the coexistence of ergodic and non-ergodic behaviors at RT in optimal compositions lead to improved energy storage properties $\left(U_{\text {rec }}=\right.$ $1.56-1.66 \mathrm{~J} / \mathrm{cm}^{3}$ and $\eta=75-82 \%$ ) even under small electric fields $(125-130 \mathrm{kV} / \mathrm{cm})$. In another study, the doping of the less polarizable $\mathrm{Nd}$ in Bi-sites stabilized the pseudocubic phase of BF-BT ceramics, with decreases in $T_{\mathrm{m}}$ and ferroelectricity. ${ }^{95)}$ At the optimal composition of $0.75\left(\mathrm{Bi}_{0.85} \mathrm{Nd}_{0.15}\right) \mathrm{FeO}_{3}$ $0.25 \mathrm{BaTiO}_{3}+0.1$ wt. $\% \mathrm{MnO}_{2}(\mathrm{BN} 15 \mathrm{~F}-\mathrm{BT})$, a maximum $U_{\text {rec }}$ of $1.82 \mathrm{~J} / \mathrm{cm}^{3}$ with an $\eta$ of $41.3 \%$ at $170 \mathrm{kV} / \mathrm{cm}$ was achieved. By utilizing the advantage of interfacial modification in improving the BDS of BN15F-BT ceramics, the authors fabricated a multilayer capacitor (of thickness $0.78 \mathrm{~mm}$ ) by using an optimized composition of BN15F-BT and Pt internal electrodes, which helped the ceramics withstand electric fields of up to $540 \mathrm{kV} / \mathrm{cm}$ and yielded a much improved $U_{\text {rec }}$ of $6.74 \mathrm{~J} / \mathrm{cm}^{3}$ and $\eta$ of $77 \%$. Moreover, the multilayered BN15F-BT capacitor exhibited fast discharging $\left(\tau_{0.9} \sim 4 \mu \mathrm{s}\right.$, the time required to release $90 \%$ of its total stored energy) and good thermal stability $\left(\Delta U_{\text {rec }} \sim 15 \%\right)$ in the temperature range $\left.30-125^{\circ} \mathrm{C} .{ }^{95}\right)$

It is well known that ST possesses high BDS and n, but low $P_{\max }$. In order to achieve a high $U_{\text {rec }}$ along with high $\eta$, many researchers adopted compositional modification to improve the $P_{\max }$ (or $\varepsilon_{\mathrm{r}}$ ) of ST-based ceramics. ${ }^{96-103)}$ For example, the incorporation of $\left(\mathrm{Na}_{0.5} \mathrm{Bi}_{0.5}\right)^{2+}$ and $\mathrm{Ba}^{2+}$ in the A-sites of ST ceramics increased the lattice disorder as well as the growth of PNRs, which in turn enhanced the relaxor behavior along with improved polarization properties. ${ }^{98,99,102,103)}$ Further, the addition of $\mathrm{ZrO}_{2}$ improved the BDS by stabiliz- 
ing the pseudocubic phase and charge on Ti and suppressing the dissociation of oxygen during the sintering of 0.6ST0.4 NBT ceramics. $\left.{ }^{100}\right)$ As the $\mathrm{ZrO}_{2}$ concentration increased from $0.1 \mathrm{~mol} \%$ to $0.5 \mathrm{~mol} \%$, the BDS increased from $220 \mathrm{kV} /$ $\mathrm{cm}$ to $285 \mathrm{kV} / \mathrm{cm}$, as a result, a maximum $U_{\text {rec }}$ of $2.84 \mathrm{~J} / \mathrm{cm}^{3}$ with an $\eta$ of $71.54 \%$ has been achieved. Similarly, $\mathrm{Sn}^{4+} \mathrm{dop}$ ing also effectively reduced the average grain size and dielectric loss and improved the BDS as well as the energy storage properties of 0.45ST-0.2NBT-0.35BT ceramics. ${ }^{103)}$

Yan et al. ${ }^{96)}$ reported that doping of $0.95 \mathrm{Bi}_{0.5} \mathrm{Na}_{0.5} \mathrm{TiO}_{3^{-}}$ $0.05 \mathrm{BaAl}_{0.5} \mathrm{Nb}_{0.5} \mathrm{O}_{3}$ (NBT-BAN) significantly enhanced the $P_{\max }$ (from $4.70 \mathrm{\mu C} / \mathrm{cm}^{2}$ to $41.81 \mu \mathrm{C} / \mathrm{cm}^{2}$ ), with a slight increase in $P_{r}$, which was accompanied by a 10.39 times improvement in the dielectric constant of the ST ceramics; this led to the realization of a high $U_{\text {rec }}$ of $1.89 \mathrm{~J} / \mathrm{cm}^{3}$ with $\eta$ being $77 \%$ at $190 \mathrm{kV} / \mathrm{cm}$ for the $0.5 \mathrm{ST}-0.5$ (NBT-BAN) system. Yang et al. ${ }^{101)}$ reported an improvement in the energy storage properties $\left(U_{\text {rec }}\right.$ of $2.83 \mathrm{~J} / \mathrm{cm}^{3}$ and $\eta$ of $85 \%$ at $320 \mathrm{kV} /$ $\mathrm{cm})$ of $0.93 \mathrm{Bi}_{0.5} \mathrm{Na}_{0.5} \mathrm{TiO}_{3}-0.07 \mathrm{Ba}_{0.94} \mathrm{La}_{0.04} \mathrm{Zr}_{0.02} \mathrm{Ti}_{0.98} \mathrm{O}_{3}(\mathrm{NBT}-$ BLZT)-doped ST ceramics due to the improvement in $P_{r^{-}}$ $P_{\max }$ and grain size.

\subsection{Antiferroelectric ceramics}

The absence of FE dipoles at smaller electric fields and the field-induced reversible $\mathrm{FE}$ phase at higher fields lead to low remnant and high saturation polarizations in $\mathrm{AFE}$ materials, which make them promising for energy storage applications. ${ }^{13,104)}$ Among the various AFE materials, PbZ$\mathrm{rO}_{3}(\mathrm{PZ}),(\mathrm{Na}, \mathrm{Bi}) \mathrm{TiO}_{3}(\mathrm{NBT})$, and $\mathrm{AgNbO}_{3}(\mathrm{AN})$ based ceramics have been widely investigated for their suitability for energy storage applications. Since a large switching electric field $\left(E_{\mathrm{AFE}-\mathrm{FE}}\right)$ and slim hysteresis (i.e., small $\Delta E=E_{\mathrm{AFE}-\mathrm{FE}}-$ $\left.E_{\mathrm{FE}-\mathrm{AFE}}\right)$ along with large polarization are required to obtain high energy storage densities in AFE ceramics, various approaches such as chemical modification, different fabrication methods, and mechanical confinement have been adopted.

\subsubsection{Lead-based AFE ceramics}

Sawaguchi et al. demonstrated that AFE behavior in $\mathrm{PZ}$ originated from the antiparallel displacement of $\mathrm{Pb}^{2+}$ in the plane perpendicular to the $c$-axis. ${ }^{105)}$ For the stabilization of the AFE phase in PZ ceramics, various dopants such as Ba, $\mathrm{La}, \mathrm{Sr}, \mathrm{Sm}$, or $\mathrm{Y}$ in the $\mathrm{Pb}$-sites and $\mathrm{Nb}, \mathrm{Sn}$, or Ti in the $\mathrm{Zr}$ sites have been used. Among the various lead-based materials, (Pb, La)(Zr, Ti) ${ }_{3}(\mathrm{PLZT}),{ }^{106,107)}(\mathrm{Pb}, \mathrm{La})(\mathrm{Zr}, \mathrm{Sn}, \mathrm{Ti}) \mathrm{O}_{3}$ (PLZST), ${ }^{108-120)} \mathrm{Pb}(\mathrm{Nb}, \mathrm{Zr}, \mathrm{Sn}, \mathrm{Ti}) \mathrm{O}_{3}$ (PNZST), ${ }^{121,122)}$ (Pb, La) (Nb, Zr, Sn, Ti)O ${ }_{3}$ (PLNZST), ${ }^{123)}$ (Pb, La, Ba)(Zr, Sn, Ti)O ${ }_{3}$ (PLBZST), ${ }^{12-130)}$ (Pb, La, Ba, Y)(Zr, Sn, Ti)O ${ }_{3}$ (PLBYZST), ${ }^{131-134)}$ (Pb, Sm)(Zr, Sn, Ti) $\mathrm{O}_{3}$ (PSZST), ${ }^{135}$ and $\mathrm{Pb}(\mathrm{Tm}, \mathrm{Nb}) \mathrm{O}_{3}-\mathrm{Pb}(\mathrm{Mg}$, $\mathrm{Nb}_{3} \mathrm{O}_{3}(\mathrm{PTN}-\mathrm{PMN})^{136)}$ based AFE ceramics have been considered as promising candidates for energy harvesting applications.

After the establishment of the triaxial phase diagram of the $\mathrm{La}^{3+}$-doped $\mathrm{Pb}(\mathrm{Zr}, \mathrm{Sn}, \mathrm{Ti}) \mathrm{O}_{3}$ system, ${ }^{137}$ the PLZST-based AFE system has been extensively investigated for energy storage applications. ${ }^{108-120)}$ At RT, the PLZST AFE ceramics exist in either the tetragonal $\left(\mathrm{AFE}_{\mathrm{T}}\right)$ phase or the orthorhombic $\left(\mathrm{AFE}_{\mathrm{O}}\right)$ phase, depending on the composition; the ceramics with the $\mathrm{AFE}_{O}$ phase display relatively higher $E_{\mathrm{AFE}-\mathrm{FE}}$ than those with the $\mathrm{AFE}_{\mathrm{T}}$ phase. In this regard, some efforts have been made to improve the stability of the $\mathrm{AFE}_{\mathrm{O}}$ phase of the PLZST ceramics via compositional modification. ${ }^{112,114,116,118,120)}$ For example, Wang et al. ${ }^{112)}$ tailored the $\mathrm{Zr} / \mathrm{Sn}$ and $\mathrm{Zr} / \mathrm{Ti}$ ratios of PLZST ceramics and realized improved energy storage properties for Zr-rich compositions due to the increase in $\mathrm{AFE}_{\mathrm{O}}$ phase stability. A higher $E_{\mathrm{AFE}-\mathrm{FE}}$ $(227 \mathrm{kV} / \mathrm{cm})$ along with a square-type hysteresis loop $(\Delta E$ $\sim 90 \mathrm{kV} / \mathrm{cm})$ and maximum polarization $\left(30 \mu \mathrm{C} / \mathrm{cm}^{2}\right)$ were achieved for $\mathrm{Zr} / \mathrm{Sn}=90 / 05$. Although larger $E_{\mathrm{AFE}-\mathrm{FE}}(275 \mathrm{kV} /$ $\mathrm{cm})$ and slanted hysteresis $(\Delta E \sim 28 \mathrm{kV} / \mathrm{cm})$ loops were realized in $\mathrm{Zr} / \mathrm{Ti}=92 / 03$ composition, $P_{\max }$ was quite low. The composition of $\mathrm{Pb}_{0.97} \mathrm{La}_{0.02}\left(\mathrm{Zr}_{0.90} \mathrm{Sn}_{0.05} \mathrm{Ti}_{0.05}\right) \mathrm{O}_{3}$ was optimal owing to its high $U_{\text {rec }}$ of $4.426 \mathrm{~J} / \mathrm{cm}^{3}$ at $300 \mathrm{kV} / \mathrm{cm}$ with an $\eta$ of $61.2 \%$. In another study, Zhang et al. ${ }^{118)}$ reported that the substitution of $\mathrm{Zr}^{4+}$ for $\mathrm{Sn}^{4+}$ transformed the crystal structure of PLZST ceramics from $\mathrm{AFE}_{\mathrm{T}}$ to $\mathrm{AFE}_{\mathrm{O}}$ and shifted the AFE-FE and FE-AFE transitions towards higher electric fields, which led to an improvement in $U_{\text {rec }}$ from $3.18 \mathrm{~J} / \mathrm{cm}^{3}$ to $4.38 \mathrm{~J} / \mathrm{cm}^{3}$. In a recent study, Liu et $a l .{ }^{120)}$ studied the effect of different concentrations of $\mathrm{Zr}$ and $\mathrm{Ti}$ on the phase transition behavior and energy storage performance of tetragonal structured $\mathrm{Pb}_{0.97} \mathrm{La}_{0.02}\left(\mathrm{Zr}_{x} \mathrm{Sn}_{0.925-x} \mathrm{Ti}_{0.075}\right) \mathrm{O}_{3} \quad(x=$ 0.58-0.82) and $\mathrm{Pb}_{0.97} \mathrm{La}_{0.02}\left(\mathrm{Zr}_{0.58} \mathrm{Sn}_{0.42-y} \mathrm{Ti}_{y}\right) \mathrm{O}_{3}(y=0.07-0.11)$ systems. Both systems exhibited small $E_{\mathrm{AFE}-\mathrm{FE}}$ and $E_{\mathrm{FE}-\mathrm{AFE}}$, with large $\mathrm{D} E$ values at the MPB compositions. As the $\mathrm{Zr}$ concentration increased (at a fixed Ti concentration), both $E_{\mathrm{AFE}-\mathrm{FE}}$ and $E_{\mathrm{FE}-\mathrm{AFE}}$ linearly decreased, while $\mathrm{D} E$ increased; as a result, $U_{\text {rec }}$ as well as $\eta$ were reduced. On the other hand, decreasing the Ti concentration (at a fixed $\mathrm{Zr}$ concentration) resulted in improved energy storage properties $\left(U_{\text {rec }}\right.$ $\sim 2.35 \mathrm{~J} / \mathrm{cm}^{3}$ and $\eta \sim 86 \%$ for $y=0.07$ ) due to increases in both $E_{\mathrm{AFE}-\mathrm{FE}}$ and $E_{\mathrm{FE}-\mathrm{AFE}}$. A few attempts have been made to replace $\mathrm{Pb}^{2+}(1.49 \AA)$ with smaller ionic radii elements ( $\mathrm{Sr}$ and $\mathrm{Sm}$ ) to reduce the tolerance factor, which can help to improve the stability of the AFE phase of PLZST ceramics. ${ }^{116,117,135)}$ Zhang et al. ${ }^{116)}$ reported that with the incorporation of the inert-gas-type outermost electron configuration $\left(4 \mathrm{~s}^{2} 4 \mathrm{p}^{6}\right)$ of $\mathrm{Sr}^{2+}$ in $\mathrm{Pb}^{2+}\left(6 \mathrm{~s}^{2}\right.$, non-inert type), the crystal structure of $\left(\mathrm{Pb}_{0.97-x} \mathrm{Sr}_{x} \mathrm{La}_{0.02}\right)\left(\mathrm{Zr}_{0.75} \mathrm{Sn}_{0.195} \mathrm{Ti}_{0.055}\right) \mathrm{O}_{3} \quad(x=0-0.025)$ changed from $\mathrm{AFE}_{\mathrm{T}}$ to $\mathrm{AFE}_{0}, \varepsilon_{\mathrm{rm}}$ and $P_{\max }$ decreased, and the $T_{\mathrm{m}}$ and switching fields $\left(E_{\mathrm{AFE}-\mathrm{FE}}\right.$ and $\left.E_{\mathrm{FE}-\mathrm{AFE}}\right)$ increased. As a result, the $U_{\text {rec }}$ increased with increasing $\mathrm{Sr}^{2+}$ concentration and reached a maximum of $5.56 \mathrm{~J} / \mathrm{cm}^{3}$, with the $\eta$ being $67.9 \%$ at $350 \mathrm{kV} / \mathrm{cm}$ for $x=0.015$. In addition, the PLZST-based ceramics exhibited good temperature stability and released their stored energy in less than $200 \mathrm{~ns} .^{115-117)}$

A few studies have attempted to investigate the effect of Ba doping on the energy storage properties of PLZST ceramics. ${ }^{124,128)}$ The doping of $\mathrm{Ba}^{2+}$ in $\mathrm{Pb}^{2+}$ sites led to enhanced energy storage properties due to the improvements in $\mathcal{E}_{\mathrm{r}}$ and $P_{\text {max }}$, however, significant decreases in the switching fields 

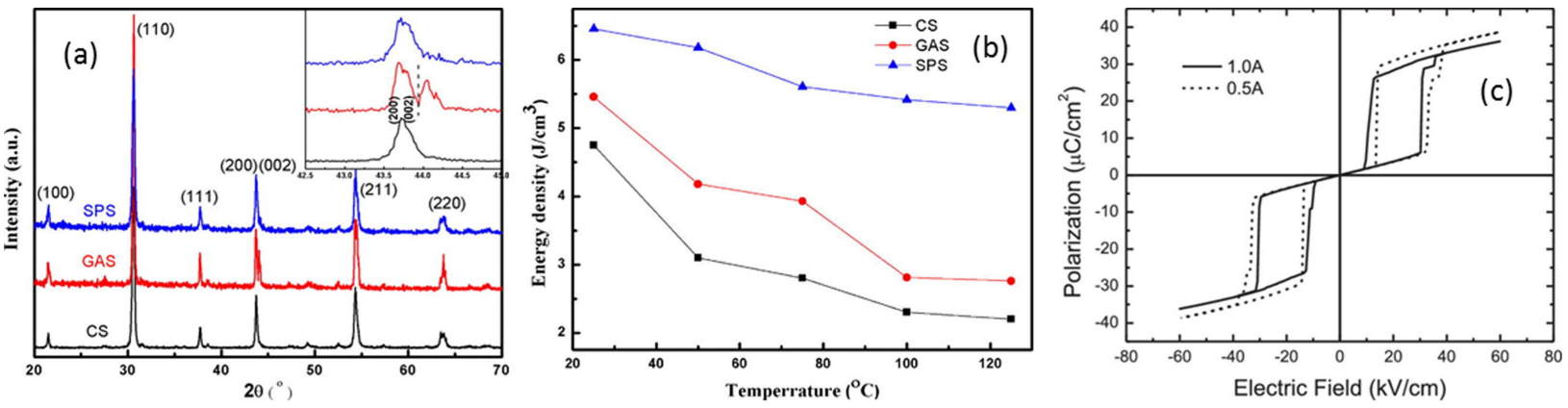

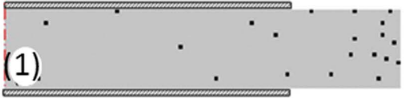

(d)
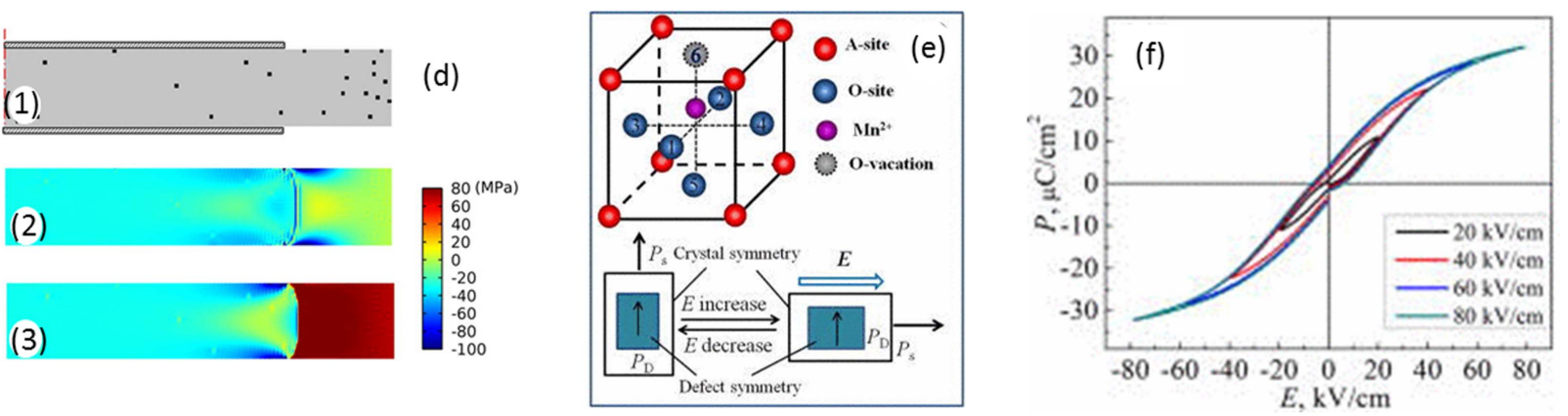

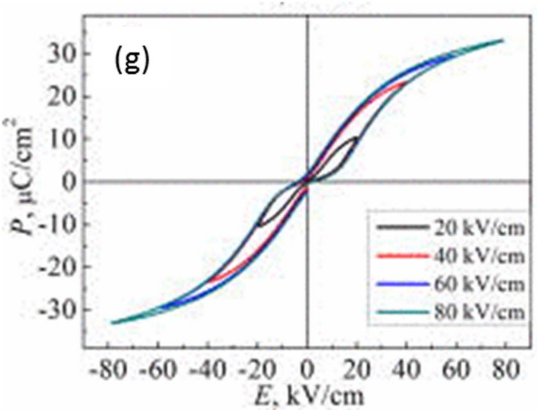

Fig. 7. (a) XRD patterns and (b) temperature dependence of the energy storage density of $\left(\mathrm{Pb}_{0.858} \mathrm{Ba}_{0.1} \mathrm{La}_{0.02} \mathrm{Y}_{0.008}\right)\left(\mathrm{Zr}_{0.65} \mathrm{Sn}_{0.3} \mathrm{Ti}_{005}\right) \mathrm{O}_{3}$ $\left(\mathrm{Pb}_{0.97} \mathrm{La}_{0.02}\right)\left(\mathrm{Zr}_{0.9} \mathrm{Sn}_{0.05} \mathrm{Ti}_{0.05}\right) \mathrm{O}_{3}$ composite ceramics subjected to conventional sintering, glass-aided sintering, and spark plasma sintering. ${ }^{134)}$ (c) Results of $P-E$ modeling for fully electroded (1.0A) and partially electroded (0.5A) $\mathrm{Pb}_{0.99} \mathrm{Nb}_{0.02}\left[\left(\mathrm{Zr}_{0.57} \mathrm{Sn}_{0.43}\right)_{0.95} \mathrm{Ti}_{0.05}\right]_{0.98} \mathrm{O}_{3}$ ceramics. (d) Axisymmetric model based simulation results of the distributions of (1) ferroelectric defects, (2) radial stress, and (3) hoop stress in the partially electroded PNZST sample under the peak electric field. ${ }^{121)}$ (e) Schematic illustration of the defect and crystal symmetries in the Mn-doped tetragonal structured $0.7\left[0.94\right.$ NBT-0.06BT]-0.3ST system. $P-E$ hysteresis loops of (f) pure and (g) Mn-doped NBBST ceramics. ${ }^{138)}$

and phase transition temperatures were noticed. On the other hand, the incorporation of the smaller ion $\mathrm{Y}^{3+}$ to substitute $\mathrm{Pb}^{2+}$ lead to decreases in oxygen vacancies and the grain size of $\left(\mathrm{Pb}_{0.87} \mathrm{Ba}_{0.1} \mathrm{La}_{0.02}\right)\left(\mathrm{Zr}_{0.65} \mathrm{Sn}_{0.3} \mathrm{Ti}_{0.05}\right) \mathrm{O}_{3}+x \mathrm{~mol} \% \mathrm{Y}$ (PBLZST- $x \mathrm{Y}, x=0-1.25)$ ceramics, which facilitated an increase in the internal stress between the grains; therefore, higher switching fields and smaller $\Delta E$ were observed. ${ }^{131)}$ For low concentrations (up to $0.75 \mathrm{~mol} \%$ ) of $\mathrm{Y}$, the $U_{\text {rec }}$ of the PBLZST ceramics increased from $2.20 \mathrm{~J} / \mathrm{cm}^{3}$ to $2.75 \mathrm{~J} / \mathrm{cm}^{3}$, however, at higher concentrations, it decreased due to the reduction in $P_{\max }$. Since the electrical properties of $\mathrm{Pb}$-based AFE ceramics are mainly affected by the density and lead loss during sintering, Zhang et al. ${ }^{127)}$ adopted the hot-press (HP) method and added excess $\mathrm{PbO}$ to improve the electrical properties of PBLZST $+0.75 \mathrm{~mol} \% \mathrm{Y}$ ceramics. The HP samples exhibited improved microstructures, with relative densities of more than $98 \%$, and enhanced resistivity compared to the samples obtained by the conventional sintering method. Moreover, hot-pressed PBLZST + 0.75 mol\% Y with an appropriately excess amount of $\mathrm{PbO}(6 \mathrm{~mol} \%)$ displayed a much higher BDS and $P_{\max }$, leading to a high $U_{\text {rec }}$ of $3.2 \mathrm{~J} /$ $\mathrm{cm}^{3}$ (at $180 \mathrm{kV} / \mathrm{cm}$ ), which is almost twice that of the CS sample $\left(1.6 \mathrm{~J} / \mathrm{cm}^{3}\right)$.

The $\mathrm{AFE}_{\mathrm{T}}$ ceramics can possess larger $P_{\max }$ but smaller switching fields compared to those of the $\mathrm{AFE}_{0}$ ceramics; by utilizing the large switching field (or large BDS) of the $\mathrm{AFE}_{0}$ ceramics, it could be possible to obtain improved $U_{\text {rec }}$ in $\mathrm{AFE}_{\mathrm{T}}$ and $\mathrm{AFE}_{\mathrm{O}}$ two-phase composite ceramics. In this context, Zhang et al. ${ }^{132)}$ investigated the energy storage properties of $\left(\mathrm{Pb}_{0.858} \mathrm{Ba}_{0.1} \mathrm{La}_{0.02} \mathrm{Y}_{0.008}\right)\left(\mathrm{Zr}_{0.65} \mathrm{Sn}_{0.3} \mathrm{Ti}_{0.05}\right) \mathrm{O}_{3}-x\left(\mathrm{~Pb}_{0.97} \mathrm{La}_{0.02}\right)$ $\left(\mathrm{Zr}_{0.9} \mathrm{Sn}_{0.05} \mathrm{Ti}_{0.05}\right) \mathrm{O}_{3}$ (PLBYZST-PLZST, $\left.x=0-100 \mathrm{wt} \%\right)$ AFE composite ceramics. As the PLZST concentration was increased from 0 to $50 \mathrm{wt} \%, E_{\mathrm{AFE}-\mathrm{FE}}$ increased from $80 \mathrm{kV} / \mathrm{cm}$ to $130 \mathrm{kV} / \mathrm{cm}$ without a significant decrease in $P_{\max }$, resulting in an improved $U_{\text {rec }}$ of $4.65 \mathrm{~J} / \mathrm{cm}^{3}$ with an $\eta$ of $60 \%$ at 200 $\mathrm{kV} / \mathrm{cm}$. Moreover, the dielectric temperature stability was 
enhanced through the shifting of both the dielectric peaks $\left(\mathrm{AFE}_{\mathrm{O}}-\mathrm{AFE}_{\mathrm{T}}\right.$ and $\left.\mathrm{AFE}_{\mathrm{T}}-\mathrm{PE}\right)$ towards higher temperatures. However, both $E_{\mathrm{AFE}-\mathrm{FE}}$ and $P_{\max }$ decreased when the PLZST concentration exceeded $50 \mathrm{wt} \%$, due to enhanced compositional heterogeneity and the appearance of a secondary phase. In order to suppress the diffusion occurring between the two phases of PLBYZST-PLZST AFE composite ceramics during sintering, the SPS method and glass-aided sintering (GAS) have been employed. ${ }^{133,134)}$ As can be seen from Fig. 7(a), there is a clear split in the (002) and (200) peaks for the SPS and GAS samples compared with the case of the conventionally sintered samples, indicating reduced diffusion, which helped in improving the contributions of both the $\mathrm{AFE}_{0}$ and $\mathrm{AFE}_{\mathrm{T}}$ phases. ${ }^{134)}$ As a result, much higher $U_{\text {rec }}$ were realized for the SPS $\left(6.46 \mathrm{~J} / \mathrm{cm}^{3}\right)$ and GAS $\left(5.46 \mathrm{~J} / \mathrm{cm}^{3}\right)$ samples compared to the conventionally sintered sample $\left(4.65 \mathrm{~J} / \mathrm{cm}^{3}\right)$ that can be attributed to the increased AFE-FE transition and improved saturation polarization (Fig. 7(b)). In addition, the SPS sample displayed good temperature stability $\left(25-125^{\circ} \mathrm{C}\right)$ relative to the other samples owing to its higher $\mathrm{AFE}_{\mathrm{O}}-\mathrm{AFE}_{\mathrm{T}}$ transition temperature.

It is well known that $\mathrm{Pb}$-based complex perovskites such as $\mathrm{Pb}\left(\mathrm{B}_{1 / 2} \mathrm{Nb}_{1 / 2}\right) \mathrm{O}_{3}(\mathrm{~B}=\mathrm{Lu}, \mathrm{In}, \mathrm{Yb}, \mathrm{Tm})$ exhibit typical AFE characteristics and good temperature stability, though not many studies have been dedicated to evaluating their energy storage properties owing to their low saturation polarization. Recently, Xu et al. ${ }^{136)}$ used $\mathrm{Pb}\left(\mathrm{Mg}_{1 / 3} \mathrm{Nb}_{2 / 3}\right) \mathrm{O}_{3}(\mathrm{PMN})$ as a dopant to stabilize the perovskite phase and modulate the polarization and switching fields of $\mathrm{Pb}\left(\mathrm{Tm}_{1 / 2} \mathrm{Nb}_{1 / 2}\right) \mathrm{O}_{3}(\mathrm{PTmN})$ ceramics. All the $(1-x) \mathrm{PTmN}-x \mathrm{PMN}(x=0.02-0.18)$ specimens exhibited the pure perovskite structure with an orthorhombic phase. Continuous decreases in the unit cell volume, structural ordering of the B-site cations, $T_{\mathrm{C}}$, and $E_{\mathrm{AFE}-\mathrm{FE}}$ and progressive improvements in $P_{\max }$ and $\varepsilon_{\mathrm{r}}$ with increasing concentration of PMN were observed. This continuous increase in $P_{\max }$ and the decrease in $E_{\mathrm{AFE}-\mathrm{FE}}$ led to the maximum $U_{\text {rec }}$ of $3.11 \mathrm{~J} / \mathrm{cm}^{3}$ at $x=0.08$, which decreased with increasing PMN concentration.

Since the AFE-FE phase transition accompanied by volumetric expansion is sensitive to the applied stress, many researchers have utilized the mechanical confining effect to improve the energy storage properties. ${ }^{106,121,122)}$ Patel et al. ${ }^{106)}$ reported that the application of a mechanical stress reduces hysteresis loss and increases the AFE-FE transition by suppressing FE switching and initiating domain pinning. Gradual decreases in $P_{\mathrm{r}}$ and $P_{\max }$ along with an increase in the $E_{\mathrm{AFE}-\mathrm{FE}}$ of $\left(\mathrm{Pb}_{0.96} \mathrm{La}_{0.04}\right)\left(\mathrm{Zr}_{0.90} \mathrm{Ti}_{0.1}\right)_{0.99} \mathrm{O}_{3}$ ceramics were observed with an increase in the applied mechanical stress from 20 $\mathrm{MPa}$ to $300 \mathrm{MPa}$, which improved the $U_{\text {rec }}$ and $\eta$ by $38 \%$ and $25 \%$, respectively. On the other hand, the $U_{\text {rec }}$ of $\mathrm{Pb}_{0.99} \mathrm{Nb}_{0.02}$ $\left[\left(\mathrm{Zr}_{0.57} \mathrm{Sn}_{0.43}\right)_{0.94} \mathrm{Ti}_{0.06}\right]_{0.98} \mathrm{O}_{3}$ ceramics was enhanced by $23 \%$ (at $75 \mathrm{MPa}$ ) when a uniaxial stress was applied, whereas $17 \%$ (at $90 \mathrm{MPa}$ ) enhancement was observed for the application of a radial compressive stress. ${ }^{122)}$ In another study, Young et $a l .{ }^{121)}$ demonstrated that mechanical self-confinement led to an improvement in the energy storage density of partially electroded $\mathrm{Pb}_{0.99} \mathrm{Nb}_{0.02}\left[\left(\mathrm{Zr}_{0.57} \mathrm{Sn}_{0.43}\right)_{1-y} \mathrm{Ti}_{y}\right]_{0.98} \mathrm{O}_{3}(y=0.050-0.064)$ ceramics. A phase-field model was used to simulate the coevolution of polarization and stress and revealed that the partially electroded sample $(0.5 \mathrm{~A})$ exhibited a larger $P_{\max }$ along with a higher as well as steeper AFE-FE transition than the fully electroded sample (1.0A), as shown in Fig. 7(c). The possible reasons for the enhanced properties such as larger polarization is due to the electrostatic fringe effect and the higher AFE-FE transition that is a result of the combined effect of mechanical self-confinement and relatively low defect concentration. The simulated stress distribution of the 0.5 A sample under the peak electric field $(\sim 70$ $\mathrm{kV} / \mathrm{cm}$ ) is shown in Fig. 7(d), and the maximum stress that the sample experienced is approximately $30 \mathrm{MPa}$. All these effects resulted in a $9.2 \%$ enhancement in $U_{\text {rec }}\left(1.30 \mathrm{~J} / \mathrm{cm}^{3}\right.$ for the $0.5 \mathrm{~A}$ sample and $1.19 \mathrm{~J} / \mathrm{cm}^{3}$ for the $1.0 \mathrm{~A}$ sample), though the $\eta$ remained unchanged.

\subsubsection{Lead-free AFE ceramics}

Quite a few lead-free ceramics exhibit AFE behavior at RT; among them, $(\mathrm{Bi}, \mathrm{Na}) \mathrm{TiO}_{3}(\mathrm{BNT})$-based ${ }^{138-151)}$ and $\mathrm{AgNbO}_{3}$ (AN)-based ${ }^{152-156)}$ ceramics have been extensively studied for energy storage applications. It is well known that BNT undergoes a structural transition from the rhombohedral phase to the tetragonal phase via an intermediate AFE-like phase at around $190^{\circ} \mathrm{C}$ (depolarization temperature, $T_{\mathrm{d}}$ ); however, this can be shifted to a lower temperature through compositional modification. In this regard, BT-modified BNT system has been extensively studied to stabilize the AFE phase by modulating the FE-AFE transition temperature. ${ }^{157)} \mathrm{Li}$ et $a l .{ }^{143)}$ modulated the antiferroelectricity and corresponding energy storage properties of $0.94 \mathrm{Bi}_{0.5-x} \mathrm{Na}_{0.5-x} \mathrm{TiO}_{3}-$ $0.06 \mathrm{BaTiO}_{3}(\mathrm{BNT} x-\mathrm{BT})$ ceramics by tailoring the $\mathrm{Bi} / \mathrm{Na}$ ratio. The composition corresponding to excess amounts of $\mathrm{Bi}^{3+}$ and/or deficiency in $\mathrm{Na}^{+}$displayed a reduced $T_{\mathrm{d}}$ with a well-developed AFE-like phase at RT, which resulted in double hysteresis loops with enhanced saturation polarization. As a result, a maximum energy storage density of 1.76 $\mathrm{J} / \mathrm{cm}^{3}$ was achieved for $x=0.05$ of the BNT $x-\mathrm{BT}$ ceramics.

$\mathrm{Xu}$ et $a l .{ }^{144)}$ reported that $P_{\mathrm{r}}$ and $E_{\mathrm{C}}$ decreased while the BDS and ac-resistivity increased with the incorporation of $\mathrm{La}^{3+}$ in the BNT-BT matrix (i.e., $\left[\left(\mathrm{Bi}_{0.5} \mathrm{Na}_{0.5}\right)_{0.93} \mathrm{Ba}_{0.07}\right]_{1-x} \mathrm{La}_{x-}$ $\left.\mathrm{TiO}_{3}, \mathrm{BNBLT} 7\right)$. In this study, two kinds of dopants, namely $\mathrm{La}_{2} \mathrm{O}_{3}(x=0-0.04)$ and $\mathrm{La}\left(\mathrm{NO}_{3}\right)_{3}(x=0.04)$ powders, were used. Since the ionic radius of $\mathrm{La}^{3+}(1.06 \AA)$ is smaller than those of $\mathrm{Bi}^{3+}(1.36 \AA)$ and $\mathrm{Na}^{+}(1.39 \AA)$, shifting of diffraction peaks towards higher angles and a reduction in grain size were noticed with increasing $\mathrm{La}^{3+}$ concentration. Moreover, decreases in $P_{\mathrm{r}}$ from $44.90 \mathrm{\mu C} / \mathrm{cm}^{2}$ to $2.19 \mathrm{\mu C} / \mathrm{cm}^{2}, E_{\mathrm{C}}$ from $34.0 \mathrm{kV} / \mathrm{cm}$ to $5.70 \mathrm{kV} / \mathrm{cm}$, and an increase in the amount of the AFE-like phase of the BNBLT ceramics upon shifting the $T_{\mathrm{d}}$ to below RT were observed. Consequently, improved energy storage densities of $1.09 \mathrm{~J} / \mathrm{cm}^{3}$ (at $80 \mathrm{kV} / \mathrm{cm}$ ) and $1.21 \mathrm{~J} / \mathrm{cm}^{3}$ (at $100 \mathrm{kV} / \mathrm{cm}$ ) were realized in $\mathrm{La}_{2} \mathrm{O}_{3}$ and $\left.\mathrm{La}\left(\mathrm{NO}_{3}\right)_{3}\right)$ doped BNT-BT samples, respectively. In another study, $\mathrm{Li}$ et $a l{ }^{147)}$ reported that the incorporation of $\mathrm{La}^{3+}$ 
changed the crystal structure of BNT-BT ceramics from the FE rhombohedral phase to the AFE-like tetragonal phase and reduced the $P_{\mathrm{r}}$ and $P_{\max }$ progressively. The $\mathrm{La}^{3+}$-modified BNT-BT $\left.\left(\left(\mathrm{Bi}_{1 / 2} \mathrm{Na}_{1 / 2}\right)_{0.94} \mathrm{Ba}_{0.06}\right] \mathrm{La}_{(1-x)} \mathrm{Zr}_{x} \mathrm{TiO}_{3}, \quad \mathrm{BNBLT} 6\right)$ ceramics exhibited a maximum strain of $0.53 \%$ and a strain coefficient of $707 \mathrm{pm} / \mathrm{V}$ for $x=0.03$, while a larger $U_{\text {rec }}$ of $1.66 \mathrm{~J} / \mathrm{cm}^{3}$ at $105 \mathrm{kV} / \mathrm{cm}$ was obtained for $x=0.05$. Furthermore, addition of $\mathrm{Zr}$ increased the BDS and reduced the hysteresis loss of the BNBLT ceramics, thus, the energy storage properties were significantly improved. ${ }^{139,141)}$ Recently, Kandula et $a l{ }^{149)}$ investigated the effect of $\mathrm{Nd}^{3+}$ on the energy storage properties of BNT-BT AFE ceramics. The doping of $1 \mathrm{~mol} \% \mathrm{Nd}^{3+}$ in the BNT-BT matrix induced relaxor-like behavior $(\gamma=1.84)$ with improved permittivity ( 3500@5kHz at $\left.T_{\mathrm{m}}\right)$. With increasing temperature, both $U_{\text {rec }}$ and $\eta$ gradually increased due to the increase in domain wall mobility and the ease of domain reorientation, which resulted in the large value of $U_{\text {rec }}$ of $\sim 1.53 \mathrm{~J} / \mathrm{cm}^{3}$ and an $\eta$ of $93 \%$ at $73 \mathrm{kV} / \mathrm{cm}$ and $105^{\circ} \mathrm{C}$.

Cao et $a l .{ }^{138)}$ demonstrated defect dipole-induced slim and double hysteresis loop behavior in the $\mathrm{Mn}^{2+}$-doped 0.7[0.94NBT-0.06BT]-0.3ST (NBBST) ternary system for enhanced energy storage properties. It was reported that the incorporation of the acceptor-type $\mathrm{Mn}^{2+}$ dopant for substituting $\mathrm{Ti}^{4+}$ resulted in the formation of oxygen vacancies to ensure charge balance and the production of defect dipoles $\left(P_{\mathrm{D}}\right)$. According to the symmetry-conforming property of point defects, the symmetry of $P_{\mathrm{D}}$ follows the crystal symmetry under the equilibrium condition. On application of an external electric field, $P_{\mathrm{S}}$ tries to align in the direction of the field, but $P_{\mathrm{D}}$ shows resistance to such a change (Fig. $7(\mathrm{e})$ ). Moreover, $P_{\mathrm{D}}$ can act as an internal electric field and help the new domains get back to their original state after the field is removed. Therefore, $\mathrm{Mn}^{2+}$-doped NBBST ceramics exhibit double hysteresis loop behavior with enlarged $P_{\max }-P_{\mathrm{r}}$ values (Fig. 7(f) and $\left.7(\mathrm{~g})\right)$. As a consequence, a maximum value of $U_{\text {rec }}\left(1.06 \mathrm{~J} / \mathrm{cm}^{3}\right.$ at $\left.95 \mathrm{kV} / \mathrm{cm}\right)$ was obtained at $11 \mathrm{~mol} \% \mathrm{Mn}$ doping due to the large $P_{\max }-P_{\mathrm{r}}$ value $(37 \mu \mathrm{C} /$ $\mathrm{cm}^{2}$ ). Mishra et $a l .{ }^{145)}$ investigated the energy storage properties of $\mathrm{BiFeO}_{3}(\mathrm{BF})$ and $\mathrm{K}_{0.5} \mathrm{Na}_{0.5} \mathrm{NbO}_{3}(\mathrm{KNN})$ modified BNT-BT ceramics. In order to reduce the leakage current, $0.1 \mathrm{wt} \%$ of $\mathrm{MnO}_{2}$ was added to all the ceramics. The ternary system with the composition of 0.50BNTBT-0.50BFBT was optimal on account of its better energy storage properties $\left(U_{\text {rec }}=0.77 \mathrm{~J} / \mathrm{cm}^{3}\right.$ and $\eta=67 \%$ at $50 \mathrm{kV} / \mathrm{cm}$ ) compared to the other systems such as $0.25 \mathrm{BNTBT}-0.75 \mathrm{BFBT}$ and $0.75 \mathrm{BNTBT}$ $0.25 \mathrm{BFBT}$. Further, doping of $1 \mathrm{~mol} \% \mathrm{KNN}$ to the optimized composition significantly increased the $\eta$ from $67 \%$ to $90.3 \%$ at the cost of $U_{\text {rec }}\left(0.38 \mathrm{~J} / \mathrm{cm}^{3}\right)$. In addition, the $0.50 \mathrm{BNTBT}$ 0.50BFBT ceramics sintered using the SPS technique displayed a $U_{\text {rec }}$ of $1.3 \mathrm{~J} / \mathrm{cm}^{3}$, which was $69 \%$ larger than that of the CS sample.

The other doped BNT system of $(\mathrm{Bi}, \mathrm{Na}) \mathrm{TiO}_{3}-(\mathrm{Bi}, \mathrm{K}) \mathrm{TiO}_{3}$ (BNT-BKT or BNKT) has been extensively studied owing to its enhanced piezoelectric and ferroelectric properties at the rhombohedral-tetragonal MPB. A few attempts have been made to improve the energy storage density properties of BNT-BKT ceramics by doping and/or forming ternary solid solutions with other perovskites. ${ }^{140,142,146,148)}$ Zhao et al. ${ }^{140)}$ reported that the addition of $\mathrm{KNN}$ improved the AFE phase stability and energy storage properties of $0.84 \mathrm{Na}_{0.5} \mathrm{Bi}_{0.5} \mathrm{TiO}_{3}-$ $0.16 \mathrm{~K}_{0.5} \mathrm{Bi}_{0.5} \mathrm{TiO}_{3}(0.84 \mathrm{BNT}-0.16 \mathrm{BKT})$ ceramics. As the $x$ of $(1-x)(0.84 \mathrm{BNT}-0.16 \mathrm{BKT})-x \mathrm{KNN}$ ceramics was increased $(x=$ $0-0.15$ ), the $T_{\mathrm{d}}$ gradually decreased from $140^{\circ} \mathrm{C}$ to $75^{\circ} \mathrm{C}$ due to an increase in oxygen vacancies upon the substitution of the pentavalent $\mathrm{Nb}^{5+}(\mathrm{KNN})$ for the tetravalent $\mathrm{Ti}^{4+}$ (BNTBKT) sites, which facilitated the increase in the contribution of the AFE phase; therefore, the $P$ - $E$ loops became slim and exhibited the double hysteretic behavior at RT. The ceramic of composition $x=0.09$ exhibited the maximum $U_{\text {rec }}$ of $1.56 \mathrm{~J} / \mathrm{cm}^{3}$ with an $\eta$ of $64.5 \%$ and good temperature stability $\left(\Delta U_{\text {rec }} / U_{\text {reo@ } 100^{\circ} \mathrm{C}} \leq \pm 20 \%\right)$ due to its uniform microstructure and slim double hysteresis loops. On the other hand, doping of a complex ion $\left(\mathrm{Al}_{0.5} \mathrm{Nb}_{0.5}\right)^{4+}$ improved the BDS of the BNT-BKT ceramics. ${ }^{142}$ The substitution of $\mathrm{Al}^{3+}$ and $\mathrm{Nb}^{5+}$ for $\mathrm{Ti}^{4+}$ led to the creation of oxygen vacancies, as well as cation vacancies that compensated the charge imbalance, which increased the ability to withstand larger electric fields $(\sim 116 \mathrm{kV} / \mathrm{cm})$. Moreover, $\left(\mathrm{Al}_{0.5} \mathrm{Nb}_{0.5}\right)^{4+}$-containing BNTBKT ceramics revealed reduced values of $P_{\mathrm{r}}, P_{\max }$, and ionic and electronic conductivities. Therefore, the $U_{\text {rec }}$ continuously increased with $\left(\mathrm{Al}_{0.5} \mathrm{Nb}_{0.5}\right)^{4+}$ concentration and reached a maximum value of $1.41 \mathrm{~J} / \mathrm{cm}^{3}$ at $105 \mathrm{kV} / \mathrm{cm}$ when the doping was $8 \mathrm{~mol} \%$. Similarly, co-doping of $\mathrm{Li}^{+}, \mathrm{Nb}^{5+}, \mathrm{Sr}^{2+}$, and $\mathrm{Ta}^{5+}$ resulted in shifting the $T_{\mathrm{d}}$ to below RT, relaxorlike behavior, reduced $P_{\mathrm{r}}, P_{\max }$, and $E_{\mathrm{C}}$, and enhanced BDS of the BNT-BKT ceramics. ${ }^{148)}$ All these effects made it possible to achieve the largest $U_{\text {rec }}$ of $1.60 \mathrm{~J} / \mathrm{cm}^{3}$ at $90 \mathrm{kV} / \mathrm{cm}$ for $\quad\left(\left(\mathrm{Bi}_{0.5}\left[\left(\mathrm{Na}_{0.8} \mathrm{~K}_{0.2}\right)_{0.90} \mathrm{Li}_{0.10}\right]_{0.5}\right)_{0.96} \mathrm{Sr}_{0.04}\right)\left(\mathrm{Ti}_{0.975} \mathrm{Ta}_{0.025} \mathrm{Nb}_{0}\right) \mathrm{O}_{3}$ (BNLKSTTN-0.10/0.04/0.025/0). In addition, BNLKSTTN0.10/0.04/0.025/0 ceramics exhibited good bipolar fatigue endurances up to $10^{7}$ polarization switching cycles and good thermal stability over the temperature range $20-200^{\circ} \mathrm{C}$. In another study, Yu et al. ${ }^{146)}$ reported that the incorporation of $\mathrm{BiAlO}_{3}$ (BA) changed the crystal structure of $0.75 \mathrm{BNT}$ $0.25 \mathrm{BKT}$ ceramics from the tetragonal phase to the pseudocubic phase and improved the AFE order. TEM observations of BA-doped 0.75BNT-0.25BKT ceramics revealed the existence of AFE features based on the appearance of $1 / 2(o o e)$ spots, which belong to the in-phase $a^{0} a^{0} c^{+}$oxygen octahedron tilt system with $P 4 \mathrm{bm}$ space group. The incorporation of BA destroyed the long-range $\mathrm{FE}$ order, which is evidenced by the decrease in $P_{\mathrm{r}}, P_{\max }$, and $E_{\mathrm{C}}$ and the appearance of pinched and slim hysteresis loops. At the optimal composition of $0.94(0.75 \mathrm{BNT}-0.25 \mathrm{BKT})-0.06 \mathrm{BA}$, the maximum value of $1.15 \mathrm{~J} / \mathrm{cm}^{3}$ with an $\eta$ of $73.2 \%$ at $105 \mathrm{kV} / \mathrm{cm}$ has been achieved.

Recently, Li et al. ${ }^{150)}$ investigated the effect of doping of the AFE material $\mathrm{NaNbO}_{3}(\mathrm{NN})$ on the energy storage properties of $0.7 \mathrm{Bi}_{0.5} \mathrm{Na}_{0.5} \mathrm{TiO}_{3}-0.3 \mathrm{Bi}_{0.2} \mathrm{Sr}_{0.7} \mathrm{TiO}_{3}$ (0.7BNT-0.3BST) AFE ceramics. With the incorporation of $\mathrm{NN}$, increases in the grain size and BDS and decreases in $\varepsilon_{\mathrm{r}}, P_{\max }$, and hyster- 
esis loss were observed. Additionally, the doping of NN hindered the transformation of nanopolar clusters to macropolar clusters and resulted in slim double hysteresis loops even under large applied electric fields. Therefore, the existence of relaxor and AFE behaviors with large BDS enhanced the energy storage properties $\left(U_{\text {rec }} \sim 1.03 \mathrm{~J} / \mathrm{cm}^{3}\right.$ and $\eta \sim 85.8 \%$ at $85 \mathrm{kV} / \mathrm{cm}$ ) for $1 \mathrm{~mol} \% \mathrm{NN}$-doped (0.7BNT-0.3BST) ceramics.

In the family of lead-free $\mathrm{AFE}$ ceramics, $\mathrm{AgNbO}_{3}(\mathrm{AN})$ is considered as a promising AFE candidate for energy storage applications owing to its inherently higher BDS and polarization properties. ${ }^{152-156)}$ Tian et al. ${ }^{153)}$ demonstrated the structure-property relation and energy storage properties of AN ceramics prepared via conventional sintering. Temperature-dependent FE measurements of the AN ceramics revealed the existence of two types of polar regions, one of which was stable up to $70^{\circ} \mathrm{C}$ and the other was stable up to $170^{\circ} \mathrm{C}$. Earlier reports suggested that the transition at $170^{\circ} \mathrm{C}$ represents the freezing temperature of the antipolar dipoles of the $\mathrm{Pbcm}$ lattice. At RT, AN ceramics exhibited the typical AFE-like double hysteresis $P-E$ loop with a $P_{\max }$ of $40 \mathrm{\mu C} / \mathrm{cm}^{2}$ and a BDS of $175 \mathrm{kV} / \mathrm{cm}$, which led to the realization of a maximum $U_{\text {rec }}$ value of $\sim 2.1 \mathrm{~J} / \mathrm{cm}^{3}$, though the $\eta$ was too low $(<50 \%)$. Further, Zhao et al. ${ }^{152)}$ considered $\mathrm{MnO}_{2}$ doping (0-0.3 wt\%) to improve the $\eta$ of $\mathrm{AN}$ ceramics. The addition of $\mathrm{MnO}_{2}$ reduced the sintering temperature, promoted densification, and improved the dielectric properties of AN ceramics. With increasing $\mathrm{MnO}_{2}$ concentration, the $P_{\mathrm{r}}$ decreased and both the switching fields increased monotonically, while the $P_{\max }$ increased first and then decreased at the turning point of $x=0.1$. The reduced $P_{\mathrm{r}}$ and $\Delta E$ and enhanced $P_{\max }$ at $x=0.1$ resulted in the $U_{\text {rec }}$ increasing from $1.6 \mathrm{~J} / \mathrm{cm}^{3}$ to $2.5 \mathrm{~J} / \mathrm{cm}^{3}$ and $\eta$ from $37 \%$ to $57 \%$. In addition to the improved $U_{\text {rec }}$ and $\eta$, Mn-doped AN ceramics displayed excellent temperature stability over the temperature range $20-180^{\circ} \mathrm{C}$. Inspired by the above results, various dopants such as $\mathrm{Ta}_{2} \mathrm{O}_{5},{ }^{154)} \mathrm{WO}_{3},{ }^{155)}$ and $\mathrm{Bi}_{2} \mathrm{O}_{3}{ }^{156)}$ were introduced into AN ceramics to reduce the $P_{\mathrm{r}}$ and $\Delta E$ and increase the $P_{\max }$ and switching fields, which succeeded in realizing larger values of $U_{\text {rec }}\left(2.6-4.2 \mathrm{~J} / \mathrm{cm}^{3}\right)$ and $\eta(50-86 \%)$.

\section{Conclusions and Future Prospects}

The recent developments in pulsed power technology and hybrid electric vehicles propel the exploration of highly efficient energy storage materials having large energy storage and power densities, sustainability, and good fatigue lives. Dielectric ceramics are of particular interest for energy storage applications owing to their moderate energy storage density, large power density, fast charging/discharging, good mechanical and temperature stability, and good fatigue endurance. In this work, an overview of the technological developments towards improving the energy storage properties of various types of dielectric ceramics, including LD, PE, FE, RFE, and AFE materials have been presented. To achieve high energy storage properties in dielectric ceram- ics, various approaches such as chemical modification, grain refinement, core-shell structuring, the use of special sintering techniques, multilayered structures, interfacial engineering, mechanical confinement, self-confinement, and the fabrication of materials in which different phases coexist (near the MPB) have been utilized.

Even though significant progress has been made in realizing high energy storage properties, a few challenges remain to be resolved, including obtaining high $\varepsilon_{\mathrm{r}}$, low $\tan \delta$, high BDS, low $P_{\mathrm{r}}$, and high $P_{\max }$ in the same dielectric material. Therefore, careful control of the processing parameters and design of a new dielectric material that can balance high polarization, low hysteresis, and high BDS are highly essential. Most of the studies have concentrated on improving the BDS rather than simultaneously improving both $\varepsilon_{\mathrm{r}}$ and BDS. However, the application of large electric fields to realize large $U_{\text {rec }}$ causes several safety issues. Moreover, for practical applications, high $\eta$ is essential along with high $U_{\text {rec }}$, therefore, the fabrication of high-permittivity nanocrystalline materials and/or materials in which the RFE and AFE phases coexist are highly recommended. In addition, the fabrication of multilayered structures consisting of appropriate combinations of high permittivity and low loss (or high BDS) layers is also a feasible route to high $U_{\text {rec }}$ as well as high $\eta$. Recently, Xu et al. ${ }^{158)}$ reported their firstprinciple based theoretical predictions on the energy storage features of the rare-earth element $\mathrm{Nd}$-modified $\mathrm{BiFeO}_{3}$ system, which is capable of achieving very high energy densities $\left(100-150 \mathrm{~J} / \mathrm{cm}^{3}\right)$ and efficiencies $(80-88 \%)$ even at practically available electric fields $(2000-3000 \mathrm{kV} / \mathrm{cm})$. Likewise, several theoretical studies combined with experimental strategies are required to design a material with enormous energy storage properties. Furthermore, the development of a standard evaluation system is required for replacing the currently used static and dynamic methods.

\section{Acknowledgments}

This study was supported by the Basic Science Research Program of the National Research Foundation of Korea (NRF) funded by the Ministry of Science, ICT \& Future Planning (NRF-2016R1A2B4011663).

\section{REFERENCES}

1. C. A. Randall, H. Ogihara, J. R. Kim, G. Y. Yang, C. S. Stringer, S. Trolier-McKinstry, and M. Lanagan, "High Temperature and High Energy Density Dielectric Materials"; pp. 346-351 in Proceedings of the 2009 IEEE Pulsed Power Conference. IEEE, Washington, DC, 2009.

2. T. D. Huan, S. Boggs, G. Teyssedre, C. Laurent, M. Cakmak, S. Kumar, and R. Ramprasad, "Advanced Polymeric Dielectrics for High Energy Density Applications," Prog. Mater. Sci., 83 236-69 (2016).

3. Z. Yao, Z. Song, H. Hao, Z. Yu, M. Cao, S. Zhang, M. T. Lanagan, and H. Liu, "Homogeneous/Inhomogeneous- 
Structured Dielectrics and Their Energy-Storage Performances," Adv. Mater., 29 [20] 1601727 (2017).

4. J. R. Laghari and W. J. Sarjeant, "Energy-Storage PulsedPower Capacitor Technology," IEEE Trans. Power Electron., 7 [1] 251-57 (1992).

5. Prateek, V. K. Thakur, and R. K. Gupta, "Recent Progress on Ferroelectric Polymer-Based Nanocomposites for High Energy Density Capacitors: Synthesis, Dielectric Properties, and Future Aspects," Chem. Rev., 116 [7] 4260-317 (2016).

6. H. Palneedi, M. Peddigari, G.-T. Hwang, D.-Y. Jeong, and J. Ryu, "High-Performance Dielectric Ceramic Films for Energy Storage Capacitors: Progress and Outlook," Adv. Funct. Mater., 28 [42] 1803665 (2018).

7. P. Barber, S. Balasubramanian, Y. Anguchamy, S. Gong, A. Wibowo, H. Gao, J. H. Ploehn, and H.-C. Zur Loye, "Polymer Composite and Nanocomposite Dielectric Materials for Pulse Power Energy Storage," Materials, 2 [4] 1697-733 (2009).

8. X. Hao, "A Review on the Dielectric Materials for High Energy-Storage Application," J. Adv. Dielectr., 03 [01] 1330001 (2013).

9. Z.-M. Dang, J.-K. Yuan, S.-H. Yao, and R.-J. Liao, "Flexible Nanodielectric Materials with High Permittivity for Power Energy Storage," Adv. Mater., 25 [44] 6334-65 (2013).

10. Y. Shen, Y. Lin, and Q. M. Zhang, "Polymer Nanocomposites with High Energy Storage Densities," MRS Bull. 40 [9] 753-59 (2015).

11. Q. Chen, Y. Shen, S. Zhang, and Q. M. Zhang, "PolymerBased Dielectrics with High Energy Storage Density," Ann. Rev. Mater. Res., 45 [1] 433-58 (2015).

12. Z.-M. Dang, M.-S. Zheng, P.-H. Hu, and J.-W. Zha, "Dielectric Polymer Materials for Electrical Energy Storage and Dielectric Physics: A Guide,” J. Adv. Phys., 4 [4] 302-13 (2015).

13. A. Chauhan, S. Patel, R. Vaish, and R. C. Bowen, "AntiFerroelectric Ceramics for High Energy Density Capacitors," Materials, 8 [12] 8009-31 (2015).

14. D. P. Shay, N. J. Podraza, and C. A. Randall, "High Energy Density, High Temperature Capacitors Utilizing MnDoped $0.8 \mathrm{CaTiO}_{3}-0.2 \mathrm{CaHfO}_{3}$ Ceramics," J. Am. Ceram. Soc., 95 [4] 1348-55 (2012).

15. J. Zheng, G. H. Chen, X. Chen, Q. N. Li, J. W. Xu, C. L. Yuan, and C. R. Zhou, "Dielectric Properties and Energy Storage Behaviors in $\mathrm{ZnNb}_{2} \mathrm{O}_{6}$-Doped $\mathrm{Sr}_{0.97} \mathrm{Nd}_{0.02} \mathrm{TiO}_{3}$ Ceramics," J. Mater. Sci. Mater. Electron., 27 [4] 3759-64 (2016).

16. H. Y. Zhou, X. N. Zhu, G. R. Ren, and X. M. Chen, "Enhanced Energy Storage Density and Its Variation Tendency in $\mathrm{CaZr}_{x} \mathrm{Ti}_{1-x} \mathrm{O}_{3}$ Ceramics," J. Alloys Compd., 688 687-91 (2016).

17. Z. C. Li, G. H. Chen, C. L. Yuan, C. R. Zhou, T. Yang, and Y. Yang, "Effects of $\mathrm{NiNb}_{2} \mathrm{O}_{6}$ Doping on Dielectric Property, Microstructure and Energy Storage Behavior of $\mathrm{Sr}_{0.97} \mathrm{La}_{0.02} \mathrm{TiO}_{3}$ Ceramics," J. Mater. Sci. Mater. Electron., 28 [2] 1151-58 (2017).

28. Z. Yao, Q. Luo, G. Zhang, H. Hao, M. Cao, and H. Liu, "Improved Energy-Storage Performance and Breakdown
Enhancement Mechanism of $\mathrm{Mg}$-Doped $\mathrm{SrTiO}_{3}$ Bulk Ceramics for High Energy Density Capacitor Applications," J. Mater. Sci. Mater. Electron., 28 [15] 11491-99 (2017).

19. G. Zhao, Y. Li, H. Liu, J. Xu, H. Hao, M. Cao, and Z. Yu, "Effect of $\mathrm{SiO}_{2}$ Additives on the Microstructure and Energy Storage Density of $\mathrm{SrTiO}_{3}$ Ceramics," J. Ceram. Process. Res., 13 [3] 310-14 (2012).

20. H. Y. Zhou, X. Q. Liu, X. L. Zhu, and X. M. Chen, "CaTiO Linear Dielectric Ceramics with Greatly Enhanced Dielectric Strength and Energy Storage Density," J. Am. Ceram. Soc., 101 [5] 1999-2008 (2017).

21. F. Zeng, M. Cao, L. Zhang, M. Liu, H. Hao, Z. Yao, and H. Liu, "Microstructure and Dielectric Properties of $\mathrm{SrTiO}_{3}$ Ceramics by Controlled Growth of Silica Shells on $\mathrm{SrTiO}_{3}$ Nanoparticles," Ceram. Int., 43 [10] 7710-16 (2017).

22. H. Yang, F. Yan, Y. Lin, and T. Wang, "Enhanced Recoverable Energy Storage Density and High Efficiency of $\mathrm{SrTiO}_{3}$-Based Lead-Free Ceramics," Appl. Phys. Lett., 111 [25] 253903 (2017).

23. B. Luo, X. Wang, E. Tian, H. Song, H. Wang, and L. Li, "Enhanced Energy-Storage Density and High Efficiency of Lead-Free $\mathrm{CaTiO}_{3}-\mathrm{BiScO}_{3}$ Linear Dielectric Ceramics," ACS Appl. Mater. Interfaces, 9 [23] 19963-72 (2017).

24. N. H. Fletcher, A. D. Hilton, and B. W. Ricketts, "Optimization of Energy Storage Density in Ceramic Capacitors," J. Phys. D: Appl. Phys., 29 [1] 253 (1996).

25. G. Dong, S. Ma, J. Du, and J. Cui, "Dielectric Properties and Energy Storage Density in Zno-Doped $\mathrm{Ba}_{0.3} \mathrm{Sr}_{0.7} \mathrm{TiO}_{3}$ Ceramics," Ceram. Int., 35 [5] 2069-75 (2009).

26. Q. Zhang, L. Wang, J. Luo, Q. Tang, and J. Du, " $\mathrm{Ba}_{0.4} \mathrm{Sr}_{0.6} \mathrm{TiO}_{3}$ / $\mathrm{MgO}$ Composites with Enhanced Energy Storage Density and Low Dielectric Loss for Solid-State Pulse-Forming Line," Int. J. Appl. Ceram. Technol., 7 [s1] E124-28 (2009).

27. Z. Song, H. Liu, S. Zhang, Z. Wang, Y. Shi, H. Hao, M. Cao, Z. Yao, and Z. Yu, "Effect of Grain Size on the Energy Storage Properties of $\left(\mathrm{Ba}_{0.4} \mathrm{Sr}_{0.6}\right) \mathrm{TiO}_{3}$ Paraelectric Ceramics," J. Eur. Ceram. Soc., 34 [5] 1209-17 (2014).

28. Y. Shi, H. Liu, H. Hao, M. Cao, Z. Yao, Z. Song, G. Li, W. Tang, and J. Xie, "Investigation of Dielectric Properties for $\mathrm{Ba}_{0.4} \mathrm{Sr}_{0.6} \mathrm{TiO}_{3}$ Ceramics with Various Grain Sizes," Ferroelectrics, 487 [1] 109-21 (2015).

29. Z. Song, H. Liu, H. Hao, S. Zhang, M. Cao, Z. Yao, Z. Wang, W. Hu, Y. Shi, and B. Hu, "The Effect of Grain Boundary on the Energy Storage Properties of $\left(\mathrm{Ba}_{0.4} \mathrm{Sr}_{0.6}\right) \mathrm{Tio}_{3}$ Paraelectric Ceramics by Varying Grain Sizes," IEEE Trans. Ultrason. Ferroelectr. Freq. Control, 62 [4] 609-16 (2015).

30. Z. Song, S. Zhang, H. Liu, H. Hao, M. Cao, Q. Li, Q. Wang, Z. Yao, Z. Wang, and T. Lanagan Michael, "Improved Energy Storage Properties Accompanied by Enhanced Interface Polarization in Annealed Microwave-Sintered BST,” J. Am. Ceram. Soc., 98 [10] 3212-22 (2015).

31. Y. H. Huang, Y. J. Wu, J. Li, B. Liu, and X. M. Chen, "Enhanced Energy Storage Properties of Barium Strontium Titanate Ceramics Prepared by Sol-Gel Method and Spark Plasma Sintering," J. Alloys Compd., 701 439-46 (2017).

32. Y. J. Wu, Y. H. Huang, N. Wang, J. Li, M. S. Fu, and X. M. Chen, "Effects of Phase Constitution and Microstructure 
on Energy Storage Properties of Barium Strontium Titanate Ceramics," J. Eur. Ceram. Soc., 37 [5] 2099-104 (2017).

33. Q. Jin, Y.-P. Pu, C. Wang, Z.-Y. Gao, and H.-Y. Zheng, "Enhanced Energy Storage Performance of $\mathrm{Ba}_{0.4} \mathrm{Sr}_{0.6} \mathrm{TiO}_{3}$ Ceramics: Influence of Sintering Atmosphere," Ceram. Int. 43 S232-38 (2017).

34. X. Y. Ye, Y. M. Li, and J. J. Bian, "Dielectric and Energy Storage Properties of Mn-Doped $\mathrm{Ba}_{0.3} \mathrm{Sr}_{0.475} \mathrm{La}_{0.12} \mathrm{Ce}_{0.03} \mathrm{TiO}_{3}$ Dielectric Ceramics," J. Eur. Ceram. Soc., 37 [1] 107-14 (2017).

35. Y. Gao, H. Liu, Z. Yao, H. Hao, Z. Yu, and M. Cao, "Effect of Layered Structure on Dielectric Properties and Energy Storage Density in $x \mathrm{Ba}_{0.7} \mathrm{Sr}_{0.3} \mathrm{TiO}_{3}-\mathrm{SrTiO}_{3}$ Multilayer Ceramics," Ceram. Int., 43 [11] 8418-23 (2017).

36. J. Wang, C. Xu, B. Shen, and J. Zhai, "Enhancing Energy Storage Density of $(\mathrm{Ba}, \mathrm{Sr}) \mathrm{TiO}_{3}$ Ceramic Particles by Coating with $\mathrm{Al}_{2} \mathrm{O}_{3}$ and $\mathrm{SiO}_{2}$," J. Mater. Sci. Mater. Electron., 24 [9] 3309-14 (2013).

37. X. Lu, Y. Tong, H. Talebinezhad, L. Zhang, and Z. Y. Cheng, "Dielectric and Energy-Storage Performance of $\mathrm{Ba}_{0.5} \mathrm{Sr}_{0.5} \mathrm{TiO}_{3}-\mathrm{SiO}_{2}$ Ceramic-Glass Composites," J. Alloys Compd., 745 127-34 (2018).

38. Y. H. Huang, Y. J. Wu, B. Liu, T. N. Yang, J. J. Wang, J. Li, L.-Q. Chen, and X. M. Chen, "From Core-Shell $\mathrm{Ba}_{0.4} \mathrm{Sr}_{0.6} \mathrm{TiO}_{3} @ \mathrm{SiO}_{2}$ Particles to Dense Ceramics with High Energy Storage Performance by Spark Plasma Sintering," J. Mater. Chem. A, 6 [10] 4477-84 (2018).

39. H. Yang, F. Yan, Y. Lin, and T. Wang, "Enhanced Energy Storage Properties of $\mathrm{Ba}_{0.4} \mathrm{Sr}_{0.6} \mathrm{TiO}_{3}$ Lead-Free Ceramics with $\mathrm{Bi}_{2} \mathrm{O}_{3}-\mathrm{B}_{2} \mathrm{O}_{3}-\mathrm{SiO}_{2}$ Glass Addition," J. Eur. Ceram. Soc., 38 [4] 1367-73 (2018).

40. G.-F. Zhang, H. Liu, Z. Yao, M. Cao, and H. Hao, "Effects of Ca Doping on the Energy Storage Properties of ( $\mathrm{Sr}$, Ca) $\mathrm{TiO}_{3}$ Paraelectric Ceramics," J. Mater. Sci. Mater. Electron., 26 [5] 2726-32 (2015).

41. M. Zhou, R. Liang, Z. Zhou, C. Xu, X. Nie, X. Chen, and X. Dong, "High Energy Storage Properties of $\left(\mathrm{Ni}_{1 / 3} \mathrm{Nb}_{2 / 3}\right)^{4+}$ Complex-Ion Modified $\left(\mathrm{Ba}_{0.85} \mathrm{Ca}_{0.15}\right)\left(\mathrm{Zr}_{0.10} \mathrm{Ti}_{0.90}\right) \mathrm{O}_{3}$ Ceramics," Mater. Res. Bull., 98 166-72 (2018).

42. X. Dong, H. Chen, M. Wei, K. Wu, and J. Zhang, "Structure, Dielectric and Energy Storage Properties of $\mathrm{BaTiO}_{3}$ Ceramics Doped with $\mathrm{YNbO}_{4}$," J. Alloys Compd., 744 72127 (2018).

43. F. Gao, X. Dong, C. Mao, F. Cao, and G. Wang, "c/a RatioDependent Energy-Storage Density in $(0.9-x) \mathrm{Bi}_{0.5} \mathrm{Na}_{0.5} \mathrm{TiO}_{3}-$ $x \mathrm{BaTiO}_{3}-0.1 \mathrm{~K}_{0.5} \mathrm{Na}_{0.5} \mathrm{NbO}_{3}$ Ceramics," J. Am. Ceram. Soc., 94 [12] 4162-64 (2011).

44. G. Viola, H. Ning, M. J. Reece, R. Wilson, T. M. Correia, P. Weaver, M. G. Cain, and H. Yan, "Reversibility in Electric Field-Induced Transitions and Energy Storage Properties of Bismuth-Based Perovskite Ceramics," J. Phys. D: Appl. Phys., 45 [35] 355302 (2012).

45. Q. Xu, J. Xie, Z. He, L. Zhang, M. Cao, X. Huang, M. T. Lanagan, H. Hao, Z. Yao, and H. Liu, "Energy-Storage Properties of $\mathrm{Bi}_{0.5} \mathrm{Na}_{0.5} \mathrm{TiO}_{3}-\mathrm{BaTiO}_{3}-\mathrm{KNbO}_{3}$ Ceramics Fabricated by Wet-Chemical Method," J. Eur. Ceram. Soc., 37 [1] 99-106 (2017).

46. V. S. Puli, D. K. Pradhan, D. B. Chrisey, M. Tomozawa, G. L. Sharma, J. F. Scott, and R. S. Katiyar, "Structure,
Dielectric, Ferroelectric, and Energy Density Properties of $(1-x)$ BZT $-x$ BCT Ceramic Capacitors for Energy Storage Applications," J. Mater. Sci., 48 [5] 2151-57 (2013).

47. V. S. Puli, D. K. Pradhan, B. C. Riggs, D. B. Chrisey, and R. S. Katiyar, "Structure, Ferroelectric, Dielectric and Energy Storage Studies of $\mathrm{Ba}_{0.70} \mathrm{Ca}_{0.30} \mathrm{TiO}_{3}, \mathrm{Ba}\left(\mathrm{Zr}_{0.20} \mathrm{Ti}_{0.80}\right) \mathrm{O}_{3}$ Ceramic Capacitors," Integr. Ferroelectr., 157 [1] 139-46 (2014).

48. Y. Zhang, Y. Li, H. Zhu, Z. Fu, and Q. Zhang, "Sintering Temperature Dependence of Dielectric Properties and Energy-Storage Properties in $(\mathrm{Ba}, \mathrm{Zr}) \mathrm{TiO}_{3}$ Ceramics," J. Mater. Sci. Mater. Electron., 28 [1] 514-18 (2017).

49. T. Wang, X. Wei, Q. Hu, L. Jin, Z. Xu, and Y. Feng, "Effects of $\mathrm{ZnNb}_{2} \mathrm{O}_{6}$ Addition on $\mathrm{BaTiO}_{3}$ Ceramics for Energy Storage," Mater. Sci. Eng. B, 178 [16] 1081-86 (2013).

50. R. Ma, B. Cui, M. Shangguan, S. Wang, Y. Wang, Z. Chang, and Y. Wang, "A Novel Double-Coating Approach to Prepare Fine-Grained $\mathrm{BaTiO}_{3} @ \mathrm{La}_{2} \mathrm{O}_{3} @ \mathrm{SiO}_{2}$ Dielectric Ceramics for Energy Storage Application," J. Alloys Compd., 690 438-45 (2017).

51. J.-P. Ma, X.-M. Chen, W.-Q. Ouyang, J. Wang, H. Li, and J.-L. Fang, "Microstructure, Dielectric, and Energy Storage Properties of $\mathrm{BaTiO}_{3}$ Ceramics Prepared Via Cold Sintering," Ceram. Int., 44 [4] 4436-41 (2018).

52. J. Wan, Y. Pu, C. Hui, C. Cui, and Y. Guo, "Synthesis and Characterizations of $\mathrm{NaNbO}_{3}$ Modified $0.92 \mathrm{BaTiO}_{3}-$ $0.08 \mathrm{~K}_{0.5} \mathrm{Bi}_{0.5} \mathrm{TiO}_{3}$ Ceramics for Energy Storage Applications," J. Mater. Sci. Mater. Electron., 29 [6] 5158-62 (2018).

53. B. Qu, H. Du, Z. Yang, and Q. Liu, "Large Recoverable Energy Storage Density and Low Sintering Temperature in Potassium-Sodium Niobate-Based Ceramics for Multilayer Pulsed Power Capacitors," J. Am. Ceram. Soc., 100 [4] 1517-26 (2017).

54. T. F. Zhang, X. G. Tang, X. X. Huang, Q. X. Liu, Y. P. Jiang, and Q. F. Zhou, "High-Temperature Dielectric Relaxation Behaviors of Relaxer-Like $\mathrm{PbZrO}_{3}-\mathrm{SrTiO}_{3}$ Ceramics for Energy-Storage Applications," Energy Technol., 4 [5] 63340 (2016).

55. A. N. Bakshi, A. A. B. Moghal, N. A. Madhar, S. Patel, and R. Vaish, "Effect of Stress on Energy Conversion and Storage Characteristics of $(1-x-y) \mathrm{PIN}-x \mathrm{PMN}-y \mathrm{PT}$ Single Crystals," Ferroelectr. Lett. Sect., 42 [4-6] 107-14 (2015).

56. A. Chauhan, S. Patel, and R. Vaish, "Effect of Directional Mechanical Confinement on the Electrical Energy Storage Density in $68 \mathrm{~Pb}\left(\mathrm{Mn}_{1 / 3} \mathrm{Nb}_{2 / 3}\right) \mathrm{O}_{3}-32 \mathrm{PbTiO}_{3}$ Single Crystals," Ferroelectrics, 478 [1] 40-53 (2015).

57. T. F. Zhang, X. G. Tang, Q. X. Liu, Y. P. Jiang, X. X. Huang, and Q. F. Zhou, "Energy-Storage Properties and HighTemperature Dielectric Relaxation Behaviors of Relaxor Ferroelectric $\mathrm{Pb}\left(\mathrm{Mg}_{1 / 3} \mathrm{Nb}_{2 / 3}\right) \mathrm{O}_{3}-\mathrm{PbTiO}_{3}$ Ceramics," J. Phys. D: Appl. Phys., 49 [9] 095302 (2016).

58. B. Li, Q.-X. Liu, X.-G. Tang, T.-F. Zhang, Y.-P. Jiang, W.H. Li, and J. Luo, "Antiferroelectric to Relaxor Ferroelectric Phase Transition in PbO Modified $\left(\mathrm{Pb}_{0.97} \mathrm{La}_{0.02}\right)\left(\mathrm{Zr}_{0.95} \mathrm{Ti}_{0.05}\right) \mathrm{O}_{3}$ Ceramics with a Large Energy-Density for Dielectric Energy Storage," RSC Adv., 7 [68] 43327-33 (2017).

59. J. Gao, Y. Liu, Y. Wang, D. Wang, L. Zhong, and X. Ren, "High Temperature-Stability of $\left(\mathrm{Pb}_{0.9} \mathrm{La}_{0.1}\right)\left(\mathrm{Zr}_{0.65} \mathrm{Ti}_{0.35}\right) \mathrm{O}_{3}$ Ceramic for Energy-Storage Applications at Finite Electric Field Strength," Scr. Mater., 137 114-18 (2017). 
60. H. R. Jo and C. S. Lynch, "A High Energy Density Relaxor Antiferroelectric Pulsed Capacitor Dielectric," J. Appl. Phys., 119 [2] 024104 (2016).

61. H. Ogihara, A. Randall Clive, and S. Trolier-McKinstry, "High-Energy Density Capacitors Utilizing 0.7 $\mathrm{BaTiO}_{3}-$ 0.3BiScO ${ }_{3}$ Ceramics,” J. Am. Ceram. Soc., 92 [8] 1719-24 (2009).

62. T. Wang, L. Jin, C. Li, Q. Hu, and X. Wei, "Relaxor Ferroelectric $\mathrm{BaTiO}_{3}-\mathrm{Bi}\left(\mathrm{Mg}_{2 / 3} \mathrm{Nb}_{1 / 3}\right) \mathrm{O}_{3}$ Ceramics for Energy Storage Application," J. Am. Ceram. Soc., 98 [2] 559-66 (2014).

63. W.-B. Li, D. Zhou, and L.-X. Pang, "Enhanced Energy Storage Density by Inducing Defect Dipoles in Lead Free Relaxor Ferroelectric $\mathrm{BaTiO}_{3}$-Based Ceramics," Appl. Phys. Lett., 110 [13] 132902 (2017).

64. Q. Hu, L. Jin, T. Wang, C. Li, Z. Xing, and X. Wei, "Dielectric and Temperature Stable Energy Storage Properties of 0.88BaTiO ${ }_{3}-0.12 \mathrm{Bi}\left(\mathrm{Mg}_{1 / 2} \mathrm{Ti}_{1 / 2}\right) \mathrm{O}_{3}$ Bulk Ceramics," J. Alloys Compd., 640 416-20 (2015).

65. Q. Hu, T. Wang, L. Zhao, L. Jin, Z. Xu, and X. Wei, "Dielectric and Energy Storage Properties of $\mathrm{BaTiO}_{3}-\mathrm{Bi}\left(\mathrm{Mg}_{1 / 2} \mathrm{Ti}_{1 / 2}\right) \mathrm{O}_{3}$ Ceramic: Influence of Glass Addition and Biasing Electric Field," Ceram. Int., 43 [1] 35-9 (2017).

66. L. Wu, X. Wang, and L. Li, "Lead-Free $\mathrm{BaTiO}_{3}-\mathrm{Bi}\left(\mathrm{Zn}_{2 / 3} \mathrm{Nb}_{1 / 3}\right) \mathrm{O}_{3}$ Weakly Coupled Relaxor Ferroelectric Materials for Energy Storage," RSC Adv., 6 [17] 14273-82 (2016).

67. H. Yang, F. Yan, Y. Lin, T. Wang, F. Wang, Y. Wang, L. Guo, W. Tai, and H. Wei, "Lead-Free Batio3- $\mathrm{Bi}_{0.5} \mathrm{Na}_{0.5} \mathrm{TiO}_{3}$ $\mathrm{Na}_{0.73} \mathrm{Bi}_{0.09} \mathrm{NbO}_{3}$ Relaxor Ferroelectric Ceramics for High Energy Storage," J. Eur. Ceram. Soc., 37 [10] 3303-11 (2017).

68. Y. Goh, B.-H. Kim, H. Bae, and D.-K. Kwon, "Improved Temperature Stability in Dielectric Properties of 0.8Ba$\mathrm{TiO}_{3}-(0.2-x) \mathrm{NaNbO}_{3}-x \mathrm{Bi}\left(\mathrm{Mg}_{1 / 2} \mathrm{Ti}_{1 / 2}\right) \mathrm{O}_{3}$ Relaxors," J. Korean Ceram. Soc., 53 [2] 178-83 (2016).

69. L. Wu, X. Wang, and L. Li, "Core-Shell $\mathrm{BaTiO}_{3} @ \mathrm{BiScO}_{3}$ Particles for Local Graded Dielectric Ceramics with Enhanced Temperature Stability and Energy Storage Capability," $J$. Alloys Compd., 688 113-21 (2016).

70. H. Yang, F. Yan, Y. Lin, and T. Wang, "Enhanced EnergyStorage Properties of Lanthanum-Doped $\mathrm{Bi}_{0.5} \mathrm{Na}_{0.5} \mathrm{TiO}_{3}$ Based Lead-Free Ceramics," Energy Technol., 6 [2] 35765 (2017)

71. H.-P. Kim, C. W. Ahn, Y. Hwang, H.-Y. Lee, and W. Jo, "Strategies of a Potential Importance, Making Lead-Free Piezoceramics Truly Alternative to PZTs," J. Korean Ceram. Soc., 54 [2] 86-95 (2017).

72. X. Liu, C.-L. Yuan, X.-Y. Liu, F.-H. Luo, Q. Feng, J. Xu, G.-H. Chen, and C.-R. Zhou, "Microstructures, Electrical Behavior and Energy-Storage Properties of $\mathrm{Ba}_{0.06} \mathrm{Na}_{0.47} \mathrm{Bi}_{0.47} \mathrm{TiO}_{3}$ $\mathrm{Ln}_{1 / 3} \mathrm{NbO}_{3}(\mathrm{Ln}=\mathrm{la}, \mathrm{Nd}, \mathrm{Sm})$ Ceramics," Mater. Chem. Phys., 181 444-51 (2016).

73. Q.-N. Li, C.-R. Zhou, J.-W. Xu, L. Yang, X. Zhang, W.-D. Zeng, C.-L. Yuan, G.-H. Chen, and G.-H. Rao, "Ergodic Relaxor State with High Energy Storage Performance Induced by Doping $\mathrm{Sr}_{0.85} \mathrm{Bi}_{0.1} \mathrm{TiO}_{3}$ in $\mathrm{Bi}_{0.5} \mathrm{Na}_{0.5} \mathrm{TiO}_{3}$ Ceramics," J. Electron. Mater., 45 [10] 5146-51 (2016).

74. X. Zhou, C. Yuan, Q. Li, Q. Feng, C. Zhou, X. Liu, Y. Yang, and G. Chen, "Energy Storage Properties and Electrical
Behavior of Lead-Free $(1-x) \mathrm{Ba}_{0.04} \mathrm{Bi}_{0.48} \mathrm{Na}_{0.48} \mathrm{TiO}_{3}-x \mathrm{SrZrO}_{3}$ Ceramics," J. Mater. Sci. Mater. Electron., 27 [4] 3948-56 (2016)

75. Y. Pu, M. Yao, L. Zhang, and P. Jing, "High Energy Storage Density of $0.55 \mathrm{Bi}_{0.5} \mathrm{Na}_{0.5} \mathrm{TiO}_{3}-0.45 \mathrm{Ba}_{0.85} \mathrm{Ca}_{0.15} \mathrm{Ti}_{0.9-x} \mathrm{Zr}_{0.1} \mathrm{Sn}_{x} \mathrm{O}_{3}$ Ceramics," J. Alloys Compd., 687 689-95 (2016).

76. Y. Pu, L. Zhang, M. Yao, W. Ge, and M. Chen, "Improved Energy Storage Properties of Microwave Sintered 0.475BNT0.525BCTZ-xwt\%MgO Ceramics," Mater. Lett., 189232 35 (2017).

77. Y. Pu, M. Yao, L. Zhang, and M. Chen, "Enhanced Energy Storage Density of $0.55 \mathrm{Bi}_{0.5} \mathrm{Na}_{0.5} \mathrm{TiO}_{3}-0.45 \mathrm{Ba}_{0.55} \mathrm{Ca}_{0.15} \mathrm{Ti}_{0.85} \mathrm{Zr}_{0.1} \mathrm{Sn}_{0.05} \mathrm{O}_{3}$ with Mgo Addition,” J. Alloys Compd., 702 171-77 (2017).

78. L. Zhang, X. Pu, M. Chen, S. Bai, and Y. Pu, "Influence of Basno3 Additive on the Energy Storage Properties of $\mathrm{Na}_{0.5} \mathrm{Bi}_{0.5} \mathrm{TiO}_{3}$-Based Relaxor Ferroelectrics," J. Eur. Ceram. Soc., 38 [5] 2304-11 (2018).

79. H. S. Han, I. K. Hong, Y.-M. Kong, J. S. Lee, and W. Jo, "Effect of $\mathrm{Nb}$ Doping on the Dielectric and Strain Properties of Lead-Free 0.94 $\left(\mathrm{Bi}_{1 / 2} \mathrm{Na}_{1 / 2}\right) \mathrm{TiO}_{3}-0.06 \mathrm{BaTiO}_{3}$ Ceramics," J. Korean Ceram. Soc., 53 [2] 145-49 (2016).

80. J. Hao, Z. Xu, R. Chu, W. Li, D. Juan, and F. Peng, "Enhanced Energy-Storage Properties of $(1-x)\left[(1-y)\left(\mathrm{Bi}_{0.5} \mathrm{Na}_{0.5}\right) \mathrm{TiO}_{3}-\right.$ $\left.y\left(\mathrm{Bi}_{0.5} \mathrm{~K}_{0.5}\right) \mathrm{TiO}_{3}\right]-x\left(\mathrm{~K}_{0.5} \mathrm{Na}_{0.5}\right) \mathrm{NbO}_{3} \quad$ Lead-Free Ceramics," Solid State Commun., 204 19-22 (2015).

81. Q. Xu, M. T. Lanagan, X. Huang, J. Xie, L. Zhang, H. Hao, and H. Liu, "Dielectric Behavior and Impedance Spectroscopy in Lead-Free BNT-BT-NBN Perovskite Ceramics for Energy Storage," Ceram. Int., 42 [8] 9728-36 (2016).

82. X. Liu, H. Du, X. Liu, J. Shi, and H. Fan, "Energy Storage Properties of $\mathrm{BiTi}_{0.5} \mathrm{Zn}_{0.5} \mathrm{O}_{3}-\mathrm{Bi}_{0.5} \mathrm{Na}_{0.5} \mathrm{TiO}_{3}-\mathrm{BaTiO}_{3}$ Relaxor Ferroelectrics," Ceram. Int., 42 [15] 17876-79 (2016).

83. W. Tang, Q. Xu, H. Liu, Z. Yao, H. Hao, and M. Cao, "High Energy Density Dielectrics in Lead-Free $\mathrm{Bi}_{0.5} \mathrm{Na}_{0.5} \mathrm{TiO}_{3}-$ $\mathrm{NaNbO}_{3}-\mathrm{Ba}\left(\mathrm{Zr}_{0.2} \mathrm{Ti}_{0.8}\right) \mathrm{O}_{3}$ Ternary System with Wide Operating Temperature," J. Mater. Sci. Mater. Electron., 27 [6] 6526-34 (2016).

84. Q. Xu, H. Liu, L. Zhang, J. Xie, H. Hao, M. Cao, Z. Yao, and M. T. Lanagan, "Structure and Electrical Properties of Lead-Free $\mathrm{Bi}_{0.5} \mathrm{Na}_{0.5} \mathrm{TiO}_{3}$-Based Ceramics for EnergyStorage Applications," RSC Adv., 6 [64] 59280-91 (2016).

85. Y. Yao, Y. Li, N. Sun, J. Du, X. Li, L. Zhang, Q. Zhang, and $\mathrm{X}$. Hao, "Enhanced Dielectric and Energy-Storage Properties in $\mathrm{ZnO}$-Doped $0.9\left(0.94 \mathrm{Na}_{0.5} \mathrm{Bi}_{0.5} \mathrm{TiO}_{3}-0.06 \mathrm{Ba}\right.$ $\left.\mathrm{TiO}_{3}\right)-0.1 \mathrm{NaNbO}_{3}$ Ceramics," Ceram. Int., 44 [6] 5961-66 (2018).

86. H. Yang, F. Yan, Y. Lin, T. Wang, and F. Wang, "High Energy Storage Density over a Broad Temperature Range in Sodium Bismuth Titanate-Based Lead-Free Ceramics," Sci. Rep., 7 [1] 8726 (2017).

87. B. Qu, H. Du, and Z. Yang, "Lead-Free Relaxor Ferroelectric Ceramics with High Optical Transparency and Energy Storage Ability," J. Mater. Chem. C, 4 [9] 1795-803 (2016).

88. Z. Yang, H. Du, S. Qu, Y. Hou, H. Ma, J. Wang, J. Wang, $\mathrm{X}$. Wei, and Z. Xu, "Significantly Enhanced Recoverable Energy Storage Density in Potassium-Sodium NiobateBased Lead Free Ceramics," J. Mater. Chem. A, 4 [36] 13778-85 (2016).

89. B. Qu, H. Du, Z. Yang, Q. Liu, and T. Liu, "Enhanced 
Dielectric Breakdown Strength and Energy Storage Density in Lead-Free Relaxor Ferroelectric Ceramics Prepared Using Transition Liquid Phase Sintering," RSC Adv., 6 [41] 34381-89 (2016).

90. Q. Chai, D. Yang, X. Zhao, X. Chao, and Z. Yang, "LeadFree (K,Na) $\mathrm{NbO}_{3}$-Based Ceramics with High Optical Transparency and Large Energy Storage Ability," J. Am. Ceram. Soc., 101 [6] 2321-29 (2017).

91. T. Shao, H. Du, H. Ma, S. Qu, J. Wang, J. Wang, X. Wei, and Z. Xu, "Potassium-Sodium Niobate Based Lead-Free Ceramics: Novel Electrical Energy Storage Materials," J. Mater. Chem. A, 5 [2] 554-63 (2017).

92. H. Tao and J. Wu, "Optimization of Energy Storage Density in Relaxor (K, Na, Bi) $\mathrm{NbO}_{3}$ Ceramics," J. Mater. Sci. Mater. Electron., 28 [21] 16199-204 (2017).

93. D. Zheng, R. Zuo, D. Zhang, and Y. Li, "Novel $\mathrm{BiFeO}_{3}-$ $\mathrm{BaTiO}_{3}-\mathrm{Ba}\left(\mathrm{Mg}_{1 / 3} \mathrm{Nb}_{2 / 3}\right) \mathrm{O}_{3}$ Lead-Free Relaxor Ferroelectric Ceramics for Energy-Storage Capacitors," J. Am. Ceram. Soc., 98 [9] 2692-95 (2015).

94. D. Zheng and R. Zuo, "Enhanced Energy Storage Properties in $\mathrm{La}\left(\mathrm{Mg}_{1 / 2} \mathrm{Ti}_{1 / 2}\right) \mathrm{O}_{3}$-Modified $\mathrm{BiFeO}_{3}-\mathrm{BaTiO}_{3}$ Lead-Free Relaxor Ferroelectric Ceramics within a Wide Temperature Range," J. Eur. Ceram. Soc., 37 [1] 413-18 (2017).

95. D. Wang, Z. Fan, D. Zhou, A. Khesro, S. Murakami, A. Feteira, Q. Zhao, X. Tan, and I. Reaney, "Bismuth FerriteBased Lead-Free Ceramics and Multilayers with High Recoverable Energy Density," J. Mater. Chem. A, 6 [9] 4133-44 (2018).

96. F. Yan, H. Yang, Y. Lin, and T. Wang, "Dielectric and Ferroelectric Properties of $\mathrm{SrTiO}_{3}-\mathrm{Bi}_{0.5} \mathrm{Na}_{0.5} \mathrm{TiO}_{3}-\mathrm{BaAl}_{0.5} \mathrm{Nb}_{0.5} \mathrm{O}_{3}$ Lead-Free Ceramics for High-Energy-Storage Applications," Inorg. Chem., 56 [21] 13510-16 (2017).

97. H. Yang, F. Yan, Y. Lin, and T. Wang, "Improvement of Dielectric and Energy Storage Properties in $\mathrm{SrTiO}_{3}$-Based Lead-Free Ceramics," J. Alloys Compd., 728 780-87 (2017).

98. C. Cui, Y. Pu, Z. Gao, J. Wan, Y. Guo, C. Hui, Y. Wang, and Y. Cui, "Structure, Dielectric and Relaxor Properties in Lead-Free ST-NBT Ceramics for High Energy Storage Applications," J. Alloys Compd., 711 319-26 (2017).

99. H. Yang, F. Yan, Y. Lin, T. Wang, L. He, and F. Wang, "A Lead Free Relaxation and High Energy Storage Efficiency Ceramics for Energy Storage Applications," J. Alloys Compd., 710 436-45 (2017).

100. C. Cui and Y. Pu, "Improvement of Energy Storage Density with Trace Amounts of $\mathrm{ZrO}_{2}$ Additives Fabricated by Wet-Chemical Method,” J. Alloys Compd., 747 495-504 (2018).

101. H. Yang, F. Yan, Y. Lin, and T. Wang, "Novel Strontium Titanate-Based Lead-Free Ceramics for High-Energy Storage Applications," ACS Sustainable Chem. Eng., 5 [11] 10215-22 (2017).

102. C. Cui, Y. Pu, and R. Shi, "High-Energy Storage Performance in Lead-Free $(0.8-x) \mathrm{SrTiO}_{3}-0.2 \mathrm{Na}_{0.5} \mathrm{Bi}_{0.5} \mathrm{TiO}_{3}-x \mathrm{Ba}$ $\mathrm{TiO}_{3}$ Relaxor Ferroelectric Ceramics," J. Alloys Compd., 740 1180-87 (2018).

103. C. Cui and Y. Pu, "Effect of Sn Substitution on the Energy Storage Properties of $0.45 \mathrm{SrTiO}_{3}-0.2 \mathrm{Na}_{0.5} \mathrm{Bi}_{0.5} \mathrm{TiO}_{3}-0.35 \mathrm{Ba}$ $\mathrm{TiO}_{3}$ Ceramics,” J. Mater. Sci., 53 [13] 9830-41 (2018).

104. X. Hao, J. Zhai, L. B. Kong, and Z. Xu, "A Comprehensive
Review on the Progress of Lead Zirconate-Based Antiferroelectric Materials," Prog. Mater. Sci., 63 1-57 (2014).

105. E. Sawaguchi, H. Maniwa, and S. Hoshino, "Antiferroelectric Structure of Lead Zirconate,” Phys. Rev., 83 [5] 1078 (1951).

106. P. Satyanarayan, C. Aditya, and V. Rahul, "Enhancing Electrical Energy Storage Density in Anti-Ferroelectric Ceramics Using Ferroelastic Domain Switching," Mater. Res. Exp. 1 [4] 045502 (2014).

107. B. Li, Q. Liu, X. Tang, T. Zhang, Y. Jiang, W. Li, and J. Luo, "High Energy Storage Density and Impedance Response of PLZT2/95/5 Antiferroelectric Ceramics," Materials, 10 [2] 143 (2017).

108. H. Zhang, X. Chen, F. Cao, G. Wang, X. Dong, Z. Hu, and T. Du, "Charge-Discharge Properties of an Antiferroelectric Ceramics Capacitor under Different Electric Fields," J. Am. Ceram. Soc., 93 [12] 4015-17 (2010).

109. J. Wang, T. Yang, S. Chen, and G. Li, "High Energy Storage Density Performance of Ba, Sr-Modified Lead Lanthanum Zirconate Titanate Stannate Antiferroelectric Ceramics," Mater. Res. Bull., 48 [10] 3847-49 (2013).

110. R. Xu, Z. Xu, Y. Feng, X. Wei, and J. Tian, "Nonlinear Dielectric and Discharge Properties of $\mathrm{Pb}_{0.94} \mathrm{La}_{0.04}\left[\mathrm{Zr}_{0.56^{-}}\right.$ $\left.\mathrm{Sn}_{0.44}\right)_{0.84} \mathrm{Ti}_{0.16} \mathrm{O}_{3}$ Antiferroelectric Ceramics," J. Appl. Phys., 120 [14] 144102 (2016).

111. H. Yu, J. Zhang, M. Wei, J. Huang, H. Chen, and C. Yang, "Enhanced Energy Storage Density Performance in $\left(\mathrm{Pb}_{0.97} \mathrm{La}_{0.02}\right)\left(\mathrm{Zr}_{0.5} \mathrm{Sn}_{0.44} \mathrm{Ti}_{0.06}\right)-\mathrm{BiYO}_{3}$ Anti-Ferroelectric Composite Ceramics," J. Mater. Sci. Mater. Electron., 28 [1] 832-38 (2017).

112. J. Wang, T. Yang, S. Chen, and X. Yao, "Small Hysteresis and High Energy Storage Power of Antiferroelectric Ceramics," Funct. Mater. Lett., 07 [01] 1350064 (2013).

113. Z. Liu, X. Chen, W. Peng, C. Xu, X. Dong, F. Cao, and G. Wang, "Temperature-Dependent Stability of Energy Storage Properties of $\mathrm{Pb}_{0.97} \mathrm{La}_{0.02}\left(\mathrm{Zr}_{0.58} \mathrm{Sn}_{0.335} \mathrm{Ti}_{0.085}\right) \mathrm{O}_{3}$ Antiferroelectric Ceramics for Pulse Power Capacitors," Appl. Phys. Lett., 106 [26] 262901 (2015).

114. X. Wang, J. Shen, T. Yang, Y. Dong, and Y. Liu, "High Energy-Storage Performance and Dielectric Properties of Antiferroelectric $\left(\mathrm{Pb}_{0.97} \mathrm{La}_{0.02}\right)\left(\mathrm{Zr}_{0.5} \mathrm{Sn}_{0.5-\mathrm{x}} \mathrm{Ti}_{x}\right) \mathrm{O}_{3}$ Ceramic," J. Alloys Compd., 655 309-13 (2016).

115. C. Xu, Z. Liu, X. Chen, S. Yan, F. Cao, X. Dong, and G. Wang, "High Charge-Discharge Performance of $\mathrm{Pb}_{0.98} \mathrm{La}_{0.02}$ $\left(\mathrm{Zr}_{0.35} \mathrm{Sn}_{0.55} \mathrm{Ti}_{0.10}\right)_{0.995} \mathrm{O}_{3}$ Antiferroelectric Ceramics," J. Appl. Phys., 120 [7] 074107 (2016).

116. Q. Zhang, H. Tong, J. Chen, Y. Lu, T. Yang, X. Yao, and Y. He, "High Recoverable Energy Density over a Wide Temperature Range in Sr Modified (Pb,La)(Zr,Sn,Ti) $\mathrm{O}_{3}$ Antiferroelectric Ceramics with an Orthorhombic Phase," Appl. Phys. Lett., 109 [26] 262901 (2016).

117. R. Xu, Z. Xu, Y. Feng, J. Tian, and D. Huang, "Energy Storage and Release Properties of Sr-Doped (Pb,La)(Zr,Sn,Ti) $\mathrm{O}_{3}$ Antiferroelectric Ceramics," Ceram. Int., 42 [11] 12875-79 (2016).

118. Q. Zhang, Y. Dan, J. Chen, Y. Lu, T. Yang, X. Yao, and Y. $\mathrm{He}$, "Effects of Composition and Temperature on Energy Storage Properties of $(\mathrm{Pb}, \mathrm{La})(\mathrm{Zr}, \mathrm{Sn}, \mathrm{Ti}) \mathrm{O}_{3}$ Antiferroelectric Ceramics," Ceram. Int., 43 [14] 11428-32 (2017). 
119. Z. Liu, X. Dong, Y. Liu, F. Cao, and G. Wang, "Electric Field Tunable Thermal Stability of Energy Storage Properties of PLZST Antiferroelectric Ceramics," J. Am. Ceram. Soc., 100 [6] 2382-86 (2017).

120. Z. Liu, Y. Bai, X. Chen, X. Dong, H. Nie, F. Cao, and G. Wang, "Linear Composition-Dependent Phase Transition Behavior and Energy Storage Performance of Tetragonal PLZST Antiferroelectric Ceramics," J. Alloys Compd., 691 721-25 (2017).

121. S. E. Young, J. Y. Zhang, W. Hong, and X. Tan, "Mechanical Self-Confinement to Enhance Energy Storage Density of Antiferroelectric Capacitors," J. Appl. Phys., 113 [5] 054101 (2013).

122. S. Patel, A. Chauhan, and R. Vaish, "Enhanced Electrical Energy Storage Density in Mechanical Confined Antiferroelectric Ceramic," Ferroelectrics, 486 [1] 114-25 (2015).

123. X. Chen, H. Zhang, F. Cao, G. Wang, X. Dong, Y. Gu, H. $\mathrm{He}$, and Y. Liu, "Charge-Discharge Properties of Lead Zirconate Stannate Titanate Ceramics," J. Appl. Phys., 106 [3] 034105 (2009).

124. Q. Zhang, X. Liu, Y. Zhang, X. Song, J. Zhu, I. Baturin, and J. Chen, "Effect of Barium Content on Dielectric and Energy Storage Properties of $(\mathrm{Pb}, \mathrm{La}, \mathrm{Ba})(\mathrm{Zr}, \mathrm{Sn}, \mathrm{Ti}) \mathrm{O}_{3}$ Ceramics," Ceram. Int., 41 [2] 3030-35 (2015).

125. L. Chen, X. Hao, Q. Zhang, and S. An, "Energy-Storage Performance of $\mathrm{PbO}-\mathrm{B}_{2} \mathrm{O}_{3}-\mathrm{SiO}_{2}$ Added $\left(\mathrm{Pb}_{0.92} \mathrm{Ba}_{0.05} \mathrm{La}_{0.02}\right)$ $\left(\mathrm{Zr}_{0.68} \mathrm{Sn}_{0.27} \mathrm{Ti}_{0.05}\right) \mathrm{O}_{3}$ Antiferroelectric Ceramics Prepared by Microwave Sintering Method," J. Mater. Sci. Mater. Electron., 27 [5] 4534-40 (2016).

126. R. Xu, Z. Xu, Y. Feng, H. He, J. Tian, and D. Huang, "Temperature Dependence of Energy Storage in $\mathrm{Pb}_{0.90} \mathrm{La}_{0.04} \mathrm{Ba}_{0.04}{ }^{-}$ $\left[\left(\mathrm{Zr}_{0.7} \mathrm{Sn}_{0.3}\right)_{0.88} \mathrm{Ti}_{0.12}\right] \mathrm{O}_{3}$ Antiferroelectric Ceramics," J. Am. Ceram. Soc., 99 [9] 2984-88 (2016).

127. G. Zhang, D. Zhu, X. Zhang, L. Zhang, J. Yi, B. Xie, Y. Zeng, Q. Li, Q. Wang, and S. Jiang, "High-Energy Storage Performance of $\left(\mathrm{Pb}_{0.87} \mathrm{Ba}_{0.1} \mathrm{La}_{0.02}\right)\left(\mathrm{Zr}_{0.68} \mathrm{Sn}_{0.24} \mathrm{Ti}_{0.08}\right) \mathrm{O}_{3}$ Antiferroelectric Ceramics Fabricated by the Hot-Press Sintering Method," J. Am. Ceram. Soc., 98 [4] 1175-81 (2015).

128. X. Wang, J. Shen, T. Yang, Z. Xiao, and Y. Dong, "Phase Transition and Energy Storage Performance in Ba-Doped PLZST Antiferroelectric Ceramics," J. Mater. Sci. Mater. Electron., 26 [11] 9200-4 (2015).

129. G. Zhang, P. Liu, B. Fan, H. Liu, Y. Zeng, S. Qiu, S. Jiang, Q. Li, Q. Wang, and J. Liu, "Large Energy Density in Ba Doped $\mathrm{Pb}_{0.97} \mathrm{La}_{0.02}\left(\mathrm{Zr}_{0.65} \mathrm{Sn}_{0.3} \mathrm{Ti}_{0.05}\right) \mathrm{O}_{3}$ Antiferroelectric Ceramics with Improved Temperature Stability," IEEE Trans. Dielectr. Electr. Insul., 24 [2] 744-48 (2017).

130. B. Guo, P. Liu, Y. Song, and D. Liu, "Effect of Ti Content on Energy Storage Properties of $\left(\mathrm{Pb}_{0.87} \mathrm{Ba}_{0.10} \mathrm{La}_{0.02}\right)$ $\left(\mathrm{Zr}_{0.60} \mathrm{Sn}_{0.40-x} \mathrm{Ti}_{x}\right) \mathrm{O}_{3}$ Bulk Ceramics," Ferroelectrics, 510 [1] 152-60 (2017).

131. L. Zhang, S. Jiang, Y. Zeng, M. Fu, K. Han, Q. Li, Q. Wang, and G. Zhang, "Y Doping and Grain Size CoEffects on the Electrical Energy Storage Performance of $\left(\mathrm{Pb}_{0.87} \mathrm{Ba}_{0.1} \mathrm{La}_{0.02}\right)\left(\mathrm{Zr}_{0.65} \mathrm{Sn}_{0.3} \mathrm{Ti}_{0.05}\right) \mathrm{O}_{3}$ Anti-Ferroelectric Ceramics," Ceram. Int., 40 [4] 5455-60 (2014).

132. L. Zhang, S. Jiang, B. Fan, and G. Zhang, "High Energy Storage Performance in $\left(\mathrm{Pb}_{0.858} \mathrm{Ba}_{0.1} \mathrm{La}_{0.02} \mathrm{Y}_{0.008}\right)\left(\mathrm{Zr}_{0.65} \mathrm{Sn}_{0.3} \mathrm{Ti}_{0.05}\right) \mathrm{O}_{3^{-}}$ $\left(\mathrm{Pb}_{0.97} \mathrm{La}_{0.02}\right)\left(\mathrm{Zr}_{0.9} \mathrm{Sn}_{0.05} \mathrm{Ti}_{0.05}\right) \mathrm{O}_{3}$ Anti-Ferroelectric Compos- ite Ceramics," Ceram. Int., 41 [1] 1139-44 (2015).

133. L. Zhang, S. Jiang, B. Fan, and G. Zhang, "Enhanced Energy Storage Performance in $\left(\mathrm{Pb}_{0.858} \mathrm{Ba}_{0.1} \mathrm{La}_{0.02} \mathrm{Y}_{0.008}\right)$ $\left(\mathrm{Zr}_{0.65} \mathrm{Sn}_{0.3} \mathrm{Ti}_{0.05}\right) \mathrm{O}_{3}-\left(\mathrm{Pb}_{0.97} \mathrm{La}_{0.02}\right)\left(\mathrm{Zr}_{0.9} \mathrm{Sn}_{0.05} \mathrm{Ti}_{0.05}\right) \mathrm{O}_{3} \quad$ Anti-Ferroelectric Composite Ceramics by Spark Plasma Sintering," J. Alloys Compd., 622 162-65 (2015).

134. J. Yi, L. Zhang, B. Xie, and S. Jiang, "The Influence of Temperature Induced Phase Transition on the Energy Storage Density of Anti-Ferroelectric Ceramics," J. Appl. Phys., 118 [12] 124107 (2015).

135. Q. Zhang, J. Chen, Y. Lu, T. Yang, X. Yao, and Y. He, "( $\mathrm{Pb}, \mathrm{Sm})(\mathrm{Zr}, \mathrm{Sn}, \mathrm{Ti}) \mathrm{O}_{3}$ Multifunctional Ceramics with Large Electric-Field-Induced Strain and High-Energy Storage Density," J. Am. Ceram. Soc., 99 [12] 3853-56 (2016).

136. L. Xu, C. He, X. Yang, Z. Wang, X. Li, H. N. Tailor, and X. Long, "Composition Dependent Structure, Dielectric and Energy Storage Properties of $\mathrm{Pb}\left(\mathrm{Tm}_{1 / 2} \mathrm{Nb}_{1 / 2}\right) \mathrm{O}_{3}-\mathrm{Pb}\left(\mathrm{Mg}_{1 / 3} \mathrm{Nb}_{2 / 3}\right) \mathrm{O}_{3}$ Antiferroelectric Ceramics," J. Eur. Ceram. Soc., 37 [10] 3329-34 (2017).

137. D. Berlincourt, "Transducers Using Forced Transitions between Ferroelectric and Antiferroelectric States," IEEE Trans. Sonics Ultrason., 13 [4] 116-24 (1966).

138. W. Cao, W. Li, Y. Feng, T. Bai, Y. Qiao, Y. Hou, T. Zhang, Y. Yu, and W. Fei, "Defect Dipole Induced Large Recoverable Strain and High Energy-Storage Density in LeadFree $\mathrm{Na}_{0.5} \mathrm{Bi}_{0.5} \mathrm{TiO}_{3}$-Based Systems," Appl. Phys. Lett., 108 [20] 202902 (2016).

139. Y. Wang, Z. Lv, H. Xie, and J. Cao, "High Energy-Storage Properties of $\left[\left(\mathrm{Bi}_{1 / 2} \mathrm{Na}_{1 / 2}\right)_{0.94} \mathrm{Ba}_{0.06}\right] \mathrm{La}_{(1-x)} \mathrm{Zr}_{x} \mathrm{TiO}_{3}$ Lead-Free Anti-Ferroelectric Ceramics," Ceram. Int., 40 [3] 4323-26 (2014).

140. J. Zhao, M. Cao, Z. Wang, Q. Xu, L. Zhang, Z. Yao, H. Hao, and H. Liu, "Enhancement of Energy-Storage Properties of $\mathrm{K}_{0.5} \mathrm{Na}_{0.5} \mathrm{NbO}_{3}$ Modified $\mathrm{Na}_{0.5} \mathrm{Bi}_{0.5} \mathrm{TiO}_{3}-\mathrm{K}_{0.5} \mathrm{Bi}_{0.5} \mathrm{TiO}_{3}$ Lead-Free Ceramics,” J. Mater. Sci. Mater. Electron., 27 [1] 466-73 (2016)

141. J. Cao, Y. Wang, and Z. Li, "Energy-Storage Properties and Electrical Behavior of Lead-Free Anti-Ferroelectric $\left(\mathrm{Bi}_{0.46} \mathrm{Na}_{0.46} \mathrm{Ba}_{0.05} \mathrm{La}_{0.02}\right) \mathrm{Zr}_{x} \mathrm{Ti}_{(1-x)} \mathrm{O}_{3}$ Ceramics," Ferroelectrics, 505 [1] 17-23 (2016).

142. Y. Zhao, J. Xu, L. Yang, C. Zhou, X. Lu, C. Yuan, Q. Li, G. Chen, and H. Wang, "High Energy Storage Property and Breakdown Strength of $\mathrm{Bi}_{0.5}\left(\mathrm{Na}_{0.82} \mathrm{~K}_{0.18}\right)_{0.5} \mathrm{TiO}_{3}$ Ceramics Modified by $\left(\mathrm{Al}_{0.5} \mathrm{Nb}_{0.5}\right)^{4+}$ Complex-Ion," J. Alloys Compd., 666 209-16 (2016).

143. Q. Li, C. Zhou, J. Xu, L. Yang, X. Zhang, W. Zeng, C. Yuan, G. Chen, and G. Rao, "Tailoring Antiferroelectricity with High Energy-Storage Properties in $\mathrm{Bi}_{0.5} \mathrm{Na}_{0.5} \mathrm{TiO}_{3}$ $\mathrm{BaTiO}_{3}$ Ceramics by Modulating Bi/Na Ratio," J. Mater. Sci. Mater. Electron., 27 [10] 10810-15 (2016).

144. J. Xu, X. Lu, L. Yang, C. Zhou, Y. Zhao, H. Zhang, X. Zhang, W. Qiu, and H. Wang, "Enhanced Electrical Energy Storage Properties in La-Doped $\left(\mathrm{Bi}_{0.5} \mathrm{Na}_{0.5}\right)_{0.93} \mathrm{Ba}_{0.07} \mathrm{TiO}_{3}$ LeadFree Ceramics by Addition of $\mathrm{La}_{2} \mathrm{O}_{3}$ and $\mathrm{La}\left(\mathrm{NO}_{3}\right)_{3}, " J$. Mater. Sci., 52 [17] 10062-72 (2017).

145. A. Mishra, B. Majumdar, and R. Ranjan, "A Complex Lead-Free $(\mathrm{Na}, \mathrm{Bi}, \mathrm{Ba})(\mathrm{Ti}, \mathrm{Fe}) \mathrm{O}_{3}$ Single Phase Perovskite Ceramic with a High Energy-Density and High DischargeEfficiency for Solid State Capacitor Applications," J. Eur. 
Ceram. Soc., 37 [6] 2379-84 (2017).

146. Z. Yu, Y. Liu, M. Shen, H. Qian, F. Li, and Y. Lyu, "Enhanced Energy Storage Properties of $\mathrm{BiAlO}_{3}$ Modified $\mathrm{Bi}_{0.5} \mathrm{Na}_{0.5} \mathrm{TiO}_{3}-$ $\mathrm{Bi}_{0.5} \mathrm{~K}_{0.5} \mathrm{TiO}_{3}$ Lead-Free Antiferroelectric Ceramics," Ceram. Int., 43 [10] 7653-59 (2017).

147. F. Li, Y. Liu, Y. Lyu, Y. Qi, Z. Yu, and C. Lu, "Huge Strain and Energy Storage Density of A-site $\mathrm{La}^{3+}$ Donor Doped $\left(\mathrm{Bi}_{0.5} \mathrm{Na}_{0.5}\right)_{0.94} \mathrm{Ba}_{0.06} \mathrm{TiO}_{3}$ Ceramics," Ceram. Int., 43 [1] 10610 (2017).

148. J. Yin, X. Lv, and J. Wu, "Enhanced Energy Storage Properties of $\left\{\mathrm{Bi}_{0.5}\left[\left(\mathrm{Na}_{0.8} \mathrm{~K}_{0.2}\right)_{1-z} \mathrm{Li}_{z}\right]_{0.5}\right\}_{0.96} \mathrm{Sr}_{0.04}\left(\mathrm{Ti}_{1-x-y} \mathrm{Ta}_{x} \mathrm{Nb}_{y}\right) \mathrm{O}_{3}$ Lead-Free Ceramics," Ceram. Int., 43 [16] 13541-46 (2017).

149. K. R. Kandula, K. Banerjee, S. S. K. Raavi, and S. Asthana, "Enhanced Electrocaloric Effect and Energy Storage Density of Nd-Substituted 0.92NBT-0.08BT Lead Free Ceramic," Phys. Status Solidi A, 215 [7] 1700915 (2018).

150. Q. Li, Z. Yao, L. Ning, S. Gao, B. Hu, G. Dong, and H. Fan, "Enhanced Energy-Storage Properties of $(1-x)\left(0.7 \mathrm{Bi}_{0.5} \mathrm{Na}_{0.5} \mathrm{TiO}_{3}\right.$ $0.3 \mathrm{Bi}_{0.2} \mathrm{Sr}_{0.7} \mathrm{TiO}_{3}$ )- $x \mathrm{NaNbO}_{3}$ Lead-Free Ceramics," Ceram. Int., 44 [3] 2782-88 (2018).

151. P. Chen and B. Chu, "Improvement of Dielectric and Energy Storage Properties in $\mathrm{Bi}\left(\mathrm{Mg}_{1 / 2} \mathrm{Ti}_{1 / 2}\right) \mathrm{O}_{3}$-Modified $\left(\mathrm{Na}_{1 / 2} \mathrm{Bi}_{1 / 2}\right)_{0.92} \mathrm{Ba}_{0.08} \mathrm{TiO}_{3}$ Ceramics," J. Eur. Ceram. Soc., 36 [1] 81-8 (2016).

152. L. Zhao, Q. Liu, S. Zhang, and J.-F. Li, "Lead-Free $\mathrm{AgNbO}_{3}$
Anti-Ferroelectric Ceramics with an Enhanced Energy Storage Performance Using $\mathrm{MnO}_{2}$ Modification," J. Mater. Chem. C, 4 [36] 8380-84 (2016).

153. Y. Tian, L. Jin, H. Zhang, Z. Xu, X. Wei, E. D. Politova, S. Y. Stefanovich, N. V. Tarakina, I. Abrahams, and H. Yan, "High Energy Density in Silver Niobate Ceramics," J. Mater. Chem. A, 4 [44] 17279-87 (2016).

154. L. Zhao, Q. Liu, J. Gao, S. Zhang, and J.-F. Li, "Lead-Free Antiferroelectric Silver Niobate Tantalate with High Energy Storage Performance," Adv. Mater., 29 [31] 1701824 (2017).

155. L. Zhao, J. Gao, Q. Liu, S. Zhang, and J.-F. Li, "Silver Niobate Lead-Free Antiferroelectric Ceramics: Enhancing Energy Storage Density by B-site Doping," ACS Appl. Mater. Interfaces, 10 [1] 819-26 (2018).

156. Y. Tian, L. Jin, H. Zhang, Z. Xu, X. Wei, G. Viola, I. Abrahams, and H. Yan, "Phase Transitions in Bismuth-Modified Silver Niobate Ceramics for High Power Energy Storage," J. Mater. Chem. A, 5 [33] 17525-31 (2017).

157. B. W. Eerd, D. Damjanovic, N. Klein, N. Setter, and J. Trodahl, "Structural Complexity of $\left(\mathrm{Na}_{0.5} \mathrm{Bi}_{0.5}\right) \mathrm{TiO}_{3}-\mathrm{BaTiO}_{3}$ as Revealed by Raman Spectroscopy," Phys. Rev. B, 82 [10] 104112 (2010).

158. B. Xu, J. Íñiguez, and L. Bellaiche, "Designing Lead-Free Antiferroelectrics for Energy Storage," Nat. Commun., 8 15682 (2017) 